ISSN 2223-3792

Машинное обучение и анализ данных

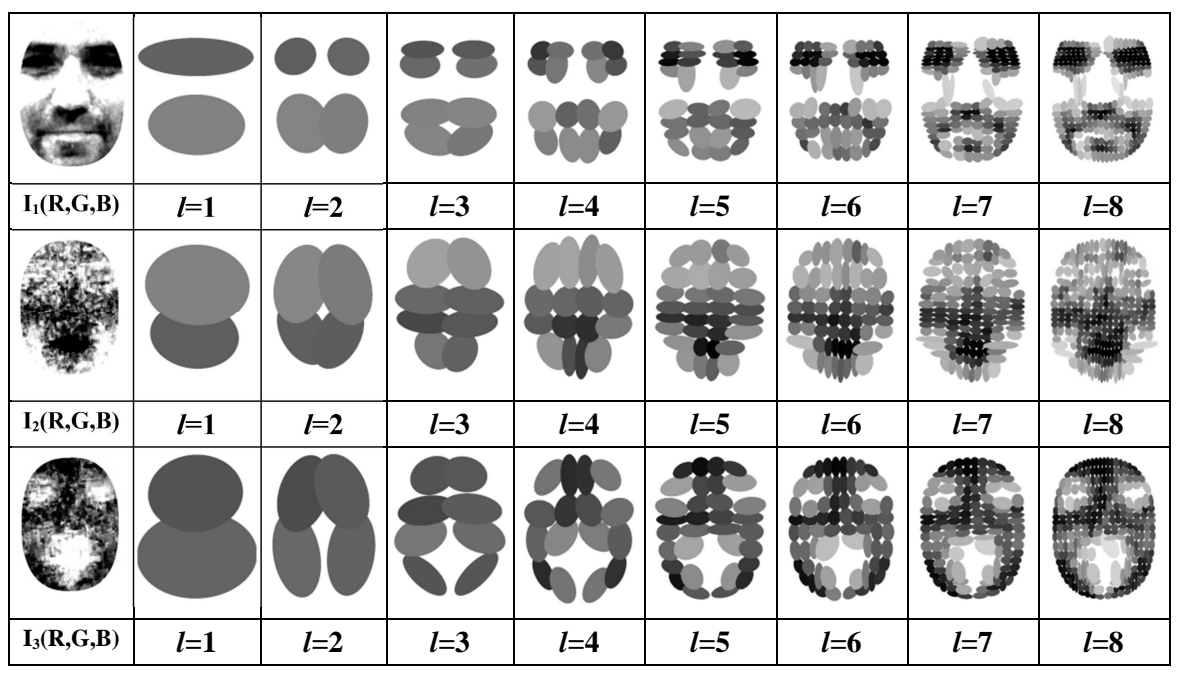




\section{Машинное обучение и анализ данных}

Журнал «Машинное обучение и анализ данных» публикует новые теоретические и обзорные статьи с результатами научных исследований в области искусственного интеллекта, теоретических основ информатики и приложений. Цель журнала - развитие теории машинного обучения, интеллектуального анализа данных и методов проведения вычислительных экспериментов. Принимаются статьи на английском и русском языках.

Журнал включен в российский индекс научного цитирования РИНЦ. Информация о цитировании статей находится на сайте Российского индекса научного цитирования, ISSN 2223-3792, номер свидетельства о регистрации ЭЛ № ФС 77-55486. Журнал зарегистрирован в системе Crossref, doi http://dx.doi.org/10.21469/22233792.

- Новостной сайт http://jmlda.org/

- Электронная система подачи статей http://jmlda.org/papers/

- Правила подготовки статей http://jmlda.org/papers/doc/authors-guide.pdf

\section{Тематика журнала:}

- классификация, кластеризация, регрессионный анализ;

- алгебраический подход к проблеме синтеза корректных алгоритмов;

- многомерный статистический анализ;

- выбор моделей и сложность;

- глубокое обучение;

- статистическая теория обучения;

- методы прогнозирования временных рядов;

- методы обработки и распознавания сигналов;

- методы оптимизации в задачах машинного обучения и анализа данных;

- методы анализа больших данных;

- методы визуализации данных;

- обработка и распознавание речи и изображений;

- анализ и понимание текста;

- информационный поиск;

- прикладные задачи анализа данных.

Редакционный совет

Ю. Г. Евтушенко, акад.

Ю. И. Журавлёв, акад.

Д.Н. Зорин, проф.

К. В. Рудаков, акад.
Редколлегия

К. В. Воронцов, д.ф.-м.н.

А. Г. Дьяконов, д.ф.-м.н.

И. А. Матвеев, д.т.н.

Л. М. Местецкий, д.т.н.

В. В. Моттль, д.т.н.

М. Ю. Хачай, д.ф.-м.н.
Координаторы

В. Р. Бунакова

Ш. Х. Ишкина

М. П. Кузнецов

А. П. Мотренко

Редактор: В.В.Стрижов, д.ф.-м.н. (strijov@ccas.ru)

Вычислительный центр им. А. А. Дородницына ФИЦ ИУ РАН

Московский физико-технический институт

Факультет управления и прикладной математики

Кафедра «Интеллектуальные системы»

Москва, 2017 


\section{Journal of Machine Learning and Data Analysis}

The journal Machine Learning and Data Analysis publishes original research papers and reviews of the developments in the field of artificial intelligence, theoretical computer science and its applications. The journal aims to promote the theory of machine learning and data mining and methods of conducting computational experiments. Papers are accepted in English and Russian.

The journal is included in the Russian science citation index RSCI. Information about citation to articles can be found at the Russian science citation index website. ISSN 22233792. Mass media registration certificate ЭЛ № $Ф C ~ 77-55486$. The Crossref journal doi is http://dx.doi.org/10.21469/22233792.

- Journal news and archive http://jmlda.org/

- Open journal system for papers submission http://jmlda.org/papers/

- Style guide for authors http://jmlda.org/papers/doc/authors-guide.pdf

\section{The scope of the journal:}

- classification, clustering, regression analysis;

- multidimensional statistical analysis;

- Bayesian methods for regression and classification;

- model selection and complexity;

- deep learning;

- Statistical Learning Theory;

— time series forecasting techniques;

- methods of signal processing and speech recognition;

- optimization methods for solving machine learning and data mining problems;

- methods of big data analysis;

- data visualization techniques;

- methods of image processing and recognition;

- text analysis, text mining and information retrieval;

- applied data analysis problems.

\section{Editorial Council}

Yu. G. Evtushenko, acad.

K. V. Rudakov, acad.

Yu. I. Zhuravlev, acad.

D. N. Zorin, prof.
Editorial Board

A. G. Dyakonov, D.Sc.

M. Yu. Khachay, D.Sc.

I. A. Matveev, D.Sc.

L. M. Mestetskiy, D.Sc.

V. V. Mottl, D.Sc.

K. V. Vorontsov, D.Sc.
Editorial Support

V.R. Bunakova

Sh. Kh. Ishkina

M. P. Kuznetsov

A. P. Motrenko

Editor-in-Chief: V.V. Strijov, D.Sc. (strijov@ccas.ru)

Dorodnicyn Computing Centre FRC CSC RAS

Moscow Institute of Physics and Technology

Department of Control and Applied Mathematics

Division "Intelligent Systems"

Moscow, 2017 


\section{Содержание}

А. С. Кулунчаков

Порождение параметрических правил упрощения алгебраических выражений в задаче символьной регрессии . . . . . . . . . . . . . . . . . . . . . 6

П. А. Измаилов, Д. А. Кропотов

Быстрый метод обучения модели гауссовских процессов для задач классификации 20

А. В. Михеева, И. И. Калинников

Алгоритмы и методы геоинформационно-экспертного анализа данных в ГИС

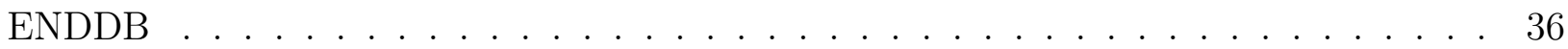

С. Д. Двоенко, Д. О. Пиеничный

Обусловленность матриц парных сравнений при коррекции метрических нарушений 50

А. Н. Каркищенко, В. Б. Мнухин

Применение гауссовых вращений для защиты графической информации . . . . . . 61

С. Н. Ганебных, М. М. Ланге

Об эффективности схем комплексирования данных для распознавания образов по ансамблю изображений . . . . . . . . . . . . . . . . . . . . . . 76 


\section{Contents}

A.S. Kulunchakov

Creation of parametric rules to rewrite algebraic expressions in Symbolic Regression . 6

P. A. Izmailov and D. A. Kropotov

Faster variational inducing input Gaussian process classification . . . . . . . . . . 20

A. V. Mikheeva and I. I. Kalinnikov

The GIS-ENDDB algorithms and methods for geoinformation-expert data analysis . . 36

S. D. Dvoenko and D. O. Pshenichny

The conditionality of matrices of pairwise comparisons after metric corrections . . . . 50

A. N. Karkishchenko and V.B. Mnukhin

Gaussian rotations for graphic information protection . . . . . . . . . . . . 61

S. N. Ganebnykh and M. M. Lange

On efficiency of fusion schemes for pattern recognition in ensemble of images . . . . 76 


\title{
Creation of parametric rules to rewrite algebraic expressions in Symbolic Regression*
}

\author{
A.S. Kulunchakov \\ kulu-andrej@yandex.ru \\ Moscow Institute of Physics and Technology, 9 Institutskiy per., Dolgoprudny, Moscow, Russia \\ This paper investigates the problem of bloat in Symbolic Regression (SR). It develops a pro- \\ cedure to simplify superpositions generated by SR. The present approach borrows ideas of \\ equivalent decision simplification and they are applied to create parametric rules of rewriting. \\ Except from eliminating excessive parts of superpositions, these rules reduce dimensionality \\ of parameter space of generated superpositions. Computational experiment is conducted on a \\ dataset related to Brent Crude Oil options. There, the volatility of options prices is approxi- \\ mated by its strike prices and expiration date.
}

Keywords: tree bloat; rule-based simplification; symbolic regression; genetic programming

DOI: $10.21469 / 22233792.3 .1 .01$

\section{Introduction}

This paper addresses the problem of bloat in Genetic Programming (GP) [1] and SR [2]. Symbolic Regression generates superpositions of expert-given primitive functions to fit some given dataset. The applications of SR include feature generation for time series and image processing [3,4], time series forecasting [5-7], dimensionality reduction, and data visualization [8].

Symbolic regression constructs a superposition as syntax tree [9], which structure is evolved iteratively. It may generate overfitted and complex functions $[1,9]$. For example, it tends to evolve trees with introns [9], which add significant complexity to the tree structure [1,5]. Intron is an ineffective piece of code, which is likely to be removed from trees. In the superposition $\cos (x)+0 \cdot \ln (\boldsymbol{x})$, the bold function is an intron, as it does not influence the values of the rest part of the superposition. There is a number of approaches proposed to eliminate introns [10-12]. Another kind of undesirable behavior of GP is a generation of complex superpositions. For example, the function $\sin ^{2}(x)+\cos ^{2}(x)$ is identically equals 1 . Therefore, the calculation of its values is ineffective and this function should be simplified. The approach presented in [12] handles both removing of introns and model simplification. The authors of [12] simplify superpositions for postrun analysis. However, they do not either generate or make use of parametric rules of rewriting, which simplify parametric superpositions. A rule of rewriting is defined by a pair of syntax trees: pattern tree and replacement tree. Pattern tree should be more complex than the replacement tree. Each found occurrence of the pattern tree in superpositions is substituted by the replacement tree The details of this substitution is given below. Finally, the simplified superposition has lesser complexity.

The current paper develops an approach of generation of parametric rules of rewriting. These rules are used then during GP launches. The evolution of superpositions is analyzed in this case. This paper analyzes also the computational complexity of the simplification and compares it with the ones described in [12].

\footnotetext{
*The research was supported by the Russian Foundation for Basic Research grant 16-37-00486.
} 


\section{Motivation}

Several papers $[5,13,14]$ state that GP can benefit from preserving introns. Nevertheless, authors of [12] mention a number of problems caused by tree bloat:

- calculation of values produced by excessive pieces of trees which slows down the process of run;

- generation of sophisticated, uninterpretable models;

- excessive pieces of trees hide the true structural complexity of a superposition; models, proper in the context of application, could be eliminated from a population by complexity penalization;

- tree bloat makes it difficult to analyze the evolution of useful pieces of trees from iteration to iteration; and

- tree bloat masks the true blocks of trees which are inherent for a particular application; peeling these blocks from excessive pieces could improve convergence to a solution.

In this paper, these reasons are followed. The paper [12] considers only simplification of nonparametric superpositions. However, tree bloat influence on the generation of the parametric ones includes several other difficulties:

- evaluation of parameters presented in excessive blocks of code;

- excessive parameters slow down the convergence of parameters optimization procedures; and

- if a solution is found, the parameters in its introns are not defined uniquely; therefore, there is a need of penalty on the norm of parameter vector.

This paper solves these problems by means of rules of rewriting. Therefore, one needs experts to define these rules. However, the set of rules is different in different applications. Moreover, it is not guaranteed that expertly-given list of rules is complete and does not contain mistakes. To provide this, an automatic rule generation procedure has been developed. This procedure creates the full list of rules which are valid for a specific application. It is far better than looking over the primitive set and constructing rules manually.

\section{Problem Statement}

Given a finite primitive set $\mathcal{G}=\left\{f_{1}, \ldots, f_{K}\right\} \cup\left\{x_{1}, \ldots, x_{N}\right\}$ of primitives $\left\{f_{1}, \ldots, f_{K}\right\}$ (some of them are parametric) and terminals $\left\{x_{1}, \ldots x_{N}\right\}$, the set $\mathcal{F}$ of all possible superpositions of them has been considered. This set is referred to as search space. To simplify notation, only univariate superpositions will be considered: $N=1$. Therefore, denote dataset $\mathfrak{D}=\left\{x_{t}\right\}_{t=1}^{\eta}$ where $x_{t} \in \mathbb{R}$ and $\eta$ is the number of points.

Each superposition $s \in \mathcal{F}$ has structural complexity $C(s)$. It is equal to the number of elements from $\mathcal{G}$, which the superposition is composed of. For example, the structural complexity of $s=$ plus2 $\left(\operatorname{linear}\left(x_{1}\right), x_{1}\right)$ is 4 . Denote also $P(s)$ as the number of parameters $W(s)$ in superposition $s$. Given parameters $W(s)$, let $V(s, W(s), \mathfrak{D})$ be the values of $s$ on the dataset $\mathcal{D}$.

Denote the values of $s$ given $x$ over regression points are referred to as $s\left(W(s), x_{1}\right)$.

Some pairs of elements from $\mathcal{F}$ form rules of rewriting. A rule of rewriting is a pair $\left(s_{1}, s_{2}\right)$ such that functions $s_{1}$ and $s_{2}$ are equal and the inequalities $C\left(s_{2}\right)<C\left(s_{1}\right)$ and $P\left(s_{2}\right) \leqslant P\left(s_{1}\right)$ hold. The definition of the equality between $s_{1}$ and $s_{2}$ depends on two cases.

1. Both of them are nonparametric: $P\left(s_{1}\right)=P\left(s_{2}\right)=0$. Then, for each $x \in \mathfrak{D}, s_{1}(x)=s_{2}(x)$.

2. Both of them are parametric. Then, for each $\mathfrak{D}$ and $W\left(s_{1}\right)$, there exist parameters $W\left(s_{2}\right)$ that $s_{1}$ and $s_{2}$ are equal on $\mathfrak{D}: s_{1}\left(W\left(s_{1}\right), x\right)=s_{2}\left(W\left(s_{2}\right), x\right) \forall x \in \mathfrak{D}$. 
Syntax tree of

$x_{1} \tan x_{2}$.

Functions:

$$
\times \cdot \tan .
$$

Terminals:

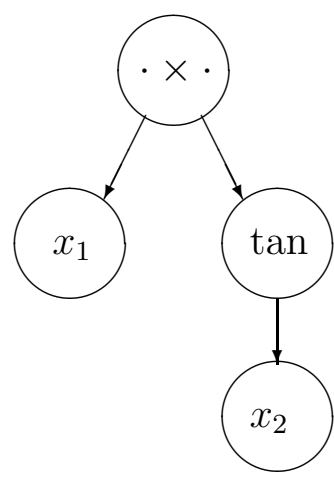

Figure 1 Syntax tree of a superposition

For example, $s_{1}=\sin \left(w_{0} x+w_{1}\right)$ and $s_{2}=\cos \left(w_{0}^{\prime} x+w_{1}^{\prime}\right)$ are equal according to this definition regardless of $\mathfrak{D}$. It holds because for each $W\left(s_{1}\right)$, the superposition $s_{2}$ can be fitted to the values $s\left(W\left(s_{1}\right), \mathfrak{D}\right)$ by optimizing of $W\left(s_{2}\right)$. To fit the superposition, the LevenbergMarquardt algorithm is used. As it does not provide exact values of optimal parameters, let us use a hyperparameter $\tau$ as a threshhold for accuracy. Therefore, two values $s_{1}\left(W\left(s_{1}\right), x\right)$ and $s_{2}\left(W\left(s_{2}\right), x\right)$ are called equal if

$$
\left|s_{1}\left(W\left(s_{1}\right), x\right)-s_{2}\left(W\left(s_{2}\right), x\right)\right|<\tau .
$$

Each superposition $s$ is represented by a syntax tree (Fig. 1). Its height is equal to the length of the longest path from the root to the leaves. The height of the syntax tree shown in Fig. 1 is equal to 2.

This paper aims at extracting all possible rules of rewriting from $\mathcal{F}$ such that the height of the patterns is at most 3. Generated rules are supposed to be mathematical identities, not only approximations on a given range of independent values.

\section{Automatic Procedure of Rules Generation}

This paper borrows ideas presented in [12] and applies them to generate parametric rules. The authors of [12] call functions equivalent, if they have equal values on a dataset. The present authors extended this definition to parametric superpositions. In this section, the procedure of parametric rules generation is described. It is based on the following algorithm (see Algorithm 1).

First, as in [12], let us define a range for $x \in \mathfrak{D}$. It depends solely on the application. If $\mathfrak{D}$ is preprocessed and scaled to a range between 0 and 1 , the range is $[0,1]$. The choice of the range is crucial for rules generation: functions, which are not mathematically identical, can be equal on small intervals. For example, smooth functions are well approximated by linear function in a small neighborhood of $x$. As this paper aims to generate pairs of mathematically identical functions, the range should be rather large. However, estimation of a function on $x$ drawn from very large range suffers from the computational issues. The range $[-3,3]$ was chosen as a rather good trade-off. The dataset of values of $x_{1}$ is drawn from this range.

Second, let us form a primitive set $\mathcal{G}$ of functions and terminals. Generate all possible simple superpositions of elements from the set. Simplicity of a superposition is user-defined. For example, this paper considers only syntax trees of height at most 3. The generated superpositions can contain parameters because parametric primitives are used. For each parametric superposition, let us set random initial parameters. If an application imposes bounds on the parameters of some primitives, the initial parameters should be drawn with respect to these requirements. If the bounds are not imposed, the parameters are drawn from standard normal distribution. 


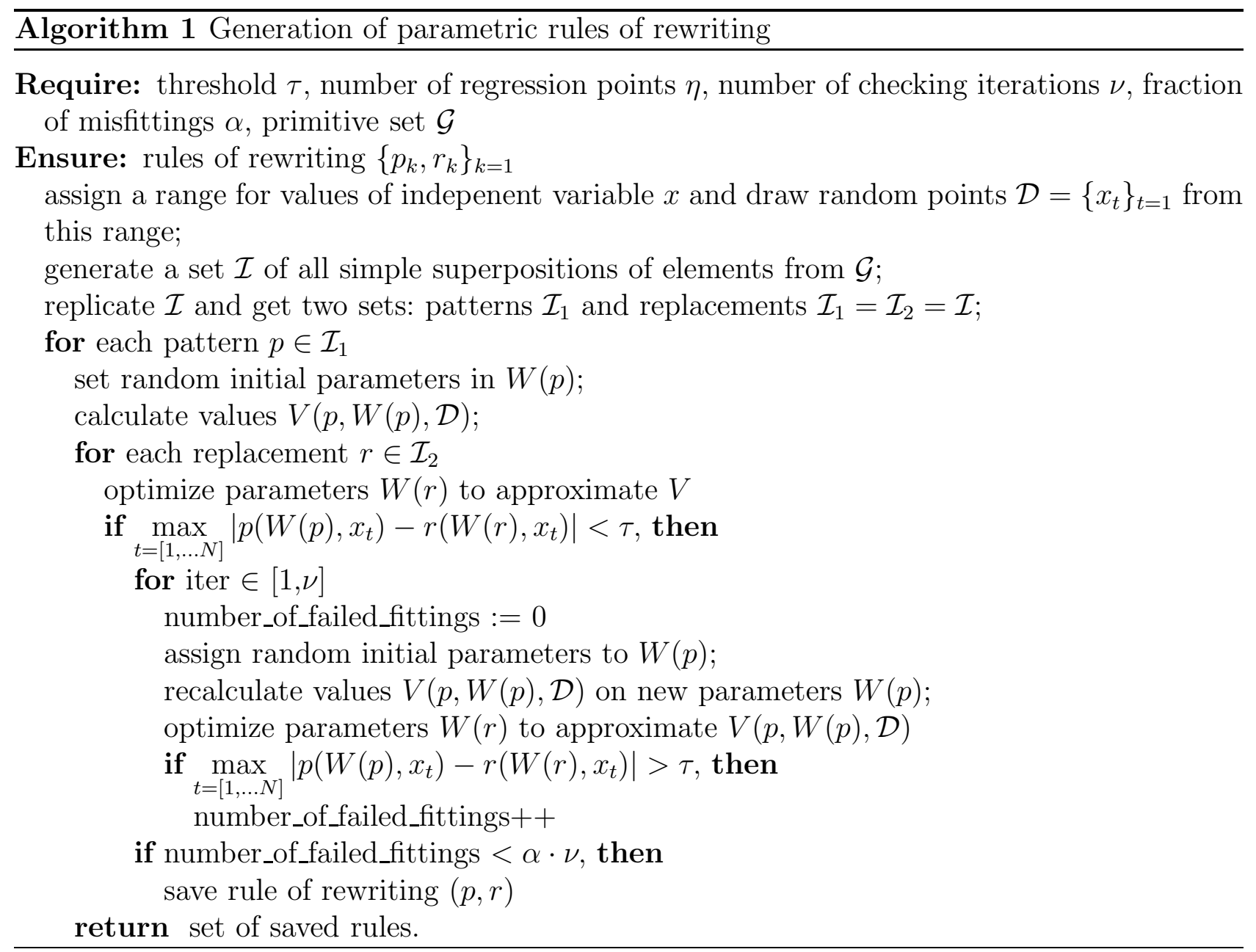

Third, the set of generated superpositions is cloned. The original set acts as a set of patterns for rules and the cloned one is a set of replacements. Let us pick up the patterns consequently and try to fit replacements to them. This requires optimization of a replacement's parameters. The paper uses Levenberg-Marquardt algorithm implemented in scipy.optimize.curve_fit to fit parameters. To check if a replacement represents the same mathematical function with a pattern on a given range, another procedure is required.

\section{Verification of Parametric Functions Equality}

In this section, it is claimed that the functions are equal if they are produced. Assume that the values produced by a pattern with random initial parameters are well approximated by a replacement. Note that one successful fitting is not enough to claim that the pattern equals the replacement. For example, $\sin w_{1} \cdot x+w_{2}$ with parameters $W=[0.01,0.01]$ is well fitted by constant zero. However, the functions are significantly different in the values they produced in general. Therefore, the equality is verified for different random parameters of patterns. Further, let us denote patterns as $p$ and replacements as $r$.

Given a set of candidates $\left\{r_{1}, \ldots, r_{j}\right\}$ to be equal to $p$, let us do the following steps to each replacement $\nu$ times where $\nu$ is user-defined. Random parameters are assigned to $W(p)$ and new dependent values $V(p, W(p), \mathfrak{D})$ are calculated. The parameters $W(r)$ are optimized to fit these values. If the fraction of misfittings is rather small with respect to a user-defined threshold $\alpha$, then $r$ is claimed to be equal to $p$. The number of algorithm applications and the threshold are user-defined. 


\section{Experimental Setup}

In this section, the experiment which consists of two steps is described. First, let us launch the procedure 1 in order to generate rules of simplification. Second, having these rules, let us use simplifying system inside the GP functionality. Here, the best approximating superposition has been extracted on each iteration. Then, the evolution of its mean squared error (MSE) is plotted via the number of iteration. The resulted plot has two lines: one corresponds to the basic version of GP and the other corresponds to the one which uses the present simplification system.

At the start, let us discuss user-defined parameters mentioned in Algorithm 1. Their values are presented in Table 1.

As the paper is aimed at producing the rules of rewriting acting as mathematical identities, the range of $x_{1}$ is chosen to be $[-3,3]$ rather than $[-1,1]$ or $[0,1]$ usually used in different applications. The reason is that, for example, smooth functions are well approximated by polynomials on the unit interval. The interval is not chosen either to be large because of numerical issues. Therefore, a trade-off is reached and it is set equal $[-3,3]$. Producing proper rules of rewriting, it is necessary to check if their do a good generalization on the outer range $(-\infty,-3) \cup(3, \infty)$.

The choice of both number of regression points and number of checking iterations is based on trade-off between computational burden and correctness of algorithm. A dataset of hundred of random regression points seems to be sufficient to produce representative values of function. In other words, the plots of the functions are sufficiently distinct and contain necessary information to make out the function corresponding to a plot.

The other parameters, namely, threshold $\tau$ and fraction of misfittings $\alpha$, are chosen empirically. Note that one $\tau$ is chosen, it does not depend on the number of regression points $\eta$. This is the main reason why there $l_{\infty}$ is preferable to more frequently used MSE. The fact that the fraction of misfittings is not zero is due to imperfection of parameter optimization procedure. As one does not have any prior knowledge about parameters domain, the initial parameters should be set randomly. Therefore, for some functions and some randomly set parameters, optimization procedure, namely, Levenberg-Marquardt algorithm, does not converge or converge in local optimum, which, nevertheless, is not global. This is the reason of why multistart is used to fit a replacement $r$ : optimization is launched from different initial guesses $W(r)$ for the parameters $M_{1}$ times. However, as most computational burden rests with optimization procedure, the use of multistart slows down the process almost in $M_{1}$ times. Therefore, $M_{1}$ is chosen rather small.

As experiment shows, $M_{1}$ is not sufficiently large for replacement parameters to be fitted exactly well, but good enough to give appropriate approximation. Therefore, as generally only a tiny fraction of replacements from $\mathcal{I}_{2}$ is fittable to a pattern, the following strategy is used. For 5 best approximated replacements from $\mathcal{I}_{2}, M_{2} \gg M_{1}$ launches are performed in multistart. This strategy notably improves the generation of rules.

Table 1 User-defined parameters

\begin{tabular}{|c|c|c|c|c|c|c|}
\hline $\begin{array}{c}\text { Range } \\
\text { for } x_{1}\end{array}$ & $\begin{array}{c}\text { Number } \\
\text { of regression } \\
\text { points } \eta\end{array}$ & $\begin{array}{c}\text { Number } \\
\text { of checking } \\
\text { iterations } \nu\end{array}$ & Threshold $\tau$ & $\begin{array}{c}\text { Fraction of } \\
\text { misfittings } \alpha\end{array}$ & $\begin{array}{c}\text { Multistart } \\
\text { iterations } \\
\text { on fitting } M_{1}\end{array}$ & $\begin{array}{c}\text { Multistart } \\
\text { iterations } \\
\text { on checking } M_{1}\end{array}$ \\
\hline$[-3,3]$ & 100 & 50 & 0.04 & 0.04 & 5 & 150 \\
\hline
\end{tabular}


Table 2 Primitive set and their frequencies in patterns

\begin{tabular}{|l|c|c|c|}
\hline \multicolumn{1}{|c|}{ Name } & Function & Number of parameters & Frequency \\
\hline $\operatorname{bump}\left(x_{1}\right)$ & $x_{1}\left[w_{0}<x_{1}\right.$ and $\left.x_{1}<w_{1}\right]$ & 2 & 0.02 \\
$\operatorname{sinc}\left(x_{1}\right)$ & $\frac{\sin \left(\pi\left(w_{1} x_{1}+w_{2}\right)\right)}{\pi\left(w_{1} x_{1}+w_{2}\right)}$ & 2 & 0.04 \\
$\operatorname{hvs}\left(x_{1}\right)$ & $x_{1}\left[w_{0}<x_{1}\right]$ & 1 & 0.02 \\
$\operatorname{sina}\left(x_{1}\right)$ & $\sin \left(w_{1} x_{1}+w_{2}\right)$ & 2 & 0.04 \\
$\operatorname{lnl}\left(x_{1}\right)$ & $\ln \left(w_{1} x_{1}+w_{2}\right)$ & 2 & 0.02 \\
$\operatorname{expl}\left(x_{1}\right)$ & $\exp \left(w_{1} x_{1}+w_{2}\right)$ & 2 & 0.07 \\
$\operatorname{plus} 2\left(x_{1}, x_{2}\right)$ & $x_{1}+x_{2}$ & 0 & 0.32 \\
$\operatorname{normal}\left(x_{1}\right)$ & $\frac{1}{w_{1}} \exp \left(-\frac{\left(x_{1}-w_{2}\right)^{2}}{w_{1}}\right)$ & 2 & 0.05 \\
$\operatorname{frac} 2\left(x_{1}, x_{2}\right)$ & $\frac{x_{1}}{x_{2}}$ & 0 & 0.26 \\
$\operatorname{neg}\left(x_{1}\right)$ & $-x_{1}$ & 0 & 0.16 \\
$\operatorname{hypot}\left(x_{1}, x_{2}\right)$ & $\sqrt{x_{1}^{2}+x_{2}^{2}}$ & 0 & 0.29 \\
$\operatorname{times} 2\left(x_{1}, x_{2}\right)$ & $x_{1} x_{2}$ & 0 & 0.33 \\
$\operatorname{linear}\left(x_{1}\right)$ & $w_{1} x_{1}+w_{2}$ & 2 & 0.14 \\
$\operatorname{parabola}\left(x_{1}\right)$ & $w_{1} x_{1}^{2}+w_{2} x_{1}+w_{3}$ & 3 & 0.10 \\
$\operatorname{unity}()$ & 1 & 0 & 0.36 \\
$\operatorname{zero}()$ & 0 & 0 & 0.18 \\
$\operatorname{parameter}()$ & $w_{1}$ & 1 & 0.41 \\
\hline
\end{tabular}

The primitive set used for construction of superpositions is shown in Table 2. This paper assumes that $x_{1}+x_{2}$ and $x_{2}+x_{1}$ represent the same function. Therefore, for each node of syntax tree corresponding to commutative primitive, its children are ordered in some way.

\section{Generation of Rules}

Now, let us generate rules which have patterns with a height of their syntax trees not exceeding 3. Given the restriction on height, let us generate the set $\mathcal{I}$ of all possible patterns. The resulted set has cardinality $\left|\mathcal{I}\left(x_{1}\right)\right|=22084$ for patterns with only one terminal (univariate case) and $\left|\mathcal{I}\left(x_{1}, x_{2}\right)\right|=42499$ for two terminals (bivariate case). All of them are called candidates as they will form the required rules. Note that the replacements will be taken from these sets as well as patterns. Tables 3 and 4 show the distributions of generated candidates according

Table 3 Distributions of superpositions from $\mathcal{I}$ according to structural complexity $C(\cdot)$ and number of parameters $P(\cdot)$ (univariate case)

\begin{tabular}{|c|c|c|c|c|c|c|c|c|c|}
\hline \multirow[b]{2}{*}{$C(\cdot)$} & \multicolumn{9}{|c|}{$P(\cdot)$} \\
\hline & 0 & 1 & 2 & 3 & 4 & 5 & 6 & 7 & 8 \\
\hline 1 & 3 & 1 & $\overline{0}$ & $\overline{0}$ & $\overline{0}$ & $\overline{0}$ & $\overline{0}$ & $\overline{0}$ & 0 \\
\hline 2 & 3 & 4 & 22 & 10 & 1 & 0 & 0 & 0 & 0 \\
\hline 3 & 30 & 22 & 51 & 63 & 169 & 93 & 17 & 1 & 0 \\
\hline 4 & 72 & 117 & 558 & 396 & 108 & 9 & 0 & 0 & 0 \\
\hline 5 & 441 & 428 & 515 & 613 & 1502 & 1179 & 384 & 59 & 4 \\
\hline 6 & 395 & 749 & 3249 & 3076 & 1325 & 275 & 20 & 0 & 0 \\
\hline 7 & 2106 & 2349 & 1278 & 345 & 46 & 0 & 0 & 0 & 0 \\
\hline
\end{tabular}


Table 4 Distributions of superpositions according to their structural complexities $C(\cdot)$ and number of parameters $P(\cdot)$ (bivariate case)

\begin{tabular}{|c|c|c|c|c|c|c|c|c|c|}
\hline \multirow{2}{*}{$C(\cdot)$} & \multicolumn{9}{|c|}{$P(\cdot)$} \\
\hline & 0 & 1 & 2 & 3 & 4 & 5 & 6 & 7 & 8 \\
\hline 1 & 4 & 1 & 0 & 0 & 0 & 0 & 0 & 0 & 0 \\
\hline 2 & 4 & 5 & 29 & 11 & 1 & 0 & 0 & 0 & 0 \\
\hline 3 & 50 & 29 & 66 & 79 & 220 & 107 & 18 & 1 & 0 \\
\hline 4 & 126 & 186 & 951 & 555 & 123 & 9 & 0 & 0 & 0 \\
\hline 5 & 984 & 741 & 843 & 971 & 2548 & 1700 & 482 & 67 & 4 \\
\hline 6 & 910 & 1534 & 7169 & 5526 & 1910 & 320 & 20 & 0 & 0 \\
\hline 7 & 6124 & 5344 & 2226 & 460 & 46 & 0 & 0 & 0 & 0 \\
\hline
\end{tabular}

to their structural complexities $C(\cdot)$ and number of parameters $P(\cdot)$. The restriction on height provides one with candidates which are either structurally or parametrically simple. One can see from the tables that there are no many candidates, which are structurally complex and have many parameters at the same time. It alleviates the computational burden of the algorithm and allows one to use multistart while preserving reasonable operating time. Note that in this paper, the use of multistart is reasonable only for the task of generation of rules. In general, the use of multistart in the framework of GP, which builds approximating superpositions to the given data, significantly increases its computational complexity.

Then, let us generate rules which have both patterns and replacements from the set of candidates $\mathcal{I}$, see the corresponding bar plot at Fig. 2. Tables 5 and 6 show the distributions of patterns from generated rules according to their structural complexities $C(\cdot)$ and number of parameters $P(\cdot)$.

The tables show that there are again not many superpositions which are simultaneously structurally complex and have many parameters. However, one can see that in the bivariate case, there are significantly more rules which contain complex patterns. Let us explain it. Take a look at Table 2 where the frequencies of primitives are shown. Some primitives tend to appear in patterns significantly more frequently than others. The primitives of zero arity are the most frequent in patterns, but the next popular primitives are bivariate functions, not univariate. It is intuitively clear that patterns, which comprise bivariate functions, tend to be more complex as they have more degrees of freedom. Moreover, they have more terminal vertices in their syntax

Table 5 Distributions of rules patterns according to their structural complexities $C(\cdot)$ and number of parameters $P(\cdot)$ (univariate case)

\begin{tabular}{|c|c|r|r|r|r|r|l|}
\hline \multirow{2}{*}{$C(\cdot)$} & \multicolumn{7}{|c|}{$P(\cdot)$} \\
\cline { 2 - 8 } & 0 & 1 & 2 & 3 & 4 & 5 & 6 \\
\hline 2 & 1 & 3 & 15 & 9 & 1 & 0 & 0 \\
3 & 10 & 8 & 12 & 2 & 3 & 2 & 0 \\
4 & 10 & 10 & 41 & 22 & 6 & 0 & 0 \\
5 & 40 & 18 & 30 & 6 & 7 & 1 & 1 \\
6 & 21 & 16 & 26 & 26 & 9 & 0 & 0 \\
7 & 73 & 78 & 36 & 0 & 0 & 0 & 0 \\
\hline
\end{tabular}


Table 6 Distributions of rules patterns according to their structural complexities $C(\cdot)$ and number of parameters $P(\cdot)$ (bivariate case)

\begin{tabular}{|c|r|r|r|r|r|r|l|}
\hline \multirow{2}{*}{$C(\cdot)$} & \multicolumn{7}{|c|}{$P(\cdot)$} \\
\cline { 2 - 8 } & 0 & 1 & 2 & 3 & 4 & 5 & 6 \\
\hline 2 & 1 & 3 & 15 & 9 & 1 & 0 & 0 \\
3 & 10 & 8 & 12 & 2 & 3 & 2 & 0 \\
4 & 9 & 10 & 41 & 22 & 6 & 0 & 0 \\
5 & 14 & 18 & 22 & 3 & 7 & 1 & 1 \\
6 & 2 & 4 & 9 & 14 & 2 & 0 & 0 \\
7 & 18 & 23 & 10 & 0 & 0 & 0 & 0 \\
\hline
\end{tabular}

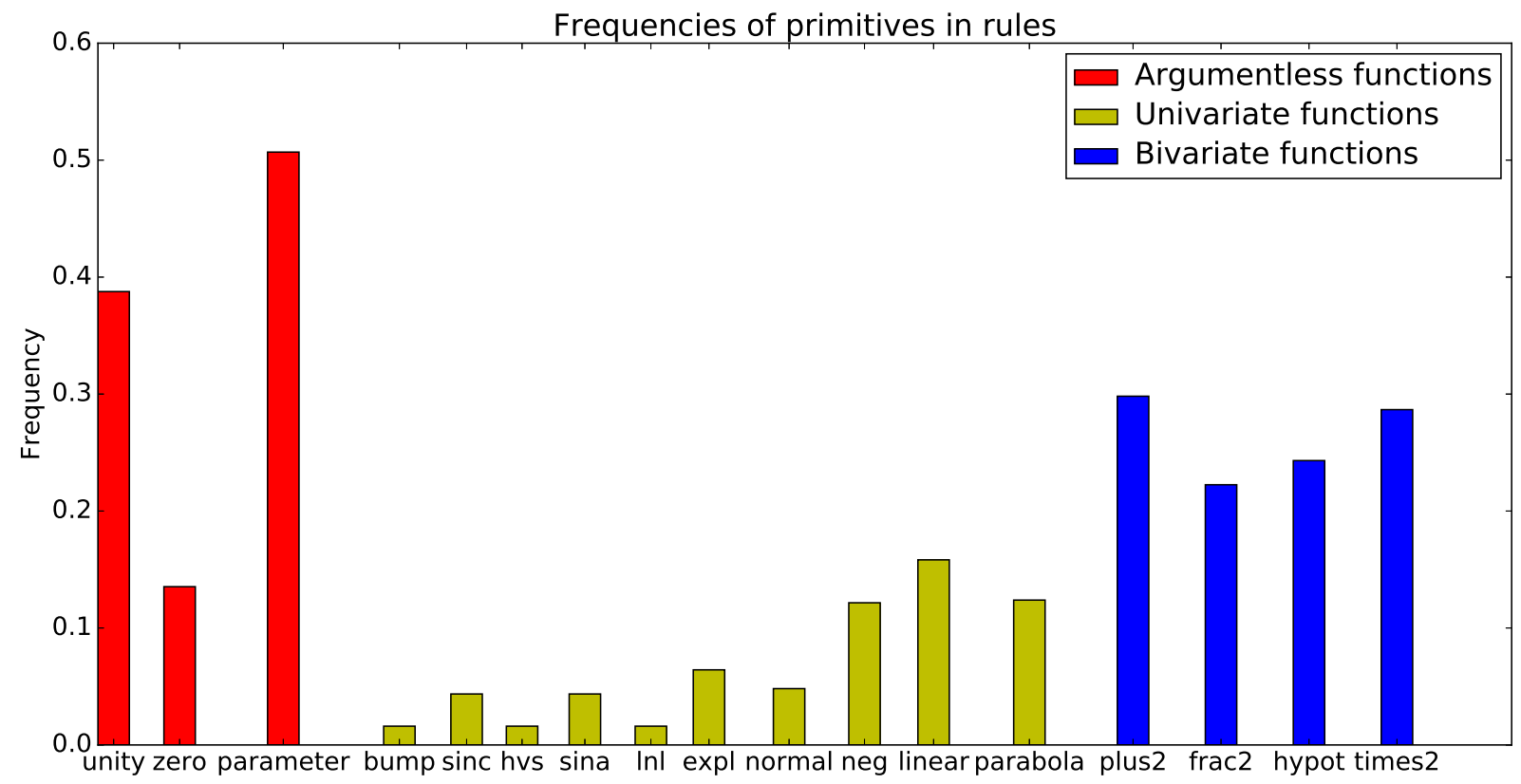

Figure 2 Frequencies of primitives in patterns

trees. Therefore, when the rules are generated in the bivariate case, there are more variants to label these vertices with variables. As a result, more possible rules can be created.

Now, add the primitive minus $2\left(x_{1}, x_{2}\right)=x_{1}-x_{2}$ to the set. Generate parametric rules again. This produces the following bar plot (Fig. 3). Note that the frequency of minus2 is approximately equal to the one of plus2. Moreover, all complex primitives such as ln and exp occur in patterns significantly rarely. This leads to a notion that one can use these frequencies as primitives order of nonlinearity. Of course, one can see that this estimation could be barely applicable to argumentless functions: though zero is a simple primitive, it is as rare as neg in patterns.

\section{Data}

Superpositions generated by GP are fitted to approximate volatility of the European stock options. An option is a contract giving the owner the right, but not the obligation, to sell 


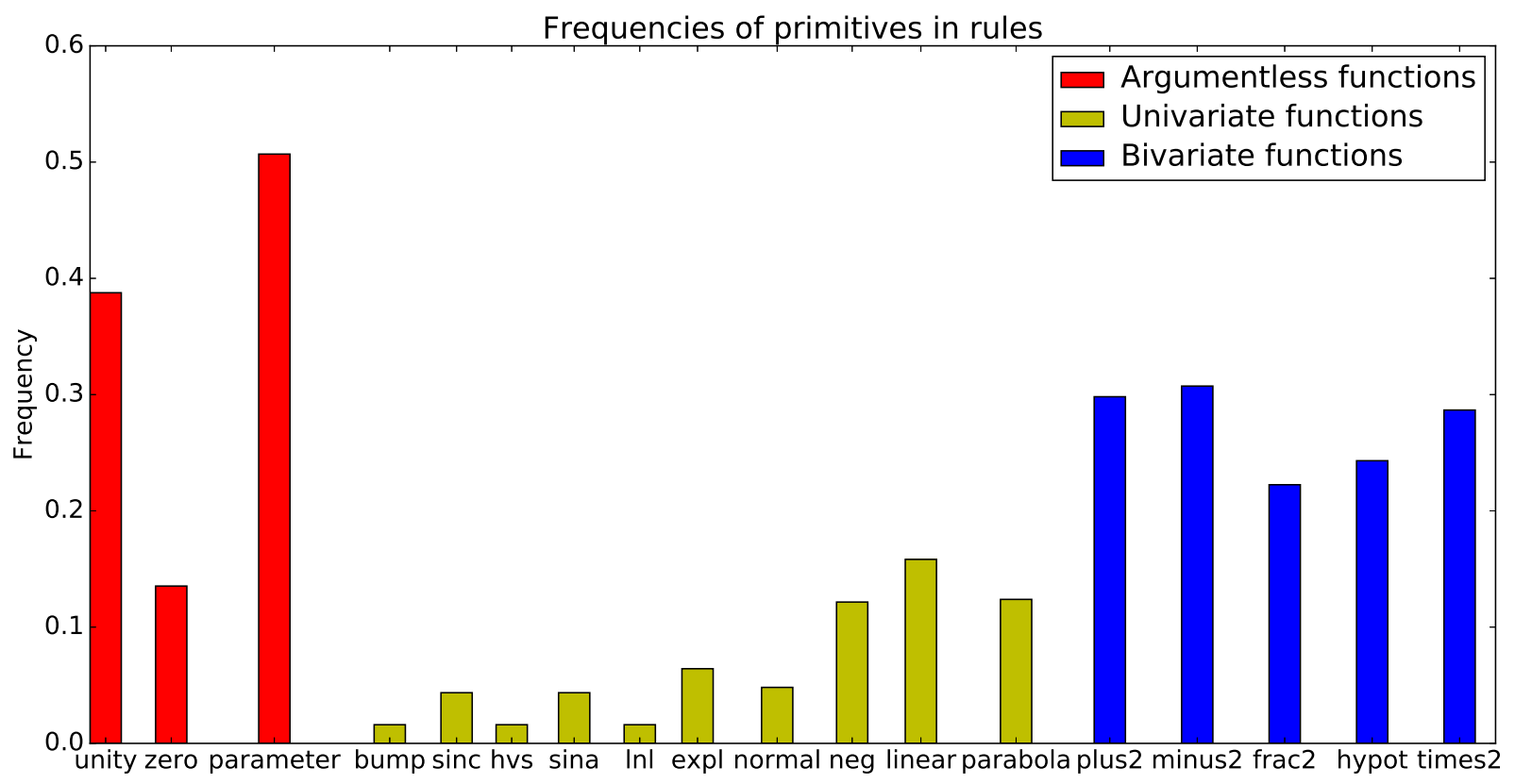

Figure 3 Frequencies of primitives in patterns (with minus2)

a specified amount of an underlying asset at a set price within a specified time called expiration date [15]. A set price of an option is called a strike price [15].

Theoretical estimation of the fair market value of European-style options is given by BlackScholes formula [15]. It has only one parameter which cannot be observed in the market. This parameter is the average future volatility of the underlying asset. Volatility is the degree of variation of a trading price series over time as measured by the standard deviation of returns. In this paper, the volatility of a financial instrument is investigated over a specified period starting at the current time and ending at the expiration date of an option. It is estimated by the market price of an instrument in assumption that the price is relevant to expected risks.

The Black-Scholes model relies on assumptions which imply the independence of the volatility from the strike price and the expiration date. It is assumed that implied volatility value $\sigma^{\text {imp }}$ is calculated as an argmin of the difference between the historical (stated on the trade) and the fair strike price in the Black-Scholes model:

$$
\sigma^{\mathrm{imp}}=\arg \min \left(\mathcal{C}_{\text {hist }}-C(\sigma, \operatorname{Pr}, B, K, t)\right)
$$

where $\mathcal{C}_{\text {hist }}$ is the historical strike price; $C$ is the fair strike price estimated by the Black-Scholes model; $\operatorname{Pr}$ is the price of the instrument; $B$ is the bank rate; $K$ is the strike price; and $t$ is the time left to the expiration date.

To estimate the fair strike price, one must approximate the dependence $\sigma(K, t)$ between the strike price of the instrument, its volatility, and the time left to the expiration date. The dataset is collected and described in [16]. In this paper, a superposition has been found which approximates this dependence.

\section{Embedding of Simplification System into Genetic Programming}

To fit the data, the superpositions of primitives have been generated using symbolic regression and genetic programming [2]. Generation algorithm iteratively creates populations of super- 
Table 7 Parameters of GP

\begin{tabular}{|c|c|c|c|c|c|c|c|}
\hline $\begin{array}{c}\text { Number } \\
\text { of } \\
\text { crossovers }\end{array}$ & $\begin{array}{c}\text { Number } \\
\text { of mutations }\end{array}$ & $\begin{array}{c}\text { Number } \\
\text { of } \\
\text { randomly } \\
\text { generated }\end{array}$ & $\begin{array}{c}\text { Number } \\
\text { of best } \\
\text { selected } \\
\text { models }\end{array}$ & $\begin{array}{c}\text { Error } \\
\text { function } \mathcal{S}\end{array}$ & $\begin{array}{c}\text { Maximum } \\
\text { number } \\
\text { of } \\
\text { parameters }\end{array}$ & $\begin{array}{c}\text { Maximum } \\
C(f)\end{array}$ & $\begin{array}{c}\text { Number } \\
\text { of } \\
\text { iterations }\end{array}$ \\
\hline 60 & 20 & 20 & 30 & $\operatorname{MSE}(f)+\lambda C(f)$ & 20 & 30 & 25 \\
\hline
\end{tabular}
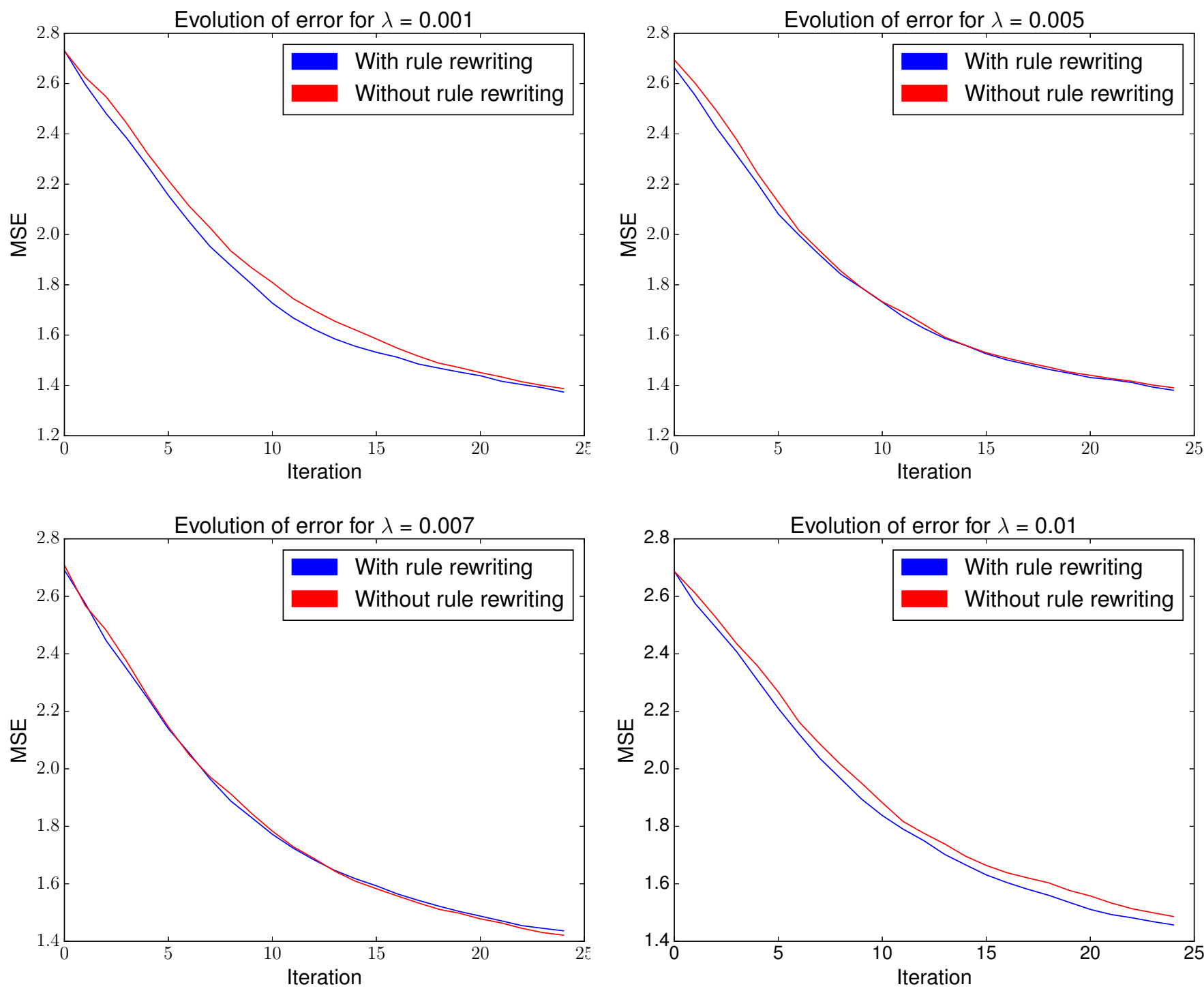

Figure 4 Evolutions of MSE for different $\lambda$

positions in the way such that MSE of the best superposition does not increase from iteration to iteration. Initial set consists of 300 randomly generated superpositions of structural complexity equal to 6. Mutation and crossover [1] are the operations used to create new superpositions. On each iteration, some randomly generated superpositions are appended to the populations in order to maintain its diversity. The parameters of the generated parametric superpositions are evaluated by Levenberg-Marquardt algorithm. Then, the best superpositions have been selected from the currently generated population according to an error function $\mathcal{S}(f)$ 

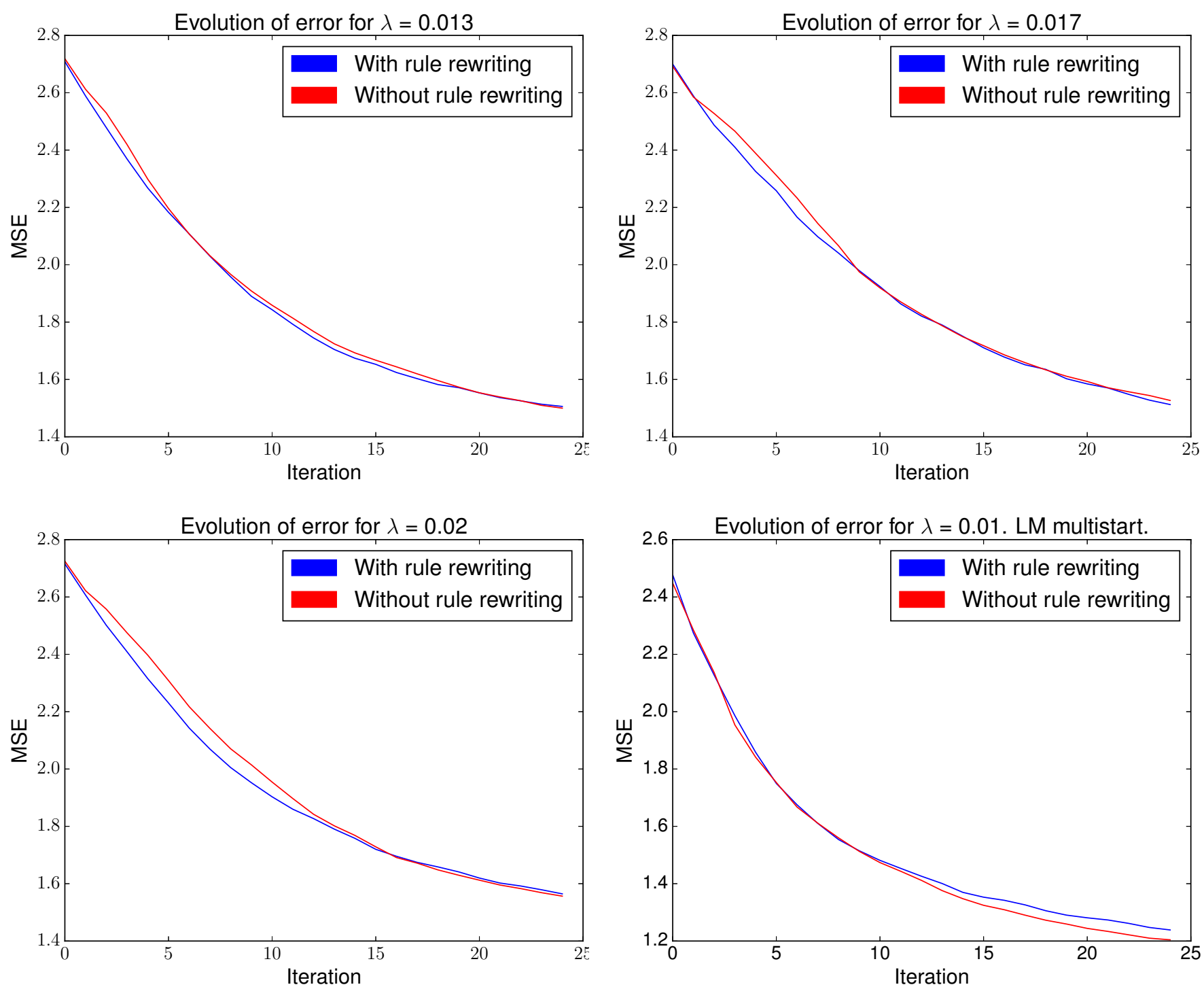

Figure 5 Evolutions of MSE for different $\lambda$

$=\mathrm{MSE}+\lambda C(f)$. On each iteration, the best 30 superpositions according to $\mathcal{S}$ form the population for the next iteration. All parameters of GP are shown in Table 7.

The parameter $\lambda$ in the expression of $\mathcal{S}$ varies for different experiments. Its values are taken from the set $\lambda \in[0.001,0.005,0.007,0.01,0.013,0.017,0.02]$. If it is either smaller than 0.001 or larger than 0.02 , the generated superpositions either complicated or inaccurate, respectively. For each value, GP was lauched 400 times, evolutions of MSE of the best approximating superposition were stored, and they were averaged over the launches. The averaged evolutions of MSE were analyzed for two approaches: the basic version of GP and the modified one, which uses simplification system. This analysis in conducted with respect to the value of $\lambda$.

The results are presented on the first 7 plots of Figs. 4 and 5 . One can see that the results are quite unstable: the gap between these two lines keeps appearing and disappearing. At the same time, it is notable that the blue line, corresponding to the rule rewriting case, is always below the red line. It means that application of the simplification system slightly improves GP. However, the relative difference between the lines becomes negligible by the 25th iteration for all values of $\lambda$. Therefore, the actual improvement of GP is not truly significant. 
Finally, take a look at the last plot in Fig. 5. In this particular experiment, the same functionality of GP has been used except for the procedure, which estimates parameters of superpositions. In the previous experiments, only one launch of Levenberg-Marquardt algorithm has been used for this purpose. Now, we make three launches with different initial random guesses: we perform the so-called multistart procedure. The evolutions of MSE in this case are plotted on the last plot of Fig. 5. One can see that here, we have growing gap between the lines and the basic version of GP is better. Therefore, the slight advantage of the modified GP version is vanished by using of multistart. However, the use of multistart significantly increases the CPU required by GP. Therefore, if one cannot increase computational complexity of GP, the modified version of GP remains a little bit preferable to the basic one.

\section{Concluding Remarks}

In this paper, an exhaustive algorithm of rules creation has been proposed. These rules are used to simplify superpositions generated by GP. It allows to improve their structural complexity and reduce dimensionality of the parameters space. The distributions of primitives have been analyzed in the created rules. It has been found that the frequency of a primitive could be treated as a crude estimation of its nonlinearity. Averaged evolutions of MSE of the best approximating superposition have been analyzed for basic and modified versions of GP. It has been shown a slight improvement of the modified version over the basic one, though asymptotically they are equivalent. This improvement is vanished when one uses multistart to tune parameters of superpositions by Levenberg-Marquardt algorithm. However, multistart significantly increases the computational complexity of GP.

\section{References}

[1] Koza, J. R. 1992. Genetic programming: On the programming of computers by means of natural selection. Cambridge, MA: MIT Press. 836 p.

[2] Zelinka, I., Z. Oplatkova, and L. Nolle. 2005. Analytic programming - symbolic regression by means of arbitrary evolutionary algorithms. Int. J. Simul. Syst. Sci. Technol. 6(9):44-56.

[3] Eads, D., D. Hill, S. Davis, et al. 2002. Genetic algorithms and support vector machines for time series classification. Applications and science of neural networks, fuzzy systems, and evolutionary computation V. Eds. B. Bosacchi, D. B. Fogel, and J. C. Bezdek. Proc. SPIE. Vol. 4787. doi: 10. $1117 / 12.453526$.

[4] Eads, D., K. Glocer, S. Perkins, and J. Theiler. 2005. Grammar-guided feature extraction for time series classification. 9th Annual Conference on Neural Information Processing Systems Proceedings. 8 p.

[5] Wagner, N., Z. Michalewicz, M. Khouja, and R. R. McGregor. 2007. Time series forecasting for dynamic environments: The dyfor genetic program model. IEEE Trans. Evolut. Comput. 11(4):433-452. doi: 10.1109/TEVC.2006.882430.

[6] Pennachin, C., M. Looks, and J.A. de Vasconcelos. 2011. Improved time series prediction and symbolic regression with affine arithmetic. Genetic programming theory and practice IX. Eds. R. Riolo, E. Vladislavleva, and J.-H. Moore. Genetic and evolutionary computation ser. New York, NY: Springer-Verlag. 97-112.

[7] Sheta, A.F., S. E. M. Ahmed, and H. Faris. 2015. Evolving stock market prediction models using multigene symbolic regression Genetic Programming. AIML 15(1).

[8] Icke, I., and A. Rosenberg. 2010. Dimensionality reduction using symbolic regression. 12th Annual Conference Companion on Genetic and Evolutionary Computation Proceedings. New York, NY: ACM. 2085-2086. doi: 10.1145/1830761.1830874. 
[9] Poli, R., W. B. Langdon, and N. F. McPhee. 2008. A field guide to Genetic Programming. Lulu Enterprises, UK Ltd. 250 p.

[10] Soule, T., J. A. Foster, and J. Dickinson. 1996. Code growth in genetic programming. 1st Annual Conference on Genetic Programming Proceedings. Cambridge, MA: MIT Press. 215-223. Available at: http://dl.acm.org/citation.cfm?id=1595536.1595563 (accessed May 31, 2017).

[11] Soule, T., and J.A. Foster. 1997. Support for multiple causes of code growth in GP. Workshop on Evolutionary Computation with Variable Size Representation at ICGA-97. East Lansing, MI.

[12] Mori, N., R. McKay, X.H. Nguyen, and D. Essam. 2007. Equivalent decision simplification: A new method for simplifying algebraic expressions in Genetic Programming. 11th Asia-Pacific Symposium on Intelligent and Evolutionary Systems Proceedings. Yokosuka, Japan.

[13] Iba, H., H. de Garis, and T. Sato. 1994. Genetic Programming using a minimum description length principle. Advances in Genetic Programming. Ed. K. E. Kinnear, Jr. Cambridge, MA: MIT Press. 265-284.

[14] Levenick, J. 1999. Swappers: Introns promote flexibility, diversity and invention. 1st Annual Conference on Genetic and Evolutionary Computation Proceedings. San Francisco, CA: Morgan Kaufmann Publishers Inc. 1:361-368.

[15] Hull, J. C. 2008. Options, futures, and other derivatives. 7th ed. Prentice Hall. 848 p.

[16] Strijov, V. 2009. The inductive generation of the volatility smile models. Ph.D. Thesis.

Received December 15, 2016

\title{
Порождение параметрических правил упрощения алгебраических выражений в задаче символьной регрессии*
}

\author{
А. С. Кулунчаков \\ kulu-andrej@yandex.ru
}

Московский физико-технический институт, Россия, г. Долгопрудный, Институтский пер., д. 9

Исследуется проблема раздувания кода в символьной регрессии. Предлагается процедура упрощения суперпозиций, порождаемых символьной регрессией. Предлагаемый подход основан на идее эквивалентных преобразований суперпозиций, которая применяется к порождению параметрических правил упрощения. Помимо удаления неэффективного кода суперпозиций эти правила сокращают размерность их пространства параметров. Вычислительный эксперимент проводится на выборке по опционам Brent Crude Oil. Их волатильность аппроксимируется через цену исполнения опциона и дату окончания его срока действия.

Ключевые слова: раздутие кода; упрощение по правилам; символьная регрессия; генетическое программирование

DOI: $10.21469 / 22233792.3 .1 .01$

\section{Литература}

[1] Koza J.R. Genetic Programming: On the programming of computers by means of natural selection. - Cambridge, MA, USA: MIT Press, 1992. 836 p.

*Работа была поддержана грантом РФФИ № 16-37-00486. 
[2] Zelinka I., Oplatkova Z., Nolle L. Analytic programming - symbolic regression by means of arbitrary evolutionary algorithms // Int. J. Simul. Syst. Sci. Technol., 2005. Vol. 6. No. 9. P. 4456.

[3] Eads D., Hill D., Davis S., et al. Genetic algorithms and support vector machines for time series classification // Applications and science of neural networks, fuzzy systems, and evolutionary computation V / Eds. B. Bosacchi, D. B. Fogel, J. C. Bezdek. - Proc. SPIE, 2002. Vol. 4787. doi: $10.1117 / 12.4535526$.

[4] Eads D., Glocer K., Perkins S., Theiler J. Grammar-guided feature extraction for time series classification // 9th Annual Conference on Neural Information Processing Systems Proceedings, 2005. 8 p.

[5] Wagner N., Michalewicz Z., Khouja M., McGregor R.R. Time series forecasting for dynamic environments: The dyfor genetic program model // IEEE Trans. Evolut. Comput., 2007. Vol. 11. No. 4. P. 433-452. doi: 10.1109/TEVC.2006.882430.

[6] Pennachin C., Looks M., de Vasconcelos J.A. Improved time series prediction and symbolic regression with affine arithmetic // Genetic programming theory and practice IX / Eds. R. Riolo, E. Vladislavleva, J.-H. Moore. - Genetic and evolutionary computation ser. - New York, NY, USA: Springer-Verlag, 2011. P. 97-112.

[7] Sheta A.F., Ahmed S/E.M., Faris H. Evolving stock market prediction models using multigene symbolic regression Genetic Programming // AIML, 2015. Vol. 15. Iss. 1.

[8] Icke I., Rosenberg A. Dimensionality reduction using symbolic regression // 12th Annual Conference Companion on Genetic and Evolutionary Computation Proceedings. - New York, NY, USA: ACM, 2010. P. 2085-2086. doi: 10.1145/1830761.1830874.

[9] Poli R., Langdon W. B., McPhee N. F. A field guide to Genetic Programming. - Lulu Enterprises, UK Ltd., 2008. 250 p.

[10] Soule T., Foster J.A., Dickinson J. Code growth in genetic programming // 1st Annual Conference on Genetic Programming Proceedings. - Cambridge, MA, USA: MIT Press, 1996. P. 215-223. http://dl.acm.org/citation.cfm?id=1595536.1595563.

[11] Soule T., Foster J.A. Support for multiple causes of code growth in GP // Workshop on Evolutionary Computation with Variable Size Representation at ICGA-97. - East Lansing, MI, USA, 1997.

[12] Mori N., McKay R., Nguyen X.H., Essam D. Equivalent decision simplification: A new method for simplifying algebraic expressions in Genetic Programming // 11th Asia-Pacific Symposium on Intelligent and EvolutionarySistems Proceedings. - Yokosuka, Japan, 2007.

[13] Iba H., de Garis H., Sato T. Genetic Programming using a minimum description length principle // Advances in Genetic Programming / Ed. K. E. Kinnear, Jr. - Cambridge, MA, USA: MIT Press, 1994. P. 265-284.

[14] Levenick J. Swappers: Introns promote flexibility, diversity and invention // 1st Annual Conference on Genetic and Evolutionary Computation Proceedings. - San Francisco, CA, USA: Morgan Kaufmann Publishers Inc., 1999. Vol. 1. P. 361-368.

[15] Hull J. C. Options, futures, and other derivatives. - 7th ed. - Prentice Hall, 2008. 848 p.

[16] Strijov $V$. The inductive generation of the volatility smile models. Ph. D. Thesis, 2009. 


\title{
Faster variational inducing input Gaussian process classification
}

\author{
P. A. Izmailov and D. A. Kropotov \\ izmailovpavel@gmail.com; dmitry.kropotov@gmail.com \\ Lomonosov Moscow State University, 1 Leninskie Gory, Moscow, Russia
}

\begin{abstract}
Background: Gaussian processes (GP) provide an elegant and effective approach to learning in kernel machines. This approach leads to a highly interpretable model and allows using the Bayesian framework for model adaptation and incorporating the prior knowledge about the problem. The GP framework is successfully applied to regression, classification, and dimensionality reduction problems. Unfortunately, the standard methods for both GP-regression and GP-classification scale as $\mathcal{O}\left(n^{3}\right)$, where $n$ is the size of the dataset, which makes them inapplicable to big data problems. A variety of methods have been proposed to overcome this limitation both for regression and classification problems. The most successful recent methods are based on the concept of inducing inputs. These methods reduce the computational complexity to $\mathcal{O}\left(\mathrm{nm}^{2}\right)$ where $m$ is the number of inducing inputs with $m$ typically much less than $n$. The present authors focus on classification. The current state-of-the-art method for this problem is based on stochastic optimization of an evidence lower bound (ELBO) that depends on $\mathcal{O}\left(\mathrm{m}^{2}\right)$ parameters. For complex problems, the required number of inducing points $m$ is fairly big, making the optimization in this method challenging.

Methods: The structure of variational lower bound that appears in inducing input GP classification has been analyzed. First, it has been noted that using quadratic approximation of several terms in this bound, it is possible to obtain analytical expressions for optimal values of most of the optimization parameters, thus sufficiently reducing the dimension of optimization space. Then, two methods have been provided for constructing necessary quadratic approximations: one is based on Jaakkola-Jordan bound for logistic function and the other is derived using Taylor expansion.

Results: Two new variational lower bounds have been proposed for inducing input GP classification that depend on a number of parameters. Then, several methods have been suggested for optimization of these bounds and the resulting algorithms have been compared with the state-of-the-art approach based on stochastic optimization. Experiments on a bunch of classification datasets show that the new methods perform the same or better results than the existing one. However, new methods do not require any tunable parameters and can work in settings within a big range of $n$ and $m$ values, thus significantly simplifying training of GP classification models.
\end{abstract}

Keywords: Gaussian process; classification; variational inference; big data; inducing inputs; optimization; variational lower bound

DOI: $10.21469 / 22233792.3 .1 .02$

\section{Introduction}

Gaussian processes provide a prior over functions and allow finding complex regularities in data. Gaussian processes are successfully used for classification/regression problems and dimensionality reduction [1]. In this work, only the classification problem is considered.

Standard methods for GP-classification scale as $\mathcal{O}\left(n^{3}\right)$ where $n$ is the size of the training dataset. This complexity makes them inapplicable to big data problems. Therefore, a variety of methods were introduced to overcome these limitations [2-4]. The focus of the paper is on the methods based on so-called inducing inputs. Paper [5] introduces the inducing inputs 
approach for training GP models for regression. This approach is based on variational inference and proposes a particular lower bound for marginal likelihood (evidence). This bound is then maximized with regard to parameters of kernel function of the GP, thus fitting the model to data. The computational complexity of this method is $\mathcal{O}\left(n m^{2}\right)$ where $m$ is the number of inducing inputs used by the model and is assumed to be substantially smaller than $n$. Paper [6] develops these ideas by showing how to apply stochastic optimization to the ELBO similar to the one used in [5]. However, a new lower bound depends on $\mathcal{O}\left(\mathrm{m}^{2}\right)$ variational parameters that makes optimization in the case of big $m$ challenging.

Paper [7] shows how to apply the approach from [6] to the GP-classification problem. It provides a lower bound that can be optimized with regard to kernel parameters and variational parameters using stochastic optimization. However, the lower bound derived in [7] is intractable and has to be approximated via Gauss-Hermite quadratures or other integral approximation techniques. This lower bound is also fit for stochastic optimization and depends on $\mathcal{O}\left(\mathrm{m}^{2}\right)$ parameters.

In this work, a new approach was developed for training inducing input GP models for classification problems. Here, a structure of variational lower bound from [7] was analyzed. It has been noted that using quadratic approximation of several terms in this bounds, it is possible to obtain analytical expressions for optimal values of the most of optimization parameters, thus sufficiently reducing the dimension of optimization space. So, two methods have been provided for constructing necessary quadratic approximations: one based on Jaakkola-Jordan bound for logistic function and the other derived using Taylor expansion.

The paper is organized as follows. In section 2, the standard GP-classification framework and its main limitations are described. In section 3, the concept of inducing inputs is introduced and the ELBO of [7] is derived. Section 4 contains the main contribution - two new tractable ELBO and different methods for their optimization. Section 5 provides experimental comparison of new methods with the existing approach from [7], The last section concludes the paper.

\section{Gaussian processes classification model}

In this section, classic GP framework and its application for classification problems (for detailed discussion, see [1]) are reviewed.

\subsection{Gaussian process definition}

A GP is a collection of random variables, any finite number of which has a joint Gaussian distribution.

Here, only the processes that take place in a finite-dimensional real space $\mathbb{R}^{d}$ are considered. In this case, $f$ is the GP if for any $k$, for any $\boldsymbol{t}_{1}, \ldots, \boldsymbol{t}_{k} \in \mathbb{R}^{d}$, the joint distribution

$$
\left(f\left(\boldsymbol{t}_{1}\right), \ldots, f\left(\boldsymbol{t}_{k}\right)\right)^{\top} \sim \mathcal{N}\left(\boldsymbol{m}_{t}, \boldsymbol{K}_{t}\right)
$$

for some $\boldsymbol{m}_{t} \in \mathbb{R}^{k}$ and $\boldsymbol{K}_{t} \in \mathbb{R}^{k \times k}$.

Mean $\boldsymbol{m}_{t}$ of this distribution is defined by the mean function $m: \mathbb{R}^{d} \rightarrow \mathbb{R}$ of the GP:

$$
\boldsymbol{m}_{t}=\left(m\left(\boldsymbol{t}_{1}\right), \ldots, m\left(\boldsymbol{t}_{k}\right)\right)^{\mathrm{T}} .
$$

Similarly, the covariance matrix $\boldsymbol{K}_{t}$ is defined by the covariance function $k: \mathbb{R}^{d} \times \mathbb{R}^{d} \rightarrow \mathbb{R}$ :

$$
\boldsymbol{K}_{t}=\left(\begin{array}{cccc}
k\left(\boldsymbol{t}_{1}, \boldsymbol{t}_{1}\right) & k\left(\boldsymbol{t}_{1}, \boldsymbol{t}_{2}\right) & \cdots & k\left(\boldsymbol{t}_{1}, \boldsymbol{t}_{n}\right) \\
k\left(\boldsymbol{t}_{2}, \boldsymbol{t}_{1}\right) & k\left(\boldsymbol{t}_{2}, \boldsymbol{t}_{2}\right) & \cdots & k\left(\boldsymbol{t}_{2}, \boldsymbol{t}_{n}\right) \\
\vdots & \vdots & \vdots & \vdots \\
k\left(\boldsymbol{t}_{n}, \boldsymbol{t}_{1}\right) & k\left(\boldsymbol{t}_{n}, \boldsymbol{t}_{2}\right) & \cdots & k\left(\boldsymbol{t}_{n}, \boldsymbol{t}_{n}\right)
\end{array}\right) .
$$




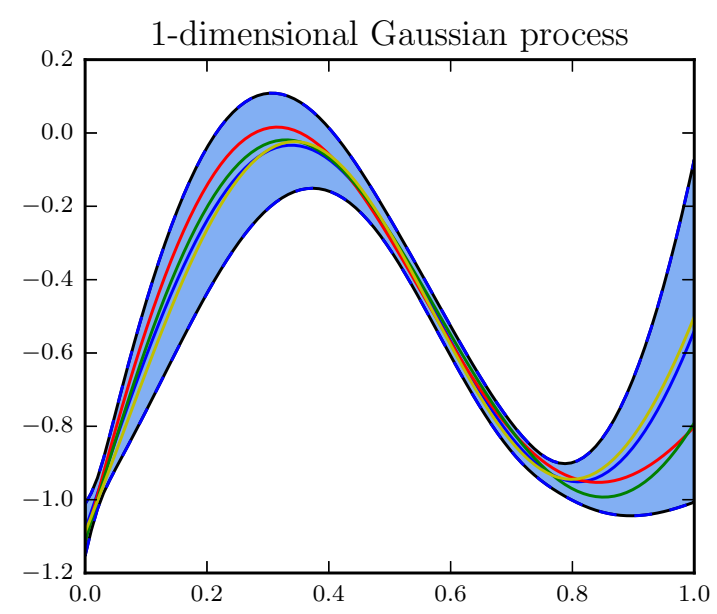

Figure 1 One-dimensional GP

Then, it is straightforward that a GP is completely defined by its mean and covariance functions. Let us use the following notation:

$$
f \sim \mathcal{G P}(m(\cdot), k(\cdot, \cdot)) .
$$

While the mean function $m$ can be an arbitrary real-valued function, the covariance function $k$ has to be a kernel, so that the covariance matrices (1) it implies are symmetric and positive definite.

Figure 1 shows an example of a one-dimensional GP. The dark blue line is the mean function of the process, the light blue region is the $3 \sigma$-region, and different color curves are the samples from the process.

\subsection{Gaussian process classification}

Now, let us apply GP to a binary classification problem. Suppose, one has a dataset $\left\{\left(\boldsymbol{x}_{i}, y_{i}\right) \mid i=\right.$ $=1, \ldots, n\}$ where $\boldsymbol{x}_{i} \in \mathbb{R}^{d}, y_{i} \in\{-1,1\}$. Denote the matrix comprised of points $\boldsymbol{x}_{1}, \ldots, \boldsymbol{x}_{n}$ by $\boldsymbol{X} \in \mathbb{R}^{n \times d}$ and the vector of corresponding class labels $y_{1}, \ldots, y_{n}$ by $\boldsymbol{y} \in\{-1,1\}^{n}$. The task is to predict the class label $y_{*} \in\{-1,1\}$ at a new point $\boldsymbol{x}_{*} \in \mathbb{R}^{d}$.

Let us consider the following model. First, let us introduce a latent function $f: \mathbb{R}^{d} \rightarrow \mathbb{R}$ and put a zero-mean GP prior over it:

$$
f \sim \mathcal{G P}(0, k(\cdot, \cdot))
$$

for some covariance function $k(\cdot, \cdot)$. For now, the covariance function is supposed to be fixed.

Then, let us consider the probability of the object $\boldsymbol{x}_{*}$ belonging to positive class to be equal to $\sigma\left(f\left(\boldsymbol{x}_{*}\right)\right)$ for the chosen sigmoid function $\sigma$ :

$$
p\left(y_{*}=+1 \mid \boldsymbol{x}_{*}\right)=\sigma\left(f\left(\boldsymbol{x}_{*}\right)\right) .
$$

In this work, the logistic function $\sigma(z)=(1+\exp (-z))^{-1}$ is used; however, one could use other sigmoid functions as well.

The probabilistic model for this setting is given by

$$
p(\boldsymbol{y}, \boldsymbol{f} \mid \boldsymbol{X})=p(\boldsymbol{y} \mid \boldsymbol{f}) p(\boldsymbol{f} \mid \boldsymbol{X})=p(\boldsymbol{f} \mid \boldsymbol{X}) \prod_{i=1}^{n} p\left(y_{i} \mid f_{i}\right)
$$




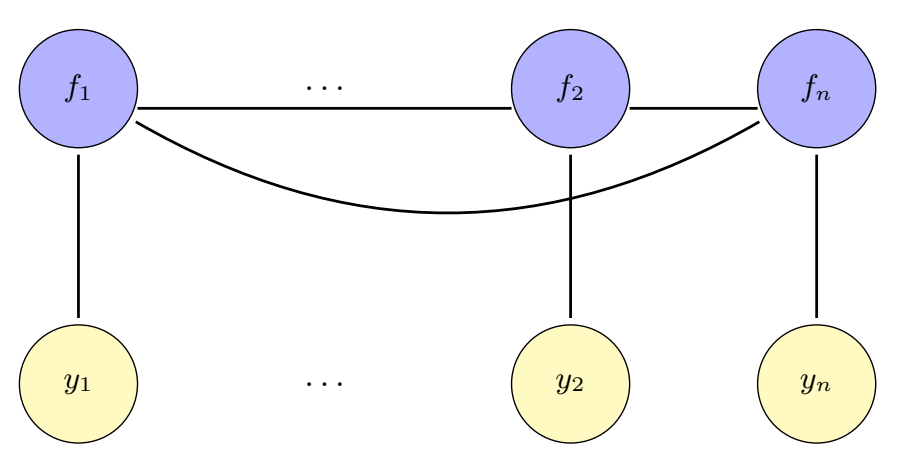

Figure 2 Gaussian process classification graphical model

where $p\left(y_{i} \mid f_{i}\right)$ is the sigmoid likelihood (2) and $p(\boldsymbol{f} \mid \boldsymbol{X})=\mathcal{N}(\boldsymbol{f} \mid \mathbf{0}, K(\boldsymbol{X}, \boldsymbol{X}))$ is the GP prior. The corresponding probabilistic graphical model is given in Fig. 2.

Now, inference in model (3) can be done in two steps. First, for new data point $\boldsymbol{x}_{*}$, one should find the conditional distribution of the corresponding value of the latent process $f_{*}$. This can be done as follows:

$$
p\left(f_{*} \mid \boldsymbol{y}, \boldsymbol{X}, \boldsymbol{x}_{*}\right)=\int p\left(f_{*} \mid \boldsymbol{f}, \boldsymbol{X}, \boldsymbol{x}_{*}\right) p(\boldsymbol{f} \mid \boldsymbol{y}, \boldsymbol{X}) d \boldsymbol{f} .
$$

Second, the probability that $\boldsymbol{x}_{*}$ belongs to the positive class is obtained by marginalizing over the latent variable $f_{*}$ :

$$
p\left(y_{*}=+1 \mid \boldsymbol{y}, \boldsymbol{X}, \boldsymbol{x}_{*}\right)=\int \sigma\left(f_{*}\right) p\left(f_{*} \mid \boldsymbol{y}, \boldsymbol{X}, \boldsymbol{x}_{*}\right) d f_{*} .
$$

Unfortunately, both integrals (4) and (5) are intractable since they involve a product of sigmoid functions and normal distributions. Thus, one has to use some integral-approximation techniques to estimate the predictive distribution.

For example, one can use Laplace approximation method, which builds a Gaussian approximation $q(\boldsymbol{f} \mid \boldsymbol{y}, \boldsymbol{X})$ to the true posterior $p(\boldsymbol{f} \mid \boldsymbol{y}, \boldsymbol{X})$. Substituting this Gaussian approximation back into (4), one obtains a tractable integral. The predictive distribution (5) remains intractable but since this is a one-dimensional integral, it can be easily estimated by quadratures or other techniques. The more detailed derivation of this algorithm and another algorithm, based on Expectation Propagation, can be found in [1].

Computational complexity of computing the predictive distribution both for the Laplace approximation method and Expectation Propagation scales as $\mathcal{O}\left(n^{3}\right)$ since they both require to invert $n \times n$ matrix $K(\boldsymbol{X}, \boldsymbol{X})$. In section 3 , the concept of inducing points aimed to reduce this complexity is described.

\subsection{Model adaptation}

In the previous subsection, it was described how to fit a GP to the data in the classification problem. However, only GP with fixed covariance functions have been considered. This model can be rather limiting.

Most of the popular covariance functions have a set of parameters, which are referred to here as covariance (or kernel) hyperparameters. For example, the squared exponential covariance function

$$
k_{\mathrm{SE}}\left(\boldsymbol{x}, \boldsymbol{x}^{\prime} ; \boldsymbol{\theta}\right)=\sigma^{2} \exp \left(-\frac{\left\|\boldsymbol{x}-\boldsymbol{x}^{\prime}\right\|^{2}}{l^{2}}\right)
$$


has two parameters $\boldsymbol{\theta}$ : variance $\sigma$ and length-scale $l$. An example of a more complicated popular covariance function is the Matern function, given by

$$
k_{\text {Matern }}\left(\boldsymbol{x}, \boldsymbol{x}^{\prime} ; \boldsymbol{\theta}\right)=\frac{2^{1-\nu}}{\Gamma(\nu)}\left(\frac{\sqrt{2 \nu}\left\|\boldsymbol{x}-\boldsymbol{x}^{\prime}\right\|}{l}\right)^{\nu} K_{\nu}\left(\frac{\sqrt{2 \nu}}{\left\|\boldsymbol{x}-\boldsymbol{x}^{\prime}\right\|} l\right),
$$

with two positive parameters $\boldsymbol{\theta}=(\nu, l)$. Here, $K_{\nu}$ is the modified Bessel function.

In order to get a good model for the data, one should find a good set of kernel hyperparameters $\boldsymbol{\theta}$. Bayesian paradigm provides a way of tuning the kernel hyperparameters of the GP-model through maximization of the model evidence (marginal likelihood) that is given by

$$
p(\boldsymbol{y} \mid \boldsymbol{X}, \boldsymbol{\theta})=\int p(\boldsymbol{y} \mid \boldsymbol{f}) p(\boldsymbol{f} \mid \boldsymbol{X}, \boldsymbol{\theta}) d \boldsymbol{f} \rightarrow \max _{\boldsymbol{\theta}}
$$

However, this integral is intractable for the model (3) since it involves a product of sigmoid functions and normal distribution. In subsequent sections, several methods to construct a variational lower bound to the marginal likelihood will be described. Maximizing this lower bound with respect to kernel hyperparameters $\boldsymbol{\theta}$, one could fit the model to the data.

\section{Variational inducing point Gaussian process classification}

In the previous section, it was shown how GP can be applied to solve classification problems. The computational complexity of GP for classification scales as $\mathcal{O}\left(n^{3}\right)$ that makes this method inapplicable to big data problems.

A number of approximate methods have been proposed in the literature for both GPregression and GP-classification [2-4]. In this paper, the methods based on the concept of inducing inputs are considered. These methods construct an approximation based on the values of the process at some $m<n$ points. These points are referred to as inducing points. The idea is the following. The hidden GP $f$ corresponds to some smooth low-dimensional surface in $\mathbb{R}^{d}$. This surface can, in fact, be well approximated by another GP with properly chosen $m$ training points $\boldsymbol{Z}=\left(\boldsymbol{z}_{1}, \ldots, \boldsymbol{z}_{m}\right)^{\top} \in \mathbb{R}^{m \times d}$ and process values at that points $\boldsymbol{u}=\left(u_{1}, \ldots, u_{m}\right)^{\top}$ (inducing inputs). Then, predictions of this new process at training points are used for constructing approximate posterior distribution for $p(\boldsymbol{f} \mid \boldsymbol{y}, \boldsymbol{X})$. The positions $\boldsymbol{Z}$ of inducing inputs can be learned within the training procedure. However, for simplicity, in the following, the dataset $\boldsymbol{X}$ will be clusterized into $m$ clusters using $K$-means and $\boldsymbol{Z}$ will be chosen to be the cluster centers. In practice, it is observed that this approach works well almost in all the cases.

\subsection{Evidence lower bound}

In the following, a variational approach will be used for solving maximum evidence problem (6). In this approach, an ELBO is introduced that is simpler to compute than the evidence itself. Then, this lower bound is maximized with regard to kernel hyperparameters $\boldsymbol{\theta}$ and additional variational parameters used for constructing the lower bound.

Let us consider the following augmented probabilistic model:

$$
p(\boldsymbol{y}, \boldsymbol{f}, \boldsymbol{u} \mid \boldsymbol{X}, \boldsymbol{Z})=p(\boldsymbol{y} \mid \boldsymbol{f}) p(\boldsymbol{f}, \boldsymbol{u} \mid \boldsymbol{X}, \boldsymbol{Z})=\prod_{i=1}^{n} p\left(y_{i} \mid f_{i}\right) p(\boldsymbol{f}, \boldsymbol{u} \mid \boldsymbol{X}, \boldsymbol{Z}) .
$$

The graphical model for the model (7) is shown in Fig. 3. Note that marginalizing the model (7) with regard to $\boldsymbol{u}$ gives the initial model (3). 


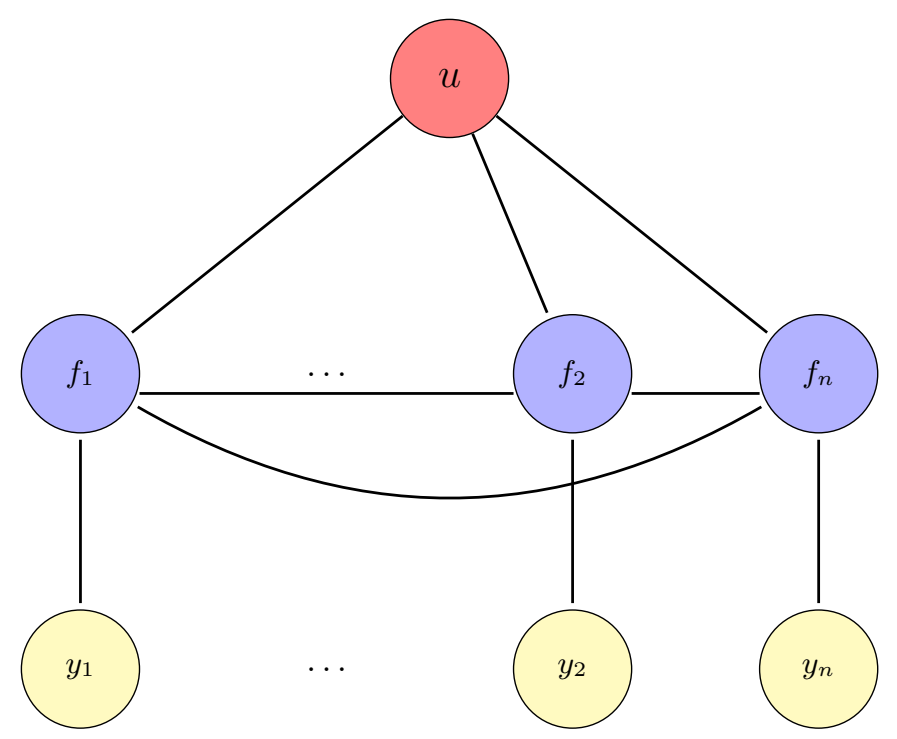

Figure 3 Gaussian process classification graphical model

Let us denote the covariance matrix comprised of pairwise values of the covariance function $k(\cdot, \cdot)$ on the points $\boldsymbol{Z}$ by $K(\boldsymbol{Z}, \boldsymbol{Z})=\boldsymbol{K}_{m m} \in \mathbb{R}^{m \times m}$. Similarly, let us define $\boldsymbol{K}_{n n}$ $=K(\boldsymbol{X}, \boldsymbol{X}) \in \mathbb{R}^{n \times n}$ and $\boldsymbol{K}_{n m}=K(\boldsymbol{X}, \boldsymbol{Z})=\boldsymbol{K}_{m n}^{\top} \in \mathbb{R}^{n \times m}$.

As $\boldsymbol{u}$ and $\boldsymbol{f}$ are generated from the same GP with zero-mean prior:

$$
\begin{aligned}
p(\boldsymbol{f}, \boldsymbol{u} \mid \boldsymbol{X}, \boldsymbol{Z}) & =\mathcal{N}([\boldsymbol{f}, \boldsymbol{u}] \mid[\mathbf{0}, \mathbf{0}], K([\boldsymbol{X}, \boldsymbol{Z}],[\boldsymbol{X}, \boldsymbol{Z}])) \\
p(\boldsymbol{u} \mid \boldsymbol{Z}) & =\mathcal{N}\left(\boldsymbol{u} \mid \mathbf{0}, \boldsymbol{K}_{m m}\right) \\
p(\boldsymbol{f} \mid \boldsymbol{u}, \boldsymbol{X}, \boldsymbol{Z}) & =\mathcal{N}\left(\boldsymbol{f} \mid \boldsymbol{K}_{n m} \boldsymbol{K}_{m m}^{-1} \boldsymbol{u}, \tilde{\boldsymbol{K}}\right)
\end{aligned}
$$

where $\tilde{\boldsymbol{K}}=\boldsymbol{K}_{n n}-\boldsymbol{K}_{n m} \boldsymbol{K}_{m m}^{-1} \boldsymbol{K}_{m n}$. In the following, for simplicity, the dependence on $\boldsymbol{X}$ and $\boldsymbol{Z}$ will be omitted in all formulas. Note that here, optimization is not considered with regard to these values.

Applying the standard variational lower bound (see, for example, [8]) to the augmented model (7), one obtains the following inequality:

$$
\log p(\boldsymbol{y}) \geqslant \mathrm{E}_{q(\boldsymbol{u}, \boldsymbol{f})} \log \frac{p(\boldsymbol{y}, \boldsymbol{u}, \boldsymbol{f})}{q(\boldsymbol{u}, \boldsymbol{f})}=\mathrm{E}_{q(\boldsymbol{u}, \boldsymbol{f})} \log p(\boldsymbol{y} \mid \boldsymbol{f})-\mathrm{KL}(q(\boldsymbol{u}, \boldsymbol{f}) \| p(\boldsymbol{u}, \boldsymbol{f}))
$$

for any distribution $q(\boldsymbol{u}, \boldsymbol{f})$. This inequality becomes equality for the true posterior distribution $q(\boldsymbol{u}, \boldsymbol{f})=p(\boldsymbol{u}, \boldsymbol{f} \mid \boldsymbol{y})$. Next, let us restrict the variational distribution $q(\boldsymbol{u}, \boldsymbol{f})$ to be of the form

$$
q(\boldsymbol{u}, \boldsymbol{f})=p(\boldsymbol{f} \mid \boldsymbol{u}) q(\boldsymbol{u})
$$

where $q(\boldsymbol{u})=\mathcal{N}(\boldsymbol{u} \mid \boldsymbol{\mu}, \boldsymbol{\Sigma})$ for some $\boldsymbol{\mu} \in \mathbb{R}^{m}, \boldsymbol{\Sigma} \in \mathbb{R}^{m \times m}$, and $p(\boldsymbol{f} \mid \boldsymbol{u})$ is determined by (8). This is the key approximation step in inducing points approach for GP. The chosen family (9) subsumes that with large enough $m$, all information about the hidden process values $\boldsymbol{f}$ at training points can be successfully restored from the values $\boldsymbol{u}$ at inducing inputs, i. e., $p(\boldsymbol{f} \mid \boldsymbol{u}, \boldsymbol{y}) \approx p(\boldsymbol{f} \mid \boldsymbol{u})$.

Form (9) of the variational distribution implies a Gaussian marginal distribution:

$$
q(\boldsymbol{f})=\int p(\boldsymbol{f} \mid \boldsymbol{u}) q(\boldsymbol{u}) d \boldsymbol{u}=\mathcal{N}\left(\boldsymbol{f} \mid \boldsymbol{K}_{n m} \boldsymbol{K}_{m m}^{-1} \boldsymbol{\mu}, \boldsymbol{K}_{n n}+\boldsymbol{K}_{n m} \boldsymbol{K}_{m m}^{-1}\left(\boldsymbol{\Sigma}-\boldsymbol{K}_{m m}\right) \boldsymbol{K}_{m m}^{-1} \boldsymbol{K}_{m n}\right) .
$$


As $\log p(\boldsymbol{y} \mid \boldsymbol{f})$ depends on $\boldsymbol{u}$ only through $\boldsymbol{f}$, the expectation

$$
\mathrm{E}_{q(\boldsymbol{u}, \boldsymbol{f})} \log p(\boldsymbol{y} \mid \boldsymbol{f})=\mathrm{E}_{q(\boldsymbol{f})} \log p(\boldsymbol{y} \mid \boldsymbol{f})=\sum_{i=1}^{n} \mathrm{E}_{q\left(f_{i}\right)} \log p\left(y_{i} \mid f_{i}\right)
$$

where $q\left(f_{i}\right)$ is the marginal distribution of $q(\boldsymbol{f})$ :

$$
q\left(f_{i}\right)=\mathcal{N}\left(f_{i} \mid \boldsymbol{k}_{i}^{\top} \boldsymbol{K}_{m m}^{-1} \boldsymbol{\mu}, \boldsymbol{K}_{i i}+\boldsymbol{k}_{i}^{\top} \boldsymbol{K}_{m m}^{-1}\left(\boldsymbol{\Sigma}-\boldsymbol{K}_{m m}\right) \boldsymbol{K}_{m m}^{-1} \boldsymbol{k}_{i}\right)=\mathcal{N}\left(f_{i} \mid m_{i}, S_{i}^{2}\right)
$$

and $\boldsymbol{k}_{i}$ is the $i$ th column of matrix $\boldsymbol{K}_{m n}$.

Finally,

$$
\mathrm{KL}(q(\boldsymbol{u}, \boldsymbol{f}) \| p(\boldsymbol{u}, \boldsymbol{f}))=\mathrm{KL}(q(\boldsymbol{u}) p(\boldsymbol{f} \mid \boldsymbol{u}) \| p(\boldsymbol{u}) p(\boldsymbol{f} \mid \boldsymbol{u}))=\mathrm{KL}(q(\boldsymbol{u}) \| p(\boldsymbol{u})) .
$$

Combining everything back together, one obtains the ELBO:

$$
\log p(\boldsymbol{y}) \geqslant \sum_{i=1}^{n} \mathrm{E}_{q\left(f_{i}\right)} \log p\left(y_{i} \mid f_{i}\right)-\mathrm{KL}(q(\boldsymbol{u}) \| p(\boldsymbol{u})) .
$$

Note that the KL-divergence term in the lower bound (11) can be computed analytically since it is a KL-divergence between two normal distributions. In order to compute the expectations $\mathrm{E}_{q\left(f_{i}\right)} \log p\left(y_{i} \mid f_{i}\right)$, one has to use integral approximating techniques.

The ELBO (11) can be maximized with respect to variational parameters $\boldsymbol{\mu}, \boldsymbol{\Sigma}$, and kernel hyperparameters. Using the optimal distribution $q(\boldsymbol{u})$, one can perform predictions for new data point $\boldsymbol{x}_{*}$ as follows:

$$
\begin{aligned}
& p\left(f_{*} \mid \boldsymbol{y}\right)=\int p\left(f_{*} \mid \boldsymbol{u}, \boldsymbol{f}\right) p(\boldsymbol{u}, \boldsymbol{f} \mid \boldsymbol{y}) d \boldsymbol{u} d \boldsymbol{f} \approx \int p\left(f_{*} \mid \boldsymbol{u}, \boldsymbol{f}\right) q(\boldsymbol{u}, \boldsymbol{f}) d \boldsymbol{u} d \boldsymbol{f} \\
&=\int p\left(f_{*} \mid \boldsymbol{u}, \boldsymbol{f}\right) p(\boldsymbol{f} \mid \boldsymbol{u}) q(\boldsymbol{u}) d \boldsymbol{u} d \boldsymbol{f}=\int p\left(f_{*} \mid \boldsymbol{u}\right) q(\boldsymbol{u}) d \boldsymbol{u} .
\end{aligned}
$$

The last integral is tractable since both terms $p\left(f_{*} \mid \boldsymbol{u}\right)$ and $q(\boldsymbol{u})$ are the normal distributions.

Note that in case of regression with Gaussian noise, the distributions $p\left(y_{i} \mid f_{i}\right)$ are the Gaussians and, thus, the expectations $\mathrm{E}_{q\left(f_{i}\right)} \log p\left(y_{i} \mid f_{i}\right)$ are tractable. Paper [6] suggests maximization of the lower bound (11) with respect to $\boldsymbol{\mu}, \boldsymbol{\Sigma}$, and covariance hyperparameters with stochastic optimization techniques for GP-regression.

\subsection{Stochastic Variational Inference method}

In case of classification, one cannot analytically compute the expectations $\mathrm{E}_{q\left(f_{i}\right)} \log p\left(y_{i} \mid f_{i}\right)$ in the lower bound (11). However, the expectations are the one-dimensional Gaussian integrals and can thus be effectively approximated with a range of techniques. In paper [7], GaussHermite quadratures are used for this purpose. Note that the lower bound (11) has the form "sum over training objects." Hence, this bound can be maximized using stochastic optimization techniques. Paper [7] suggests to maximize the lower bound (11) with respect to the variational parameters $\boldsymbol{\mu}, \boldsymbol{\Sigma}$, and kernel hyperparameters $\boldsymbol{\theta}$ using stochastic optimization. This method is referred to as svi (Stochastic Variational Inference) method. The lower bound (11) and all its derivatives can be computed in $\mathcal{O}\left(n m^{2}+m^{3}\right)$. This complexity has a linear dependence on $n$; hence, svi method can be applied for the case of big training data. 


\section{Tractable evidence lower bound for Gaussian process classification}

In the previous section, the svi method has been described. It is based on stochastic optimization of the lower bound (11) for marginal likelihood and the lower bound itself is computed in $\mathcal{O}\left(n m^{2}\right)$. But the bound depends on $\mathcal{O}\left(\mathrm{m}^{2}\right)$ parameters which makes the optimization problem hard to solve when a big number of inducing points is needed.

For GP-regression, the situation is similar. Paper [6] describes a method analogical to the svi method for classification. The only difference is that the lower bound becomes tractable in case of regression. Then, the paper [5] tries to solve the problem of big $\mathcal{O}\left(\mathrm{m}^{2}\right)$ number of parameters in the algorithm from [6] in the following way. In case of regression, the lower bound (11) can be analytically optimized with respect to variational parameters $\boldsymbol{\mu}$ and $\boldsymbol{\Sigma}$. Doing so and substituting the optimal values back into the lower bound, one can obtain a new lower bound to the marginal likelihood that depends solely on kernel hyperparameters $\boldsymbol{\theta}$. This simplifies the optimization problem by dramatically reducing the number of optimization parameters. Unfortunately, this new bound does not have a form of "sum over objects;" hence, stochastic optimization methods are no longer applicable here. However, in their experiments, the present authors have found that even for fairly big datasets, the method from [5] outperforms [6] despite the lack of stochastic optimization.

In the following subsection, an approach similar to the method of [5] is devised for the case of classification. A tractable ELBO is provided and it is analytically maximized with respect to variational parameters $\boldsymbol{\mu}$ and $\boldsymbol{\Sigma}$. Substituting the optimal values of these parameters back into the lower bound, one obtains a new lower bound that depends only on kernel hyperparameters $\boldsymbol{\theta}$.

\subsection{Global evidence lower bound}

In order to derive a tractable lower bound for (11), let us seek a quadratic approximation to the $\log$-logistic function $\log p\left(y_{i} \mid f_{i}\right)=\log \sigma\left(y_{i} f_{i}\right)$ where $\log \sigma(t)=-\log (1+\exp (-t))$. Paper [9] provides a global parametric quadratic lower bound for this function:

$$
\log \sigma(t) \geqslant \frac{t}{2}-\frac{\xi_{t}}{2}+\log \sigma\left(\xi_{t}\right)-\lambda\left(\xi_{t}\right)\left(t^{2}-\xi_{t}^{2}\right), \forall t
$$

where $\lambda\left(\xi_{t}\right)=\tanh \left(\xi_{t}\right) /\left(4 \xi_{t}\right)$ and $\xi_{t} \in \mathbb{R}$ is the parameter of the bound. This bound is tight when $t^{2}=\xi_{t}^{2}$.

Substituting this bound back to (11) with separate values $\boldsymbol{\xi}=\left\{\xi_{i} \mid i=1, \ldots, n\right\}$ for every data point, one obtains a tractable lower bound:

$$
\begin{aligned}
& \log p(y) \geqslant \sum_{i=1}^{n} \mathrm{E}_{q\left(f_{i}\right)} \log p\left(y_{i} \mid f_{i}\right)-\mathrm{KL}(q(\boldsymbol{u}) \| p(\boldsymbol{u}))=\sum_{i=1}^{n} \mathrm{E}_{q\left(f_{i}\right)} \log \sigma\left(y_{i} f_{i}\right)-\operatorname{KL}(q(\boldsymbol{u}) \| p(\boldsymbol{u})) \\
& \geqslant \geqslant \sum_{i=1}^{n}\left(\mathrm{E}_{q\left(f_{i}\right)}\left[\log \sigma\left(\xi_{i}\right)+\frac{y_{i} f_{i}-\xi_{i}}{2}-\lambda\left(\xi_{i}\right)\left(f_{i}^{2}-\xi_{i}^{2}\right)\right]\right)-\mathrm{KL}(q(\boldsymbol{u}) \| p(\boldsymbol{u})) \\
&=\sum_{i=1}^{n}\left(\log \sigma\left(\xi_{i}\right)-\frac{\xi_{i}}{2}+\lambda\left(\xi_{i}\right) \xi_{i}^{2}\right)+\frac{1}{2} \boldsymbol{\mu}^{\top} \boldsymbol{K}_{m m}^{-1} \boldsymbol{K}_{m n} \boldsymbol{y} \\
&-\operatorname{tr}\left(\boldsymbol{\Lambda}(\boldsymbol{\xi})\left(\boldsymbol{K}_{n n}+\boldsymbol{K}_{n m} \boldsymbol{K}_{m m}^{-1}\left(\boldsymbol{\Sigma}-\boldsymbol{K}_{m m}\right) \boldsymbol{K}_{m m}^{-1} \boldsymbol{K}_{m n}\right)\right) \\
& \quad-\boldsymbol{\mu}^{\top} \boldsymbol{K}_{m m}^{-1} \boldsymbol{K}_{m n} \boldsymbol{\Lambda}(\boldsymbol{\xi}) \boldsymbol{K}_{n m} \boldsymbol{K}_{m m}^{-1} \boldsymbol{\mu}-\mathrm{KL}(q(\boldsymbol{u}) \| p(\boldsymbol{u}))=J(\boldsymbol{\mu}, \boldsymbol{\Sigma}, \boldsymbol{\xi}, \boldsymbol{\theta})
\end{aligned}
$$


where

$$
\boldsymbol{\Lambda}(\boldsymbol{\xi})=\left(\begin{array}{cccc}
\lambda\left(\xi_{1}\right) & 0 & \cdots & 0 \\
0 & \lambda\left(\xi_{2}\right) & \ddots & 0 \\
\vdots & \ddots & \ddots & \vdots \\
0 & 0 & \cdots & \lambda\left(\xi_{n}\right)
\end{array}\right)
$$

Differentiating $J$ with respect to $\boldsymbol{\mu}$ and $\boldsymbol{\Sigma}$ and setting the derivatives to zero, one obtains:

$$
\begin{aligned}
\hat{\boldsymbol{\Sigma}}(\boldsymbol{\xi}) & =\left(2 \boldsymbol{K}_{m m}^{-1} \boldsymbol{K}_{m n} \boldsymbol{\Lambda}(\boldsymbol{\xi}) \boldsymbol{K}_{n m} \boldsymbol{K}_{m m}^{-1}+\boldsymbol{K}_{m m}^{-1}\right)^{-1} \\
\hat{\boldsymbol{\mu}}(\boldsymbol{\xi}) & =\frac{1}{2} \hat{\boldsymbol{\Sigma}}(\boldsymbol{\xi}) \boldsymbol{K}_{m m}^{-1} \boldsymbol{K}_{m n} \boldsymbol{y} .
\end{aligned}
$$

Substituting the optimal values of variational parameters back to the lower bound $J$ and omitting the terms not depending on $\boldsymbol{\theta}$ and $\boldsymbol{\xi}$, one obtains a compact lower bound:

$$
\begin{aligned}
\hat{J}(\boldsymbol{\theta}, \boldsymbol{\xi})=\sum_{i=1}^{n}\left(\log \sigma\left(\xi_{i}\right)-\frac{\xi_{i}}{2}+\lambda\left(\xi_{i}\right) \xi_{i}^{2}\right)+\frac{1}{8} \boldsymbol{y}^{\top} \boldsymbol{K}_{n m} \boldsymbol{B}^{-1} \boldsymbol{K}_{m n} \boldsymbol{y} & \\
& +\frac{1}{2} \log \left|\boldsymbol{K}_{m m}\right|-\frac{1}{2} \log |\boldsymbol{B}|-\operatorname{tr}(\boldsymbol{\Lambda}(\boldsymbol{\xi}) \tilde{\boldsymbol{K}})
\end{aligned}
$$

where

$$
\begin{aligned}
\tilde{\boldsymbol{K}} & =\boldsymbol{K}_{n n}-\boldsymbol{K}_{n m} \boldsymbol{K}_{m m}^{-1} \boldsymbol{K}_{m n} \\
\boldsymbol{B} & =2 \boldsymbol{K}_{m n} \boldsymbol{\Lambda}(\boldsymbol{\xi}) \boldsymbol{K}_{n m}+\boldsymbol{K}_{m m}
\end{aligned}
$$

In the following, three different methods will be considered for maximizing the lower bound $\hat{J}(\boldsymbol{\theta}, \boldsymbol{\xi})$.

Note that given the values of $\boldsymbol{\mu}, \boldsymbol{\Sigma}$, and $\boldsymbol{\theta}$, one can maximize $J(\boldsymbol{\mu}, \boldsymbol{\Sigma}, \boldsymbol{\xi}, \boldsymbol{\theta})$ with respect to $\boldsymbol{\xi}$ analytically. The optimal values for $\boldsymbol{\xi}$ are given by

$$
\xi_{i}^{2}=\mathrm{E}_{q(\boldsymbol{f})} f_{i}^{2}=m_{i}^{2}+S_{i}^{2} .
$$

The values $m_{i}$ and $S_{i}$ were defined in (10). In the first method, the analytical formulas (14) are used to recompute the values of $\boldsymbol{\xi}$ and the gradient-based optimization is used to maximize the bound with respect to $\boldsymbol{\theta}$. The pseudocode is given in Algorithm 1. Let us refer to this method as vi-JJ where JJ stands for Jaakkola and Jordan, the authors of [9]. Note that the computational complexity of one iteration of this method is $\mathcal{O}\left(\mathrm{nm}^{2}\right)$, the same as for the svi method.

The second method uses gradient-based optimization to maximize $\hat{J}$ with respect to both $\boldsymbol{\theta}$ and $\boldsymbol{\xi}$. Note that in this method, it is not necessary to recompute $\boldsymbol{\mu}$ and $\boldsymbol{\Sigma}$ at each iteration which makes the methods iterations empirically faster for big values of $m$. Let us refer to this method as vi-JJ-full.

Finally, vi-JJ-hybrid is a combination of the two methods described above. The general scheme of this method is the same as vi-JJ. In the vi-JJ-hybrid method, analytical formulas are used to recompute $\boldsymbol{\xi}$ as is done in the vi-JJ method at stage 1 but at stage 2, gradientbased optimization is used with respect to both $\boldsymbol{\xi}$ and $\boldsymbol{\theta}$. The virtues of this method will be described in the experiments section. 


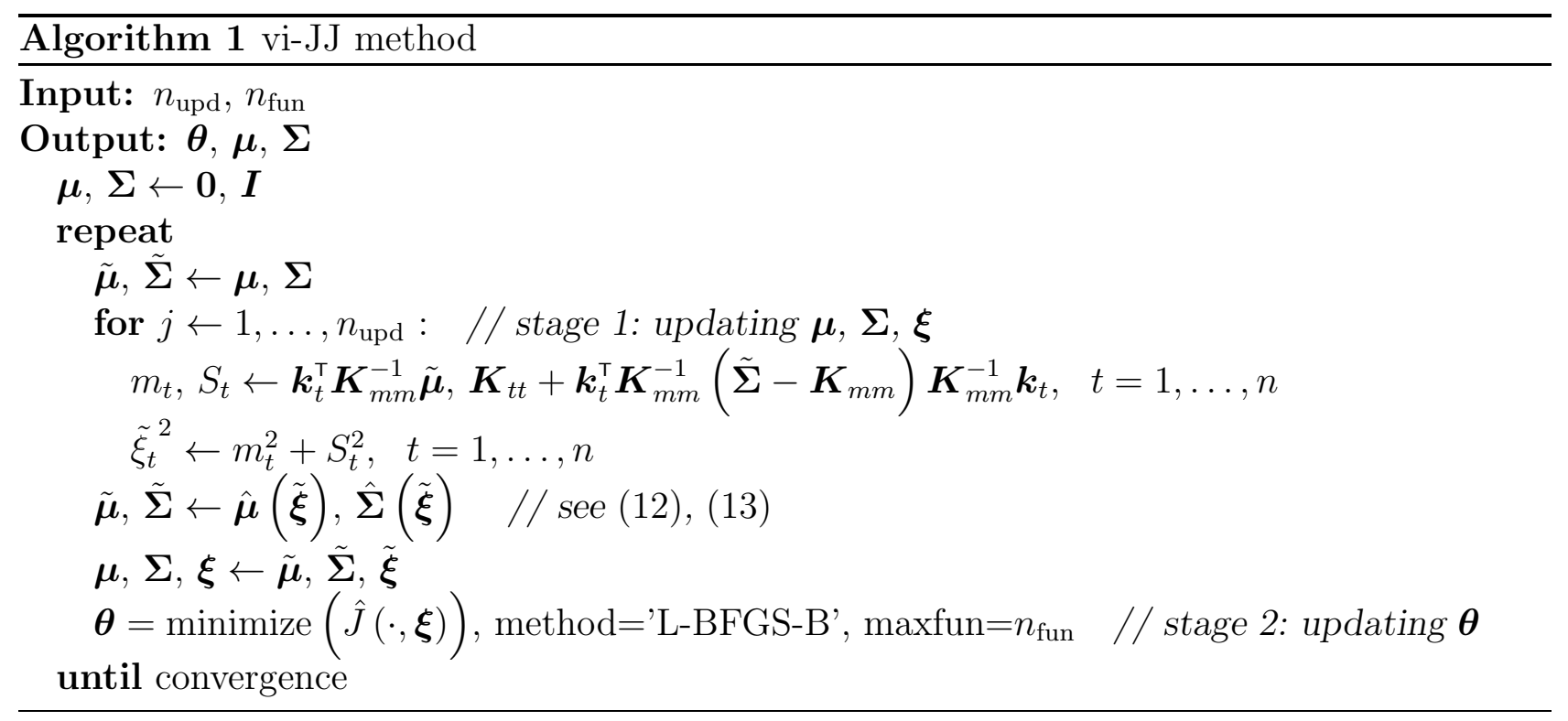

\subsection{Tractable local approximation to the evidence lower bound}

Another way to obtain a tractable approximation to the lower bound (11) is to use a local quadratic approximation for the $\log$-logistic function $\log p\left(y_{i} \mid f_{i}\right)$. In this way, let us perform a second-order Taylor expansion of this function at points $\boldsymbol{\xi}=\left\{\xi_{i} \mid i=1, \ldots, n\right\}$ :

$$
\log p\left(y_{i} \mid f_{i}\right) \approx-\log \left(1+\exp \left(-y_{i} \xi_{i}\right)\right)+\frac{y_{i}}{1+\exp \left(y_{i} \xi_{i}\right)}\left(f_{i}-\xi_{i}\right)-\frac{y_{i}^{2} \exp \left(y_{i} \xi_{i}\right)}{2\left(1+\exp \left(y_{i} \xi_{i}\right)\right)^{2}}\left(f_{i}-\xi_{i}\right)^{2}
$$

The following derivation is analogical to the derivation in the previous section. Substituting approximation (15) into the lower bound (11), one obtains

$$
\begin{aligned}
& \log p(y) \geqslant \sum_{i=1}^{n} \mathrm{E}_{q\left(f_{i}\right)} \log p\left(y_{i} \mid f_{i}\right)-\mathrm{KL}(q(\boldsymbol{u}) \| p(\boldsymbol{u})) \\
& \approx-\sum_{i=1}^{n} \log \left(1+\exp \left(-y_{i} \xi_{i}\right)\right)+\varphi(\boldsymbol{\xi})^{\top}\left(\boldsymbol{K}_{n m} \boldsymbol{K}_{m m}^{-1} \boldsymbol{\mu}-\boldsymbol{\xi}\right) \\
& -\operatorname{tr}\left(\boldsymbol{\Psi}(\boldsymbol{\xi})\left(\boldsymbol{K}_{n n}+\boldsymbol{K}_{n m} \boldsymbol{K}_{m m}^{-1}\left(\boldsymbol{\Sigma}-\boldsymbol{K}_{m m}\right) \boldsymbol{K}_{m m}^{-1} \boldsymbol{K}_{m n}\right)\right) \\
& -\left(\boldsymbol{K}_{n m} \boldsymbol{K}_{m m}^{-1} \boldsymbol{\mu}-\boldsymbol{\xi}\right)^{\top} \boldsymbol{\Psi}(\boldsymbol{\xi})\left(\boldsymbol{K}_{n m} \boldsymbol{K}_{m m}^{-1} \boldsymbol{\mu}-\boldsymbol{\xi}\right)-\frac{1}{2}\left(\log \frac{\left|\boldsymbol{K}_{m m}\right|}{|\boldsymbol{\Sigma}|}-m+\operatorname{tr}\left(\boldsymbol{K}_{m m}^{-1} \boldsymbol{\Sigma}\right)+\boldsymbol{\mu}^{\top} \boldsymbol{K}_{m m}^{-1} \boldsymbol{\mu}\right)
\end{aligned}
$$

Here, $\boldsymbol{\Psi}(\boldsymbol{\xi})$ is the diagonal matrix

$$
\boldsymbol{\Psi}(\boldsymbol{\xi})=\left(\begin{array}{cccc}
\psi\left(\xi_{1}\right) & 0 & \cdots & 0 \\
0 & \psi\left(\xi_{2}\right) & \ddots & 0 \\
\vdots & \ddots & \ddots & \vdots \\
0 & 0 & \cdots & \psi\left(\xi_{n}\right)
\end{array}\right)
$$

where

$$
\psi\left(\xi_{i}\right)=\frac{y_{i}^{2} \exp \left(y_{i} \xi_{i}\right)}{2\left(1+\exp \left(y_{i} \xi_{i}\right)\right)^{2}}
$$


Differentiating the approximate bound with respect to $\boldsymbol{\mu}, \boldsymbol{\Sigma}$, and $\boldsymbol{\xi}$ and setting the derivatives to zero, one obtains the following formulas for optimal values of these parameters:

$$
\begin{aligned}
\hat{\boldsymbol{\Sigma}}(\boldsymbol{\xi}) & =\left(2 \boldsymbol{K}_{m m}^{-1} \boldsymbol{K}_{m n} \boldsymbol{\Psi}(\boldsymbol{\xi}) \boldsymbol{K}_{n m} \boldsymbol{K}_{m m}^{-1}+\boldsymbol{K}_{m m}^{-1}\right)^{-1} \\
\hat{\boldsymbol{\mu}}(\boldsymbol{\xi}) & =\hat{\boldsymbol{\Sigma}}(\boldsymbol{\xi}) \boldsymbol{K}_{m m}^{-1} \boldsymbol{K}_{m n} \boldsymbol{v}(\boldsymbol{\xi}) \\
\xi_{i} & =m_{i}
\end{aligned}
$$

Here,

$$
\boldsymbol{v}(\boldsymbol{\xi})=\varphi(\xi)+2 \Psi(\xi) \xi
$$

and $\boldsymbol{\varphi}(\boldsymbol{\xi})$ is the vector composed of

$$
\boldsymbol{\varphi}(\boldsymbol{\xi})_{i}=\frac{y_{i}}{1+\exp \left(y_{i} \xi_{i}\right)}
$$

Substituting the optimal values for $\boldsymbol{\mu}$ and $\boldsymbol{\Sigma}$ given by (16) and (17) back into the approximate bound and omiting the terms that do not depend on $\boldsymbol{\theta}$, one obtains the following approximate lower bound:

$$
\tilde{J}_{\boldsymbol{\xi}}=\frac{1}{2} \boldsymbol{v}(\boldsymbol{\xi})^{\top} \boldsymbol{K}_{n m} \boldsymbol{B}^{-1} \boldsymbol{K}_{m n} \boldsymbol{v}(\boldsymbol{\xi})+\frac{1}{2} \log \left|\boldsymbol{K}_{m m}\right|-\frac{1}{2} \log |\boldsymbol{B}|-\operatorname{tr}(\boldsymbol{\Psi}(\boldsymbol{\xi}) \tilde{\boldsymbol{K}})
$$

where

$$
\boldsymbol{B}=2 \boldsymbol{K}_{m n} \boldsymbol{\Psi}(\boldsymbol{\xi}) \boldsymbol{K}_{n m}+\boldsymbol{K}_{m m} .
$$

Note that the lower bound (18) is not a global lower bound for the log-evidence $\log p(y)$. However, locally, a good approximation of the ELBO (11) has been got.

For maximizing the approximate lower bound (18), let us consider a method, analogical to vi-JJ. In order to specify this method, let us simply substitute the bound $\hat{J}(\cdot, \boldsymbol{\xi})$ by $\tilde{J}_{\boldsymbol{\xi}}$ in the second stage in Algorithm 1. Let us refer to this method as vi-Taylor. The computational complexity of one iteration of this method is, once again, $\mathcal{O}\left(\mathrm{nm}^{2}\right)$.

\section{Experiments}

In this section, the derived vi-JJ, vi-Taylor, vi-JJ-full, and vi-JJ-hybrid methods will be empirically compared with svi. Below, the setting of the experiments is described and their results are discussed.

\section{$5.1 \quad$ Experimental setting}

In the experiments, there have been compared 5 methods for variational inducing point GPclassification:

- svi-AdaDelta uses the AdaDelta optimization method for maximization of the lower bound (11) as it is done in paper [7];

- vi-JJ was described in subsection 4.1;

- vi-Taylor was described in subsection 4.2;

- vi-JJ-full was described in subsection 4.1; and

- vi-JJ-hybrid was described in subsection 4.1.

Also, the present authors have made an attempt to use deterministic L-BFGS-B optimization method for maximizing ELBO (11), but it worked substantially worse than all the other methods. Note that all the methods have the same complexity of epochs $\mathcal{O}\left(n m^{2}\right)$. The table 
Methods outline

\begin{tabular}{ccc}
\hline Method & $\begin{array}{c}\text { Numerically optimized } \\
\text { variables }\end{array}$ & $\begin{array}{c}\text { Analytically optimized } \\
\text { variables }\end{array}$ \\
\hline svi-AdaDelta & $\boldsymbol{\theta}, \boldsymbol{\mu} \in \mathbb{R}^{m}, \boldsymbol{\Sigma} \in \mathbb{R}^{m \times m}$ & \\
vi-JJ, vi-Taylor & $\boldsymbol{\theta}$ & $\boldsymbol{\mu} \in \mathbb{R}^{m}, \boldsymbol{\Sigma} \in \mathbb{R}^{m \times m}, \boldsymbol{\xi} \in \mathbb{R}^{n}$ \\
vi-JJ-hybrid & $\boldsymbol{\theta}, \boldsymbol{\xi} \in \mathbb{R}^{n}$ & $\boldsymbol{\mu} \in \mathbb{R}^{m}, \boldsymbol{\Sigma} \in \mathbb{R}^{m \times m}, \boldsymbol{\xi} \in \mathbb{R}^{n}$ \\
vi-JJ-full & $\boldsymbol{\theta}, \boldsymbol{\xi} \in \mathbb{R}^{n}$ & $\boldsymbol{\mu} \in \mathbb{R}^{m}, \boldsymbol{\Sigma} \in \mathbb{R}^{m \times m}$ \\
\hline
\end{tabular}

shows which variables are optimized numerically and which are optimized analytically for each method.

In the present experiments, the lower bound was not optimized with respect to the positions $\boldsymbol{Z}$ of the inducing points. Instead, $K$-means clustering procedure with $K$ equal to the number $m$ of inducing inputs was used and clusters centers were taken as $\boldsymbol{Z}$. Also, the squared exponential covariance function (see section 2) was used in all experiments with a Gaussian noise term.

The stochastic method svi-AdaDelta requires the user to manually specify the learning rate and the batch size for the optimization method. For the former, it was necessary to run the method with different learning rates and to choose the value that resulted in the fastest convergence. The learning rates have been used from a fixed grid with a step of 0.1 . It always happened that for the largest value from the grid, the method diverged and for the smallest, the method converged slower than for some medium value, verifying that the optimal learning rate was somewhere in the range. To choose the batch size, the following convention was used. For small german and sumguide datasets, the batch size was set to 50. For other datasets, approximately $n / 100$ was used as the batch size where $n$ is the size of the training set.

For the vi-JJ, vi-Taylor, and vi-JJ-hybrid in all of the experiments on every iteration, the values of $\boldsymbol{\xi}, \boldsymbol{\mu}$, and $\boldsymbol{\Sigma}$ were recomputed three times $\left(n_{\text {upd }}=3\right.$ in Algorithm 1$)$. To tune $\boldsymbol{\theta}$, on every iteration, L-BFGS-B optimization method was run constrained to do not more than 5 evaluations of the lower bound and its gradient. It was found that these values of the parameters work well for all the experimented datasets.

For the svi-AdaDelta method, optimization with regard to Cholesky factor of the matrix $\boldsymbol{\Sigma}$ was used to maintain its positive definiteness as described in [7]. AdaDelta optimization method implementation from the climin toolbox [10] was used as is done in the original paper.

For every dataset, the present authors experimented with a number of inducing points to verify that the results of the methods are close to the optimal.

The methods were evaluated plotting the accuracy of their predictions on the test data against time. All of the plots have the titles of the following format:

[name of the dataset], $n=$ [number of objects in the training set],

$$
d=\text { [number of features], } m=\text { [number of inducing inputs]. }
$$

Also, all the datasets have been preprocessed by normalizing the features setting the mean of all features to 0 and the variance to 1 . For datasets without available test data, $20 \%$ of the data have been used as a test set and $80 \%$ as a train set.

\subsection{Results and discussion}

The methods' performance was compared on 7 datasets. Here, the results are discussed. 

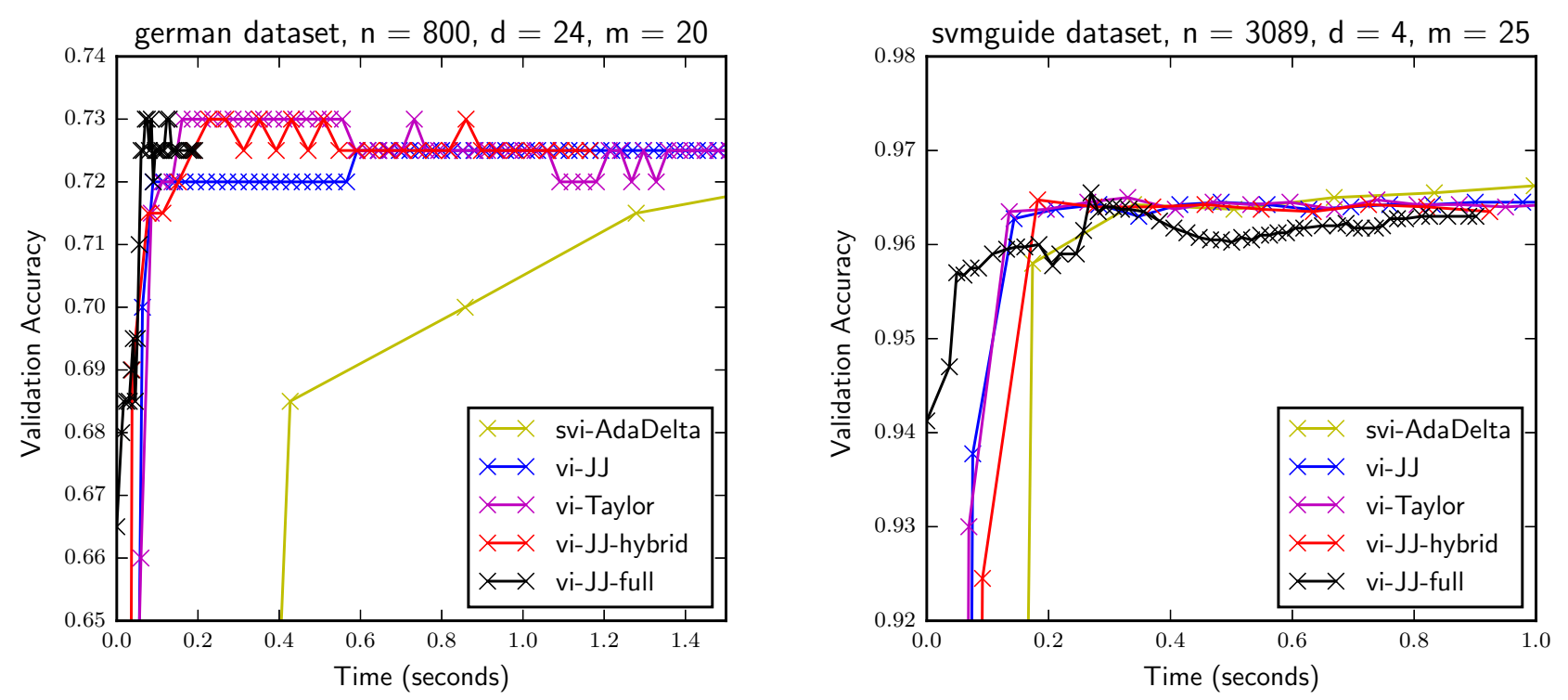

Figure 4 Methods performance on small datasets

Figure 4 provides the results for german nd svmguide datasets. As one can see, on the small german dataset, the stochastic svi-AdaDelta method struggles and it takes it longer to achieve the optimal quality than for all the other methods which show similar results. On the svmguide dataset, it takes vi-JJ-full and svi-AdaDelta a little bit longer to converge, while the other three methods show roughly the same performance.

The results on magic telescope and ijcnn datasets are provided in Fig. 5. On the magic telescope dataset, vi-JJ and vi-Taylor show poor quality on the first iterations but still manage to converge faster than svi-AdaDelta. On both datasets, the vi-JJ-hybrid method works similar to vi-JJ and vi-Taylor but shows better quality on the first iterations on the magic telescope data. The method vi-JJ-full cannot converge to a reasonable quality on both datasets.
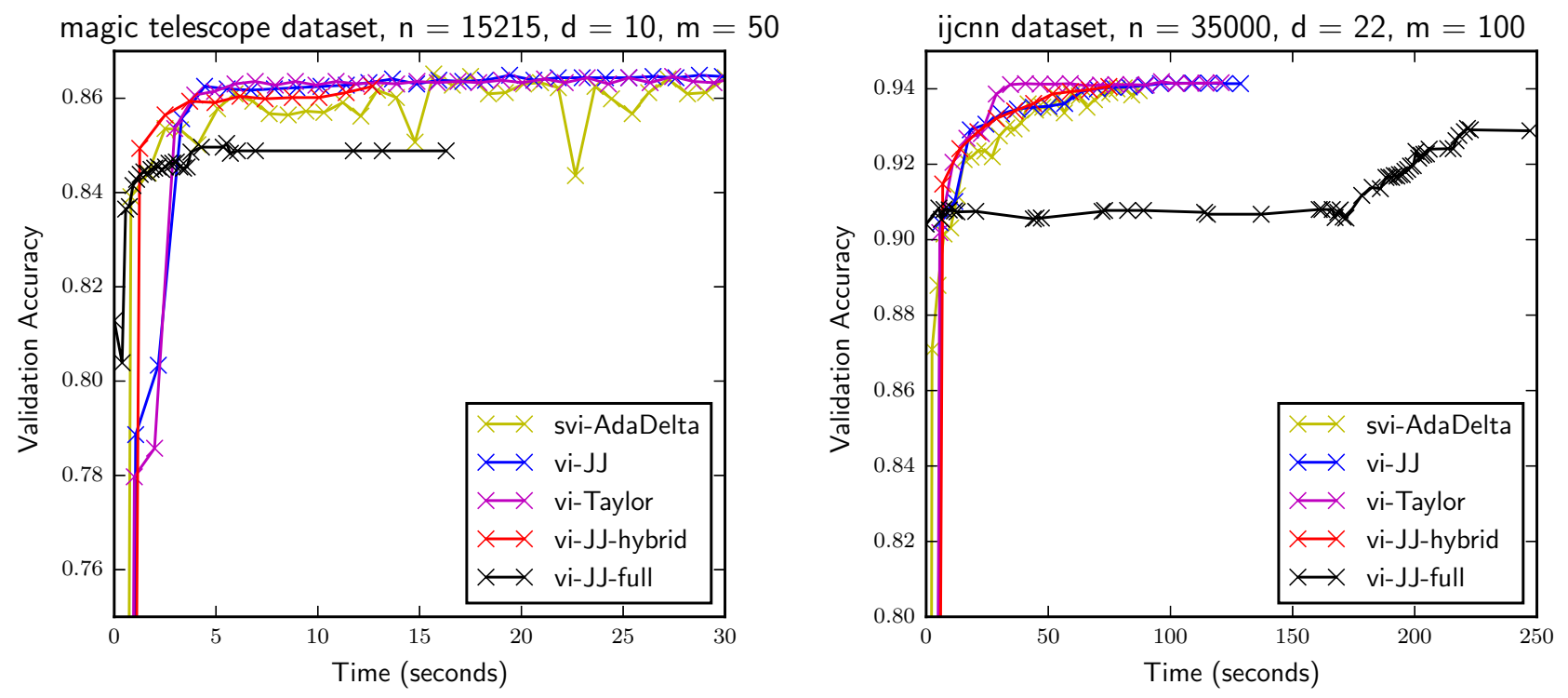

Figure 5 Methods performance on medium datasets 

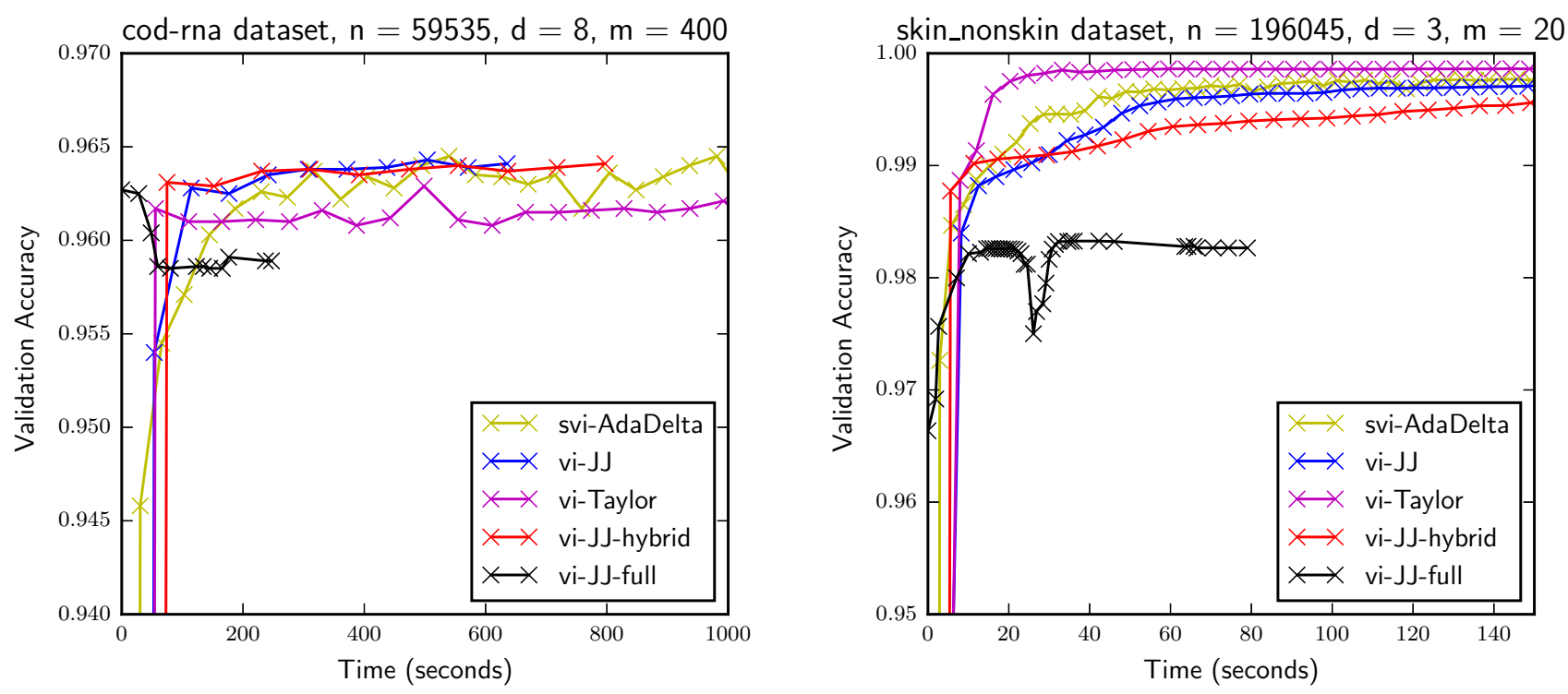

Figure 6 Methods performance on big datasets

Figure 6 provides the results on big cod-rna and skin_nonskin datasets. On these datasets, vi-JJ-full once again fails to achieve a reasonable quality, while the other methods work similarly.

Finally, the results on $a 8 a$ data are provided in Fig. 7. Here, a rather big amount of $m=500$ inducing inputs were used. As one can see, vi-JJ-full and vi-JJ-hybrid are the fastest to achieve the optimal quality. The svi-AdaDelta method also converges reasonably fast, while vi-JJ and vi-Taylor struggle a little bit.

In general, the vi-JJ, vi-Taylor, and vi-JJ-hybrid methods perform similar to the svi-AdaDelta method. On the big dataset skin_nonskin with only three features, vi-JJ-hybrid is a little bit slower than the stochastic svi-AdaDelta method but on all other datasets, it is

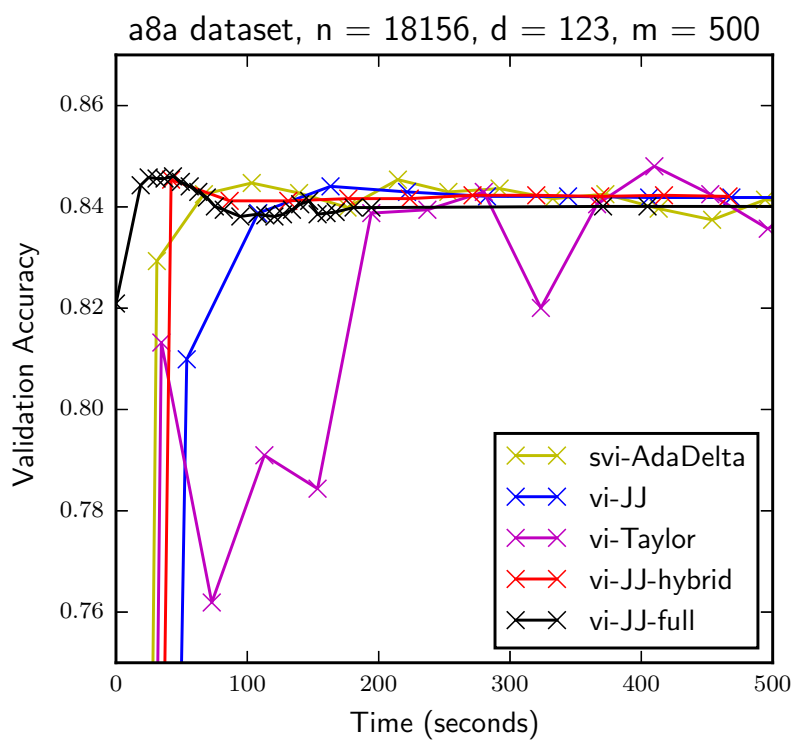

Figure 7 Methods performance on the $a 8 a$ dataset 
better. The vi-Taylor and vi-JJ methods struggle with $a 8 a$ but are, otherwise, comparable to vi-JJ-hybrid. The stochastic svi-AdaDelta method performs poorly on small datasets and even on the big skin_nonskin data does not manage to substantially outperform the other methods, even provided a good value of the learning rate. Finally, vi-JJ-full works well on small data and on the $a 8 a$ but on all other datasets, it does not manage to achieve a reasonable quality.

\title{
6 Concluding remarks
}

In this paper, a new approach to training variational inducing input GP classification is presented. Two new tractable ELBO are derived and several ways to maximize them are described. The resulting methods vi-JJ, vi-JJ-full, vi-JJ-hybrid, and vi-Taylor are similar to the method of [5] for GP-regression.

An experimental comparison of the suggested methods with the current state-of-the-art method svi-AdaDelta of [7] is provided. In experimental setting, the present approach proved to be more practical as it converges to the optimal quality as fast as the svi-AdaDelta method without requiring the user to manually choose the parameters of the optimization method.

The four described vi methods showed similar performance and it is hard to distinguish them. However, note that the vi-Taylor approach is more general and can be applied to the likelihood functions that are not logistic. Also, a method, similar to vi-JJ-hybrid and vi-JJ-full for the nonlogistic case, can be easily derived but it is out of the scope of this paper.

\section{References}

[1] Rasmussen, C.E., and C. K. I. Williams. 2006. Gaussian processes for machine learning. Cambridge, MA: The MIT Press. 266 p.

[2] Smola, A., and P. Bartlett. 2001. Sparse greedy Gaussian process regression. Advances in neural information processing systems. Eds. T. K. Lean, T. G. Dietterich, and V. Tresp. The MIT Press. 13:619-625.

[3] Csato, L., and M. Opper. 2002. Sparse online Gaussian processes. Neural Comput. 14:641-668.

[4] Quinonero-Candela, J., and C. Rasmussen. 2005. A unifying view of sparse approximate Gaussian process regression. J. Mach. Learn. Res. 6:1939-1959.

[5] Titsias, M. 2009. Variational learning of inducing variables in sparse Gaussian processes. Proc. Machine Learning Res. 5:567-574.

[6] Hensman, J., N. Fusi, and N. D. Lawrence. 2013. Gaussian processes for Big data. 29th Conference on Uncertainty in Artificial Intelligence Proceedings. Eds. A. Nicholson and P. Smyth. Bellevue, WA. 282-290.

[7] Hensman, J., A. Matthews, and Z. Ghahramani. 2015. Scalable variational Gaussian process classification. Proc. Machine Learning Res. 38:351-360.

[8] Jaakkola, T. 2001. Tutorial on variational approximation methods. Advanced mean field methods: Theory and practice. Eds. M. Opper and D. Saad. Neural information processing ser. Cambridge, MA - London: The MIT Press. 129-159.

[9] Jaakkola, T., and M. Jordan. 1997. A variational approach to Bayesian logistic regression models and their extensions. Conference on Artificial Intelligence and Statistics Proceedings. Fort Lauderdale, FL.

[10] Climin. Available at: http://github.com/BRML/climin (accessed December 29, 2017).

Received November 17, 2016

\section{Быстрый метод обучения модели гауссовских процессов для задач классификации}

\author{
П. А. Измаилов, Д. А. Кропотов \\ izmailovpavel@gmail.com; dmitry.kropotov@gmail.com \\ МГУ им. М. В. Ломоносова, Россия, г. Москва, Ленинские горы, 1
}


Предлагается новый подход к настройке моделей гауссовских процессов для задач классификации. Стандартные методы для данной задачи имеют сложность $\mathcal{O}\left(n^{3}\right)$, где $n-$ размер обучающей выборки. Данное обстоятельство не позволяет применять эти методы к задачам с большим объемом данных. В связи с этим в литературе был предложен ряд подходов, основанных на использовании так называемых вспомогательных точек (inducing inputs). Изначально такие методы использовались для задачи регрессии, но в недавней работе Хенсмэна с коллегами (2015 г.) подобный метод был разработан для задач классификации. В этом методе используется глобальная нижняя оценка на правдоподобие, которая максимизируется по параметрам гауссовского процесса и по дополнительным вариационным параметрам с помощью стохастической оптимизации. Вычислительная сложность данного метода составляет $\mathcal{O}\left(\mathrm{nm}^{2}\right)$, где $m$ - число вспомогательных точек, которое обычно существенно меньше, чем $n$. Однако число переменных в оптимизации составляет $\mathcal{O}\left(m^{2}\right)$, что делает задачу поиска оптимальных параметров весьма сложной при больших значениях $m$. Предлагаются две новые оценки на маргинальное правдоподобие в модели гауссовских процессов со вспомогательными точками для задач классификации, а также несколько методов для их оптимизации. В новых оценках количество численно оптимизируемых переменных не зависит от числа вспомогательных точек $m$. В результате новые процедуры обучения становятся эффективными для широкого диапазона параметров $n$ и $m$. Кроме того, в отличие от стохастического метода из статьи Хенсмэна с коллегами (2015 г.), новые процедуры не требуют настройки параметров пользователем. Это значительно облегчает использование новых методов на практике. Проведенные эксперименты показывают, что новые методы демонстрируют сравнимое или лучшее качество по сравнению с методом из работы Хенсмэна с коллегами (2015 г.).

Ключевые слова: гауссовский процесс; классификация; болъшие данные; байесовский вариационный вывод; оптимизация

DOI: $10.21469 / 22233792.3 .1 .02$

\section{Литература}

[1] Rasmussen C.E., Williams C.K.I. Gaussian processes for machine learning. - Cambridge, MA, USA: The MIT Press, 2006. 266 p.

[2] Smola A., Bartlett P. Sparse greedy Gaussian process regression // Advances in neural information processing systems / Eds. T. K. Lean, T. G. Dietterich, V. Tresp. - The MIT Press, 2001. Vol. 13. P. 619-625.

[3] Csato L., Opper M. Sparse online Gaussian processes // Neural Comput., 2002. Vol. 14. P. 641668.

[4] Quinonero-Candela J., Rasmussen C. A unifying view of sparse approximate Gaussian process regression // J. Mach. Learn. Res., 2005. Vol. 6. P. 1939-1959.

[5] Titsias $M$. Variational learning of inducing variables in sparse Gaussian processes // Proc. Machine Learning Res., 2009. Vol. 5. P. 567-574.

[6] Hensman J., Fusi N., Lawrence N. D. Gaussian processes for Big data // 29th Conference on Uncertainty in Artificial Intelligence Proceedings / Eds. A. Nicholson, P. Smyth. - Bellevue, WA, USA, 2013. P. 282-290.

[7] Hensman J., Matthews A., Ghahramani Z. Scalable variational Gaussian process classification // Proc. Machine Learning Res., 2015. Vol. 38. P. 351-360.

[8] Jaakkola T. Tutorial on variational approximation methods // Advanced mean field methods: Theory and practice / Eds. M. Opper, D. Saad. - Neural information processing ser. - Cambridge, MA - London: The MIT Press, 2001. P. 129-159.

[9] Jaakkola T., Jordan M. A variational approach to Bayesian logistic regression models and their extensions // Conference on Artificial Intelligence and Statistics Proceedings. - Fort Lauderdale, FL, USA, 1997.

[10] Climin. http://github.com/BRML/climin. 


\title{
The GIS-ENDDB algorithms and methods for geoinformation-expert data analysis*
}

\author{
A. V. Mikheeva ${ }^{1}$ and I. I. Kalinnikov ${ }^{2}$ \\ anna@omzg.sscc.ru \\ ${ }^{1}$ Institute of Computational Mathematics and Mathematical Geophysics SB RAS, 6 Acad. \\ Lavrentjeva pr., Novosibirsk, Russia \\ ${ }^{2}$ Schmidt Institute of Physics of the Earth of RAS, 10/1 Bolshaya Gruzinskaya Str., Moscow, Russia \\ The software of the geographical information system for studying the Earth's natural disasters \\ (GIS-ENDDB) is focused on the research into cause-and-effect relations of catastrophic events \\ in our planet's history. It contains data on the Earth's seismic activity, anomalies of heat \\ flows (HF), gravitational field and tomography layers, detailed geographical relief, as well as \\ data on cosmogenic structures distribution. To develop methods for analyzing these data, it \\ has been added into the subsystems of information and mathematical software updates such \\ as: the algorithm for building seismicity lineaments in terms of the Great circles (GC) of the \\ Earth; the algorithms for constructing the contours of a maximum earthquake magnitudes and \\ of the averaging earthquake mechanisms; the functions of geophysical fields visualization and \\ the cross-section visualization of different seismicity characteristics; and tomography data. All \\ these updates help to extend the capabilities of classical methods for geotectonic studies by \\ a complex scientific-experimental approach allowing one to reveal tectonically active faults, \\ to study the spatial relationship of seismicity and cosmogenic paleostructures (related to the \\ historical past of the Earth), and, eventually, to interpret the data in terms of constructing \\ seismic-geodynamic models of the lithosphere.
}

Keywords: impact structures and seismicity catalogs; morphostructural elements; geophysical anomalies; expert-geoinformation approach

DOI: $10.21469 / 22233792.3 .1 .03$

\section{Introduction}

When solving the geotectonic and geomorphological problems, the researcher cannot take into account all the factors affecting the dynamics of real geophysical manifestations; so, interpretating the results, he/she often runs into an ambiguous and undefined choice. Such state of affairs is an unavoidable consequence of geophysical processes' multidimensionality. However, the more powerful the GIS is, the better the researcher's needs are realized toward gradual, step-by-step choice of the most reliable variant among many possible variants. Such a system is the program GIS-ENDDB $[1,2]$ that allows nonprogrammer users, communicating with a computer, to formulate and to solve their own intellectual tasks. The methodological basis of the research is the methods for physical-mathematical analysis, the GIS-methods, and the expert-geoinformation approaches $[3,4]$ to the data interpretation for the geodynamic problems solution (Fig. 1).

The data representation structures, the analysis methods, and the visualization algorithms are described in detail in [5]. Briefly, there are used algorithms for detecting linear and annular structures and subsequent analysis of their seismogeodynamic regime. The algorithms of calculation and building the zonal maps of spatial distributions of different seismic parameters (b, $A, E_{O}$, and $K_{\mathrm{AVG}}$ ) [5] (see Fig. 1) include the visualization of its spatial distributions (uses the two-dimensional Bessel linear interpolation) on uniform intervals of time, the detection

\footnotetext{
*The research was supported by the Russian Foundation for Basic Research (grant 17-05-01234).
} 


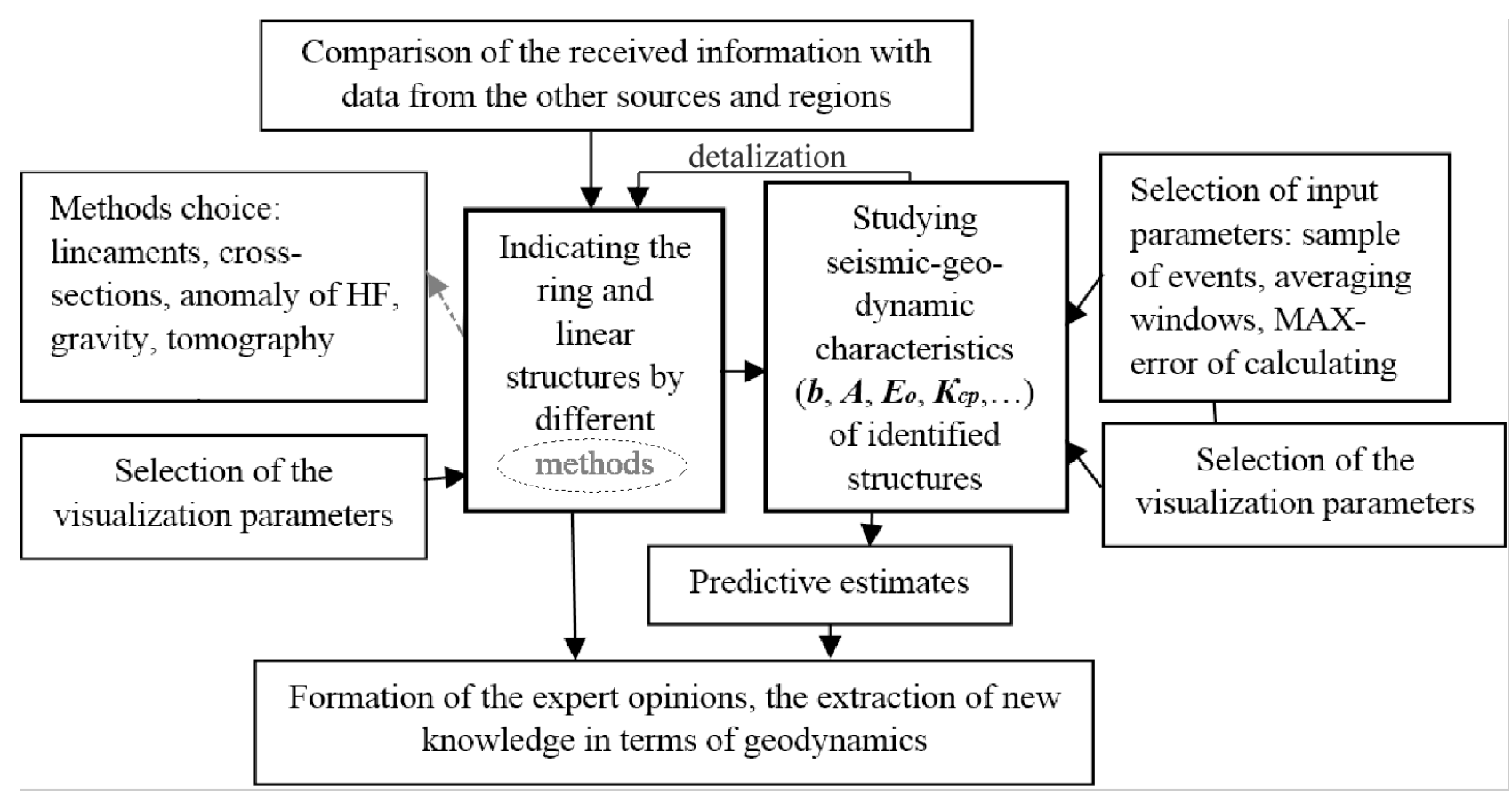

Figure 1 An example of the scenario using the GIS-ENDDB tools for "expert-geoinformation" analysis of natural disaster data

of spatial-temporal anomalies, and estimation of their statistical significance. The reliability of parameters' determination is controlled: (1) by the root-mean-square deviation $\sigma$ of the repeatability curve points with respect to the approximating straight line [5]; (2) by the representativeness of the sample [5] (an error $\varepsilon \sim N$ ); and (3) taking into account errors in the definitions of catalog parameters: $\delta \varphi, \delta \lambda$, and $\delta t_{0}$. The method (3) is realized by an iteratively adjustable grid of calculations until the anomalies stability is reached. Method (2) is operated by the constructing maps of the events $N$ (number in the computation cell). Then, the identified anomalies are verified with other geophysical data. For geophysical fields visualization, the GIS-ENDDB cartographical subsystem uses shaded-relief raster images for creating digital geographic maps. The three-dimensional (3D) effect is provided by successive triangulations and by calculating the brightness of triangles.

By mapping these obtained seismic parameters distributions and comparing them with the anomalies of geophysical fields: gravitational, HF, and tomography [6], using our shaded relief model and their digital models, we can verify the linear and ring geodynamic patterns associated with Plate, Plume, and Impact tectonics and check their validity in different territories.

At present, there are no programs of the GIS-ENDDB level for geodynamics comprehensive study, but a wide range of software products and algorithms for complex seismic process analysis or for specific geodynamic characteristics study is known [5]. However, most of them are limited territorially or aimed at solving a narrow range of tasks [3]. Their main drawback is excessive automation at the decision-making stage. The GIS-ENDDB system is a system of expert assessments avoiding unnecessary automation and mathematization. Its advantage is the synchronous analysis of seismic, volcanic, and impact structure distributions along with different geophysical fields.

In this paper, the algorithms for detecting linear and annular structures, i. e., the first of two central functional blocks (see Fig. 1) for studying the regional geotectonic, are considered in more detail. 


\section{Geoinformation technology used in the ENDDB system}

The ENDDB object base consists of a seismic, volcanic, and impact natural disasters data, in particular, 63 catalogs of historical and modern earthquakes. The comparative analysis of completeness of various seismological catalogs intersecting on the maps carried out with the help of the GIS-ENDDB (using histograms of the average events number per time unit and the dependence curve of the magnitudes registered in the events catalog on time) conditionally enables one to zone a geographical map into regions with indication to a preferable catalog.

The GIS-ENDDB methods for physical-mathematical analysis are the main principles of the probability theory and mathematical statistics, the physical laws of environment continuity destruction, other achievements of the Russian and foreign authors in the research subject area (see, for example, [3]). Methods for graphical and spatial-temporal analyses of the main seismic and geodynamic processes characteristics inherited from the analysis subsystem of the GIS-EEDB (the Expert Earthquake Database) [7, 8] and supplemented by the functions of calculating their distribution in the cross sections along the multidirectional profiles indicated by user, allow obtaining the multidimensional data visualization. In addition, in the GIS-ENDDB environment, the algorithms for detecting the events groups of the spatial and spatial-temporal range: aftershocks, swarms, scattering ellipses, clusters, chains, seismolineaments (Fig. 2a) as well as dive slabs and deep channels are being developed [5, 7, 8]. Comparison of different algorithms effectiveness for group detecting can be carried out by estimating the statistical properties of the events swarms. It shows the more effective algorithm in each case.

By revealing clusters, swarms, and seismolineaments, the structure of seismicity, which then can be compared to geological structures, has been established. In particular, the method of structural lineament construction is based on the underlying physical principles of environment destruction: the causal conditionality, which is expressed in a chronological sequence of spatially related events; the requirement of a potential energy minimum of the discontinuity surface; and the statistical reliability provided by events of a seismolineament. Despite the fact that the geophysical environment is not isotropic and has a block-layered structure and the stress field

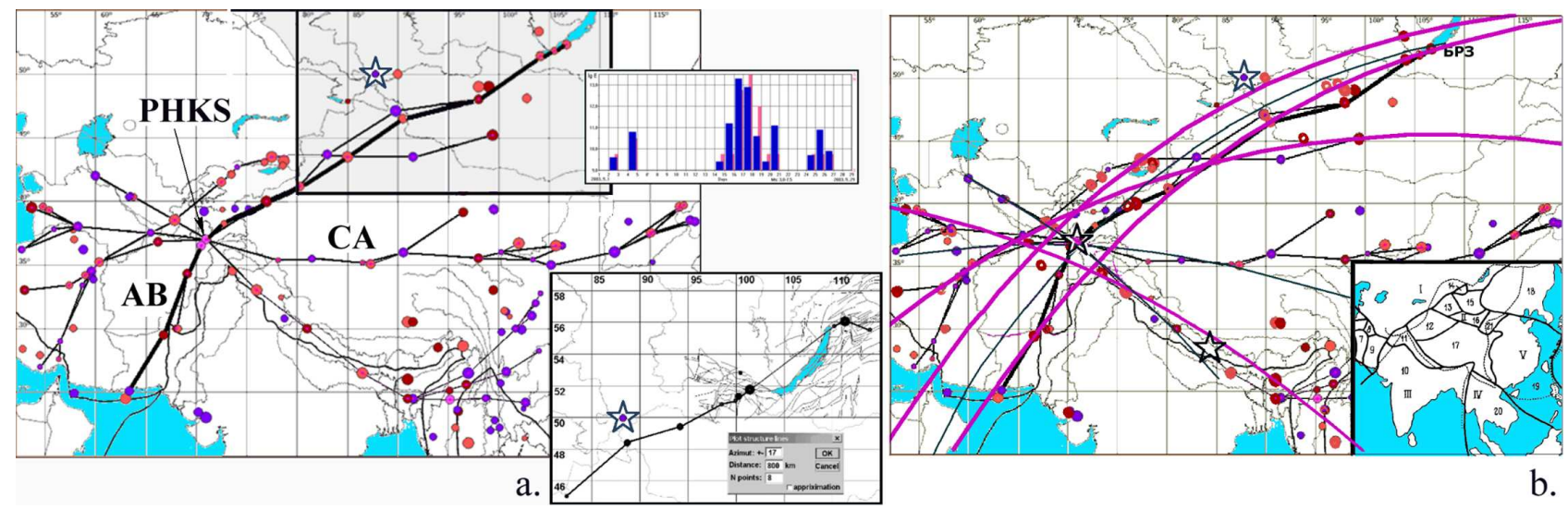

Figure 2 The seismic lineaments system of the Arabian Plate - the BRZ - the Himalayas (Significant Catalog; (-250)-2008 years): (a) the PR-lineaments [8] with the bright AB lineament. In the inserted pictures, the earthquake cluster of September 14-20, 2003, $M_{s} \geqslant 3$ in the last month (September) before the Chui earthquake (27.09.2003, $\left.M_{w}=7.3\right)$ : at the top - on the timeline with a step of 1 day; at the bottom - on the map (the Chui event marked with an asterisk); and (b) the GC-lineaments: the lilac arc lines are seismolineaments of $M_{s} \geqslant 7.2 ; 15 \leqslant H \leqslant 80 \mathrm{~km}$. In the inserted pictures, the scheme of plates and microplates borders according to different authors [9] 
is nonuniform, the final implementation of the physical laws actions at the global (interregional) scale should tend toward the lineaments, i. e., to geometrical shapes, providing a surface energy minimum. These shapes are "planes," "cylinders," "spheroids" as well as in plan: "rings," "lines," and "dendrite-like crack" [10]. In particular, by now, within the GIS-ENDDB, we have developed the algorithm for detecting linear structures involving the validity of the fundamental physics laws in the global geodynamic processes: the above-mentioned least action principle, which requires the destruction of a uniform environment on segments of the GC if a discontinuity overcomes the Moho layer (see Fig. 2). In this case, the seismolineaments reflect the results of geological processes, only partially enclosed by the instrumental seismic data (available only for the last century) and, in our opinion, allow us to reconstruct the long-term geological processes within a single mechanism of structures formation, not yet accepted in geology [11].

The term "seismolineament" is defined by the authors as linear, arc-shaped, and annular structures detected by the distribution in lateral of given rank seismicity magnitudes, which are directly or indirectly related to the active faults of the corresponding rank and reflecting the current stress-strain state of the upper layers of the lithosphere.

Let us list the main concepts of the new algorithm (conditionally called GC) having only three defined parameters: the number of points in the chain $n_{\min }$, the maximum distance between the reference events $L$ (in $\mathrm{km}$ ) and $d$ - the divisor of $L$ for calculating the bandwidth of the GC. The first parameter provides statistical representation of building and the second, the geometrical one, takes into account the effect of the Earth's crust sphericity at distances of $L$, which, at least, should twice exceed the focal zone size of the strongest earthquakes and must be essentially greater than the thickness of the Earth's crust.

1. Suppose that $N_{\max }$ is the total number of selected events (for example, only the crust ones) from the ancient times with $\left(M_{\max }-2\right) \leqslant M_{s} \leqslant M_{\max }$ and a predetermined depth, as well as with a random spatial distribution, and a temporal distribution variance $\sqrt{N_{\max }}$.

2. Calculate $R(1, i)$, i. e., the distance between the chronologically first and all the subsequent events.

3. Repeat Step 2 for all the subsequent events until the number of columns is $N=4 \sqrt{N_{\max }}$. As one may expect, this sample ensures the presence of at least one strong event with its fault.

4. Select all the events (from each of $N$ columns) where every two chronologically successive ones are located no closer than $L / 2$.

5. Between each two chronologically close events satisfying the condition posed on the distance $L / 2 \leqslant R(j, i) \leqslant L$, let us assume the presence of a stress field, which may generate an elongated tectonic fault with a minimum surface energy, i. e., throughout the GC. Therefore, through each pair of such events and the Earth's center, one may build a plane dissecting the lithosphere by the GC.

6. Compute a distance to all the events in the catalog for all the planes constructed, selecting the GC planes with a sufficient number $\left(n \geqslant n_{\min }\right)$ of closely located events (with a distance from the plane: $\Delta h \leqslant L / d)$.

The algorithm implies the expert's skill in setting the events selection and the control parameters $\Delta h$ and $L$ taking into account many complicated factors: different reliability of data on modern and ancient earthquakes; uncertainty of the criteria for throwing away the clearly false candidates for seismolineaments; etc. The advantage of the algorithm is its speed relative to the previous version of seismolineaments constructing (by pattern recognition (PR) [8], see Fig. 2a). The same structures (with some excess) are detected, in this case, in a few seconds 


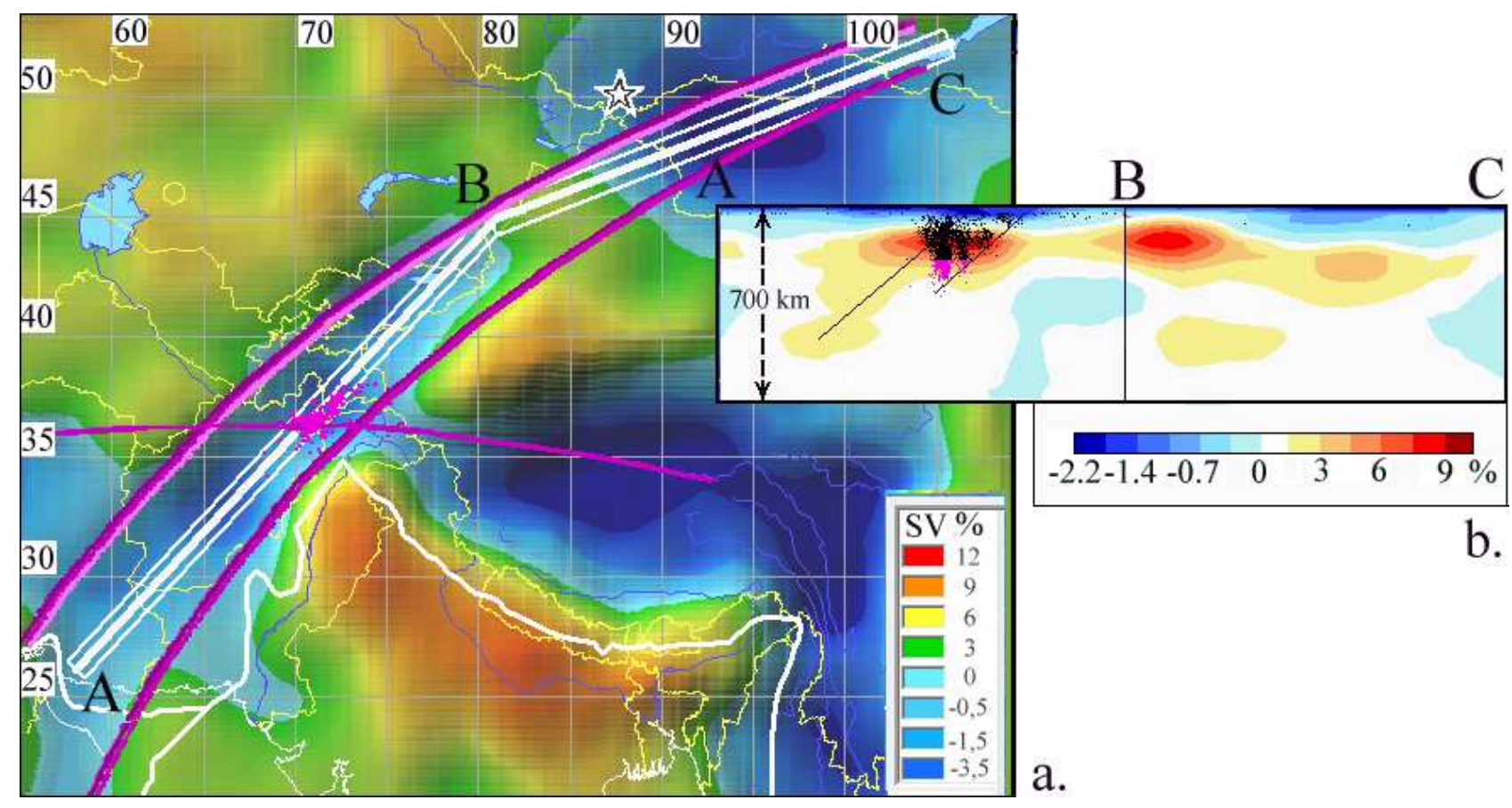

Figure 3 The association of seismicity with the tomographic anomalies: $(a)$ the seismic GC-lineaments (purple) of the CA region, the PHKS zone earthquakes swarm of $H \geqslant 200$ (lilac) and the profile $A B C$ (white) on the background map of the tomographic anomalies (perturbation from the reference $S_{V^{-}}$ velocity [6]) in layer of $H=75 \mathrm{~km}$; and (b) the tomography cross section along the profile $A B C$ and the full seismicity swarm. The asterisk in $(a)$ marks the epicenter of the Chui earthquake, white curve - the interplate border

while earlier, it took several tens of minutes. In the manual sorting mode, this enables to carry out the optimizational search for significant GC, for example, by the criterion of a minimum relationship $h=L / n_{\min }$ or the width of a fault zone $\Delta h$ definition. In these both cases, the choice should correspond to the real geophysical environment. Figure $2 b$ presents the GClineaments corresponding to local minima of $h$. They are associated with the known boundaries of tectonic plates, i. e., meet the criterion of fault deepness.

Currently, the GC-algorithm is being tested on real seismicity material in Central Asia, the Pacific subduction zone, and other seismic-prone regions. For example, with the seismolineament construction algorithms, the central-oriented regional seismolineaments system of Central Asia has been detected [12] on the temporal interval of 2250 years with the most extended "Central-Asian" (CA) and the "African-Baikal" (AB) seismolineaments (see Fig. 2) corresponding, respectively, to the Alpine-Himalayan seismic belt and the Intra-Asian mountain belt. Both these superlineaments are confirmed by the linear negative tomography anomalies up to $80 \mathrm{~km}$ depth (Fig. 3a) and by the linear "compressing" anomalies (of the same trend) of averaging mechanisms field (see details below). The representation of the $A B$-lineament in its northern part (between Balkhash and Baikal lakes) is confirmed by the Chui cluster of the same trend but of a shorter-term (1 week) and of a weaker energy (found in the events with $\left.M_{s} \geqslant 3[1,2]\right)$, which was a short-term precursor of the major Chui earthquake in the Altai region (the inserted pictures in Fig. $2 a$ ). The $A B$-lineament is confirmed, also, by the statistical analysis: by the linear shape of the isolines of the total seismic energy released per unit area or of the summary earthquakes number [13] as well as by one of the recently developed methods: $M_{\max }$-contour configuration (maximum earthquake magnitudes) (Fig. 4) where the seismolin- 


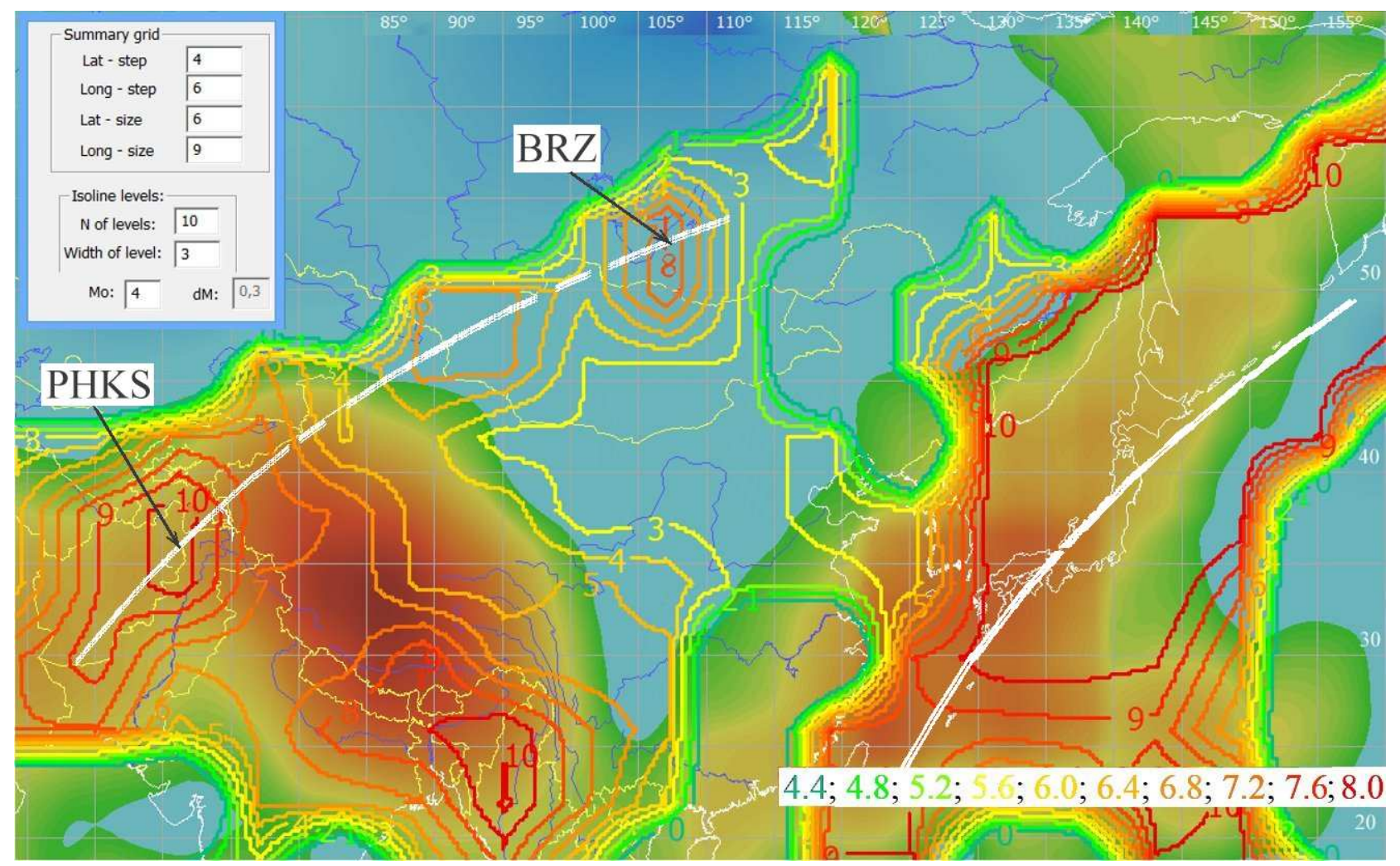

Figure 4 The $M_{\max }$-isolines according to the COMPLEX [2] catalog, $4 \leqslant M_{s} \leqslant 8$ on the regional component map background of the HF obtained by the same averaging. Parameters of building $M_{\max ^{-}}$ contours: $H \leqslant 34 \mathrm{~km}$; the averaging cell $6^{\circ} \times 9^{\circ}$; step $4^{\circ} \times 6^{\circ}$ (contour lines $1 ; 2 ; \ldots ; 10$ correspond to the magnitude of $\left.M_{s}=4.0-4.4 ; \ldots ; 7.6-8.0\right)$

eament structure is even more extended to the north-east (up to the Viluy-Lena watershed). From this corner point, the linear structure extends over the Baikal rift zone (BRZ) to the south-west with value 8 of maximum intensity (i. e., $M_{\max } \leqslant 7.2$ ) in the BRZ and 10 (i.e., $M_{\max } \leqslant 8$ ) in the Pamir Hindu Kush area (see Fig. 4). One can also see that the $M_{\max }$-contour covering the "Taiwan-Kuril" seismolineament (see Fig. 4, on the right) is constructed according to the Japanese catalog JMA with the parameters: $\left(L, n_{\text {min }}\right)=(2,550 \mathrm{~km}, 29) ; 7 \leqslant M_{s} \leqslant 9$; $15 \leqslant H \leqslant 40 \mathrm{~km}$; years 1923-2013, whose influence zone includes the Great East Japan Earthquake $\left(M_{w}=9.0\right)$ and the recent strongest events of the region $\left(2016.04 .14,16: 25 ; M_{s}=7\right.$; $\left.32.78^{\circ} \mathrm{N}, 130.73^{\circ} \mathrm{E}\right)$.

Mapping the seismolineaments on the background of the GIS-ENDDB maps in terms of digital gravimetric models of Remote Sensing Data (especially, of its regional features) or the digital tomography model [6] allows one to discover its association with a deep (mantle) origin inhomogeneities of a geophysical field. The methods for tectonic structures diagnosis on geophysical maps by the GIS-ENDDB facilities are in visual selection of an optimum color palette and foreshortening of an image (or illumination ray parameters and a pseudo-3D model shadow depth) as well as in selecting optimal averaging values (if smoothing is necessary). These procedures (as well as the procedure of cross-sections building, see Fig. 4b) allow one to obtain the most informative 3D images of a relief, gravity, HF, and tomography and to gather data for establishing standard morphostructural elements of the channel-shaped (in the vertical cross section), ring and linear (in plan) structures of endogenous or cosmic origin (see Figs. 4 and 5). 

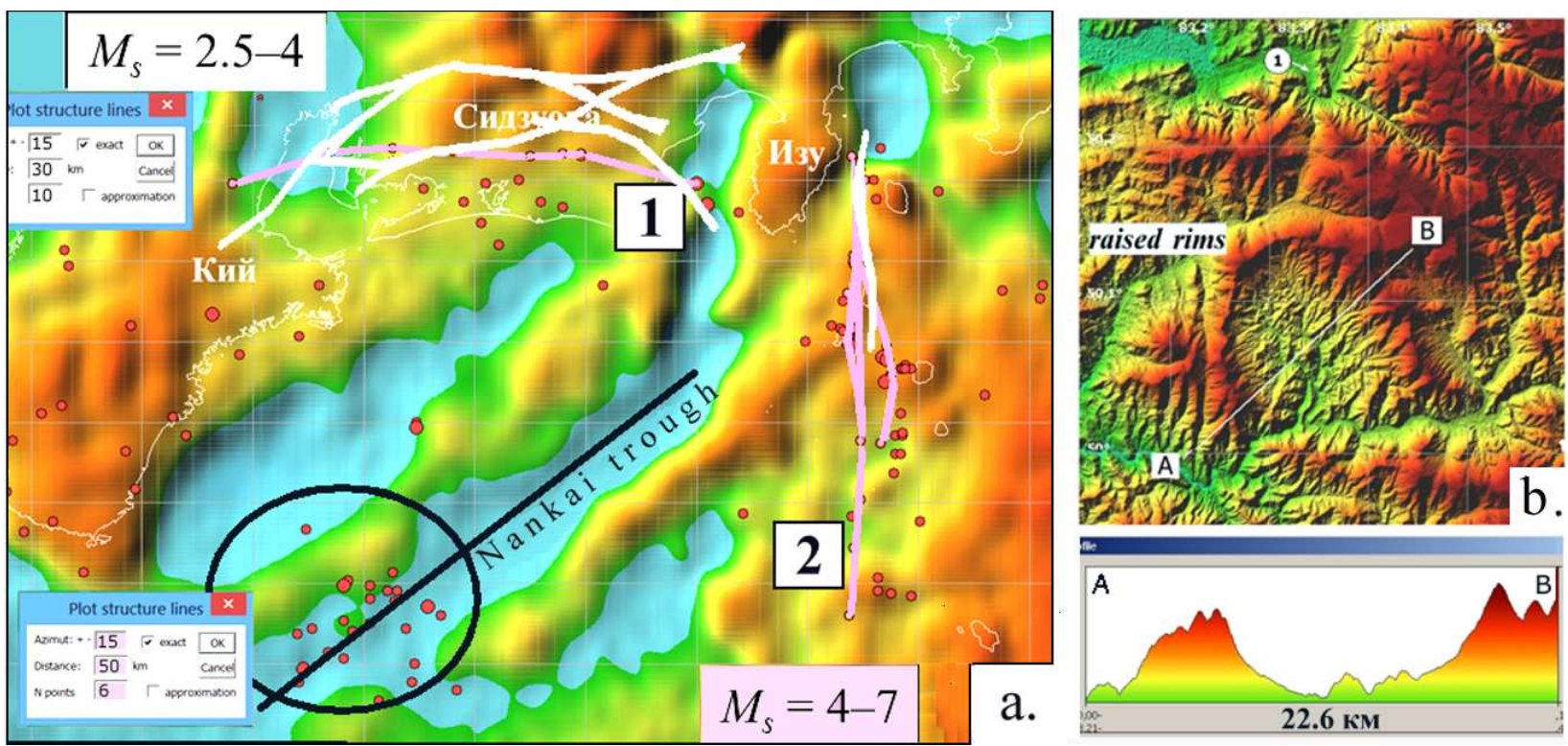

Figure 5 Examples of ring and linear structures identified by various GIS-ENDDB methods: $(a)$ by the digital model of gravity anomalies and arcuate seismicity lineament (JMA catalog, $H \leqslant 50 \mathrm{~km}$ ) around the Nankai trough area, an oval marks the area of long-term concentration of seismicity, and $(b)$ by the detailed topography ASTER GDEM (in the map and cross section) for the crater "Chasha" [14]

All expert methods for structures identification depending on the different information are the following [4]:

1. The above-mentioned seismolineaments construction in term of the linear and ring seismicity distribution in the plan $[2,12]$ (see Figs. 2 and $5 a$ ).

2. The seismicity distribution in cross sections (on the background of tomography data or without background) to detect tectonically active deep areas and "seismic nails" [15] (see Fig. $3 b)$.

3. The gravity or tomography anomalies configuration $[1,2]$ (see Fig. $3 a$ ).

4. The HF anomalies configuration and intensity [2] (see Fig. 4).

5. The configuration of anomaly distribution zones of seismic regime characteristics $[2,4,13]$ (for examlpe, of $M_{\max }$, see Fig. 4).

6. The detailed relief structures in the plan and in the cross section [2] (see Fig. 5b).

7. The averaging earthquake mechanisms anomalies configuration.

8. The geological-tectonic data from other sources (for example, the active faults and blocks, tectonomagnetic observations, etc.).

All the above-said is necessary for the formulation and solution of many geotectonic and geomorphological tasks, covering the geophysical processes multiple components. Such tasks are, for example, as follows:

- to reveal patterns of seismogenic structures (according to seismological catalogs $[1,2,7,8]$ );

- to confirm the new diagnostic morphological features [1,2] of astroblems (according to the "Earth's impact structures Catalog" [14]); and

- to detect and confirm potential structures of complex multistage genesis such as impactmagmatic, impact-tectonic (according to the entire range of data [2]: gravimetrical, thermal, seismic, cosmogenic, etc.). 
For example, let us consider the GIS-ENDDB methods when analyzing the entire range of the above-said center's data of the central-oriented seismolineament system (see Fig. 2a). This center is a special geodynamic region called the Pamir Hindu Kush seismofocal (PHKS) zone.

\section{The application results of the GIS-ENDDB methods}

First, at the point of cross-shape intersection of regional linear faults (see Fig. 2), the multiring structure with diameter of 150 to $300 \mathrm{~km}$ can be detected. This structure is independently detected according to the relief (including the satellite imagery: http://labmpg.sscc.ru/impact/ab1396.html) as well as according to the map of gravity anomalies (Fig. 6a). The multiring positive gravity anomaly (the nested ring system with common cen-
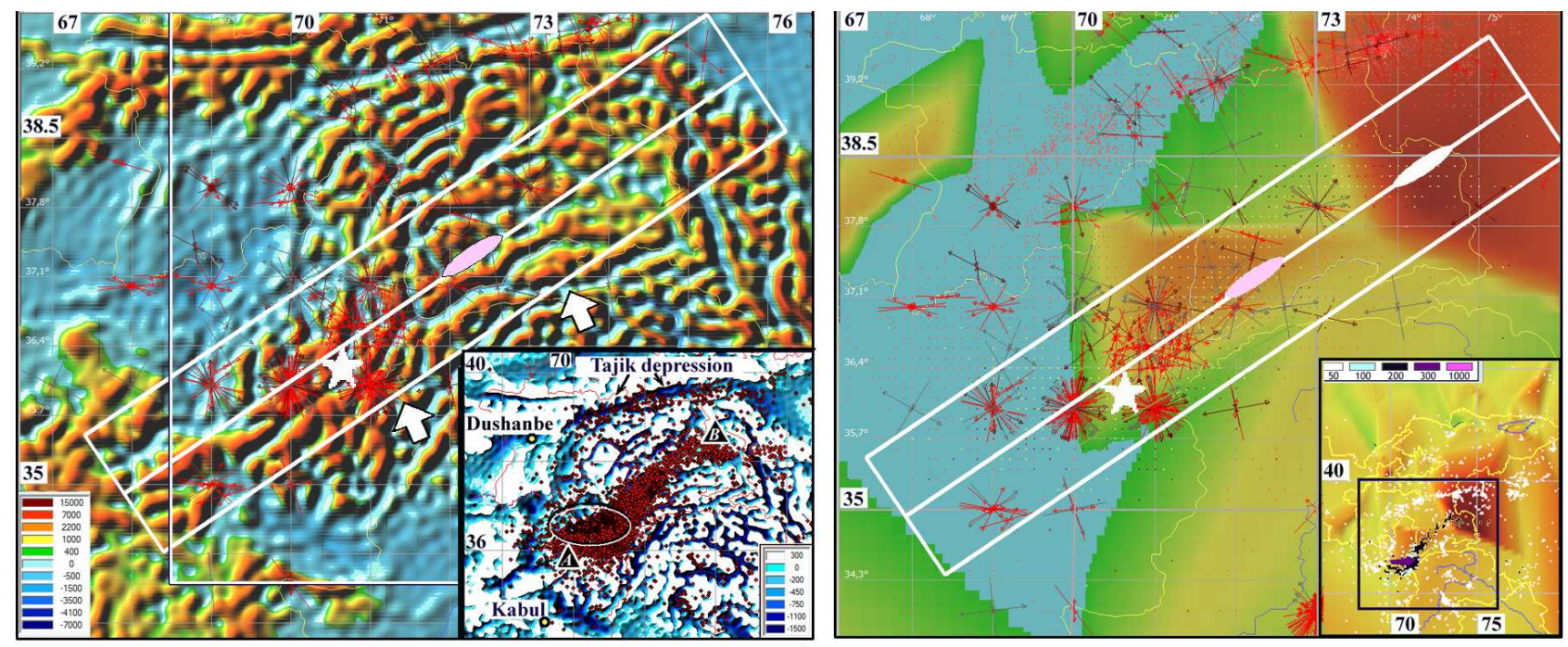

a.
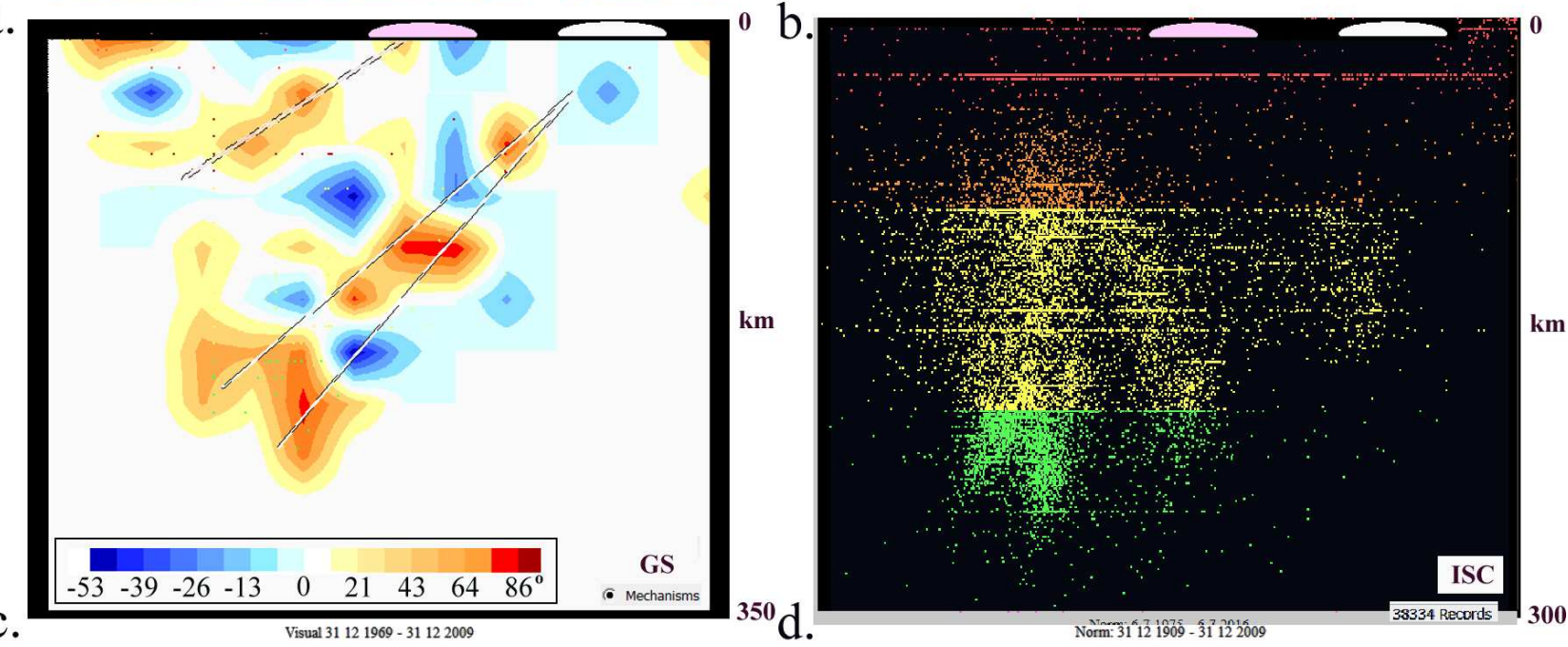

Figure 6 Structural elements of the PHKS zone based on the gravity, HF, and seismic catalogs data (ISC for 1905-2016, NEIC for 1973-2017, and GS RAS for 1993-2009): (a) the events epicenter mechanisms (catalog of GS RAS) and the cross-section profile on the background map of the multiring gravity anomaly (in MGal) distorted by the collision, in the inserted pictures: deep seismicity with $H \geqslant 50 \mathrm{~km}$ (NEIC) on the local component background of the gravity anomaly (the Andreev-Griffin transformation at $R=40 \mathrm{~km}$ ), a white oval or an asterisk marks the PHKS area of deep seismicity with $H \geqslant 200 \mathrm{~km}$; (b) the same on the background map of an HF; $(c)$ a cross section of the averaging mechanisms field (GS RAS); and ( $d$ ) a cross section of the seismicity (ISC). Colored white ovals show the locations of the gravity ring anomalies center and the HF anomalies maxima 
ter) above the PHKS zone is structurally similar to observations above the impact structures (for example, above the reliably established ones: "Vredefort," $D=140-250 \mathrm{~km}, 2.023 \mathrm{Ma}$; "Chicxulub," $D=180 \mathrm{~km}, 65.2 \mathrm{Ma}$; and "Manicouagan," $D=100 \mathrm{~km}, 210 \mathrm{Ma}$ ) [14]. However, the shape of the anomaly is more elongated and distorted by subsequent collisional processes (see Fig. 6a). The center of this anomaly is slightly offset to the NE from the epicenter of the deep seismicity cluster (the ellipse in the inserted pictures in Fig. $6 a$ ).

Second, the nearly radial (see Fig. 2) shape of seismic lineaments junction in the PHKS zone (in the plan) and $\lambda$-shaped configuration of the depth seismicity distribution (in the cross section) (see Fig. $6 d$ ) are similar to the pattern observed at the junction point of the four plates: the Philippine, the Pacific, the Okhotsk-sea, and the Eurasian, where the so-called "seismic nail" exists [15]. A similar $\lambda$-shape configuration of the depth distribution is observed in terms of weak seismicity and localized in the focal zone of the Klyuchevskoy volcanoes group [2].

Third, according to the GIS-ENDDB digital models of the HF, the increased anomalies in the thermal field (up to $276 \mathrm{~mW} / \mathrm{m}^{2}$ ) confined to the Pamir-Hindu Kush region are detected (see Fig. 6b), which enhances the similarity of this zone to the above-mentioned four plates junction in the area of the West Pacific subduction, where there is an anomaly $(D \sim 200 \mathrm{~km})$ up to $475 \mathrm{~mW} / \mathrm{m}^{2}$.

At the same time, the averaging parameters presented in Fig. 3 show a good coherence between contour configuration of $M_{\max }$ (constructed without taking into account the earthquakes of more "fragile" top layer of the Earth's crust) and the regional component of the HF field. Such a coherence may also indicate the relationship of depth seismicity averaged characteristics with the thermal field and can be indicative of controlling the depth seismicity from thermal processes in the upper mantle. The comparison of HF map with the PHKS zone seismicity shows the coincidence of this anomaly with the top of the deep seismic swarm extending from this point to the west-south-west direction, moving deep at an angle of $\sim 25^{\circ}$ to the horizontal (see Figs. $6 c$ and $6 d$ ).

These three patterns, as well as the manifestation of the material movement channel (of the same south-westerly trend in the plan) moving deep to 550-kilometer depth at the same angle $\left(\sim 25^{\circ}\right.$, see Fig. $\left.4 b\right)$, can suggest the presence in the Pamir-Hindu Kush zone (as in the other above-mentioned areas) of a seismically active sloping channel associated with a deep source of activity.

The spatial distribution of the most deep part mechanisms of seismic sources - in the PHKS zone (with $H \geqslant 100 \mathrm{~km}$ ) - shows here the upthrow mechanism preponderance which sharply distinguishes the character of the movements in this zone from the surrounding area. The "seismotectonic deformations of the near vertical uniaxial elongation" [16] predominance in the seismofocal zone suggests the presence of a deep channel of a material addition in the area. The activity of this material addition source can control the activation in the whole centeroriented seismolineament structure (possibly, being complicated by the collision processes) and can have various activities in different time periods. The GIS-ENDDB maps of "stretching" and "compressing" zones according to the summary data of the epicenters mechanisms can identify the dynamics of such tectonic activation.

\section{The averaging earthquake mechanisms field}

The "stretching" and "compressing" zones are the anomalies (Fig. 7) of the parameter Slip ${ }_{12}$, which is an average value of two Slip vectors along the first and the second nodal planes $\mathrm{np}_{1}$ and $\mathrm{np}_{2}$ from an earthquake focal-mechanism solution:

- the case: Slip $_{12}=30-90$ corresponds to a reverse-slip (upthrow) mechanism of compression; 


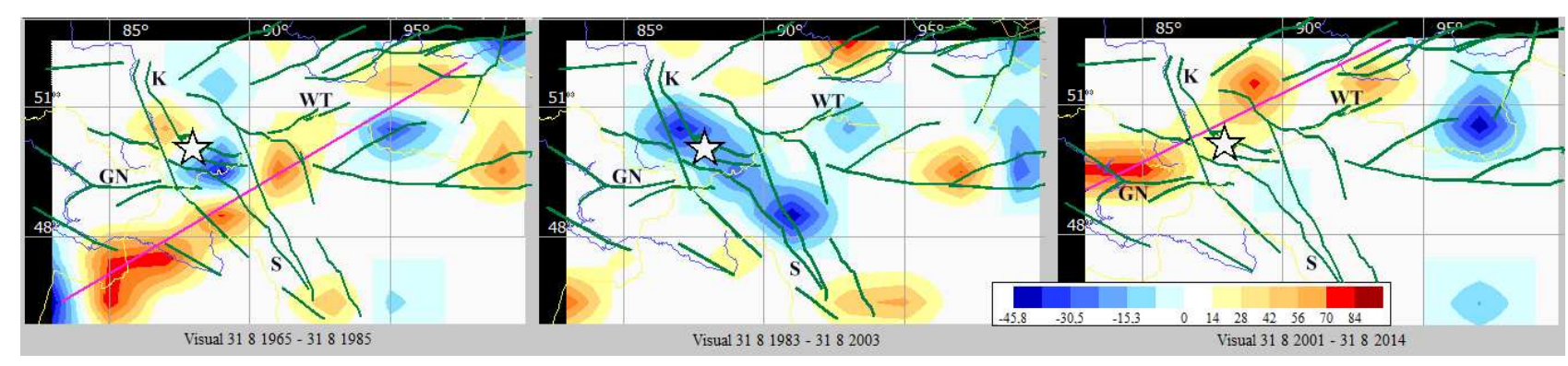

Figure 7 A map series of the averaging mechanisms field according to GS SB RAS catalog for 20-year sequential periods in the Altai-Sayan area: red color — "compressing" and blue color — "stretching" zones

- the case: Slip $_{12}=(-90)-(-30)$ corresponds to an extensional normal-slip mechanism (downthrows); and

- the case: Slip $_{12}=(-30)-30$ corresponds to a strike-slip (shift slide) mechanism.

The extension of a linear "compressing" zone to the east-north-east direction (in the period up to 1985) in the Altai-Sayan area repeats the direction of the $\mathrm{AB}$ seismolineament and corresponds to the direction of the Genghis-Narymsky (GN) and the West-Tannuola (WT) fractures (see Fig. $7 a$ ). Then, the dynamics of Slip ${ }_{12}$-distribution shows that this linear anomaly changes (in the period of 20 years before the Chui earthquake activity) by the "stretching" zone of the orthogonal direction along the Kurai $(\mathrm{K})$ and the Sagsay (S) fractures (see Fig. $7 b$ ). Beginning with the two-year period of the Chui event preparation (starting with 2001) and after it (up to now), the "compressing" zone is activating again having the same extension (to the east-north-east) but shifted to the north parallel to the location of the Chui event epicentral zone (see Fig. $7 c$ ). Such geodynamic regime restructuring possible variants was reflected in the occurrence of the above-mentioned short-term cluster along the $A B$-lineament eve of Chui event.

The area around the PHKS zone also demonstrates linear "compressing" zone presence to the east-north-east direction and local zones of the ring isometric positive anomaly of a "compressing" maximum. Although the "compressing" mechanism is usually associated with "upthrow," we associate this mechanism with the phenomenon of material addition and "swelling" of the lithosphere solid surface along center-oriented deep seismolineaments and in its active center.

Considering the latter and the fact that many characteristic features of the PHKS zone are found in other geodynamic areas: in the proven impact-magmatic structures, areas of volcanic activity, in subduction zones, one can speak about a seismotectonic control of all these areas activity by the deep mantle structures, namely, by a deep mantle focus and by the regional radial fracture system (the latter can be interpreted as derivatives of the focal source). In other words, we have identified the features (see also $[2,12,13]$ ) indicating the tectonic control of regional seismicity by both linear and point (ring) deep structures, i. e., by the long-living deep faults and by the focal depth source. The presence of the ring structure (in plan) marking a deep channel-shaped active source and of central-oriented system of deep faults may be interpreted, as one option, as signs of a possible permeant hypersonic impact of comet, generating in "fragile" top layer of the Earth's crust the structure of a "broken plate" (according to the hypotheses of "comet-galactic impacts" [17] and "shock-explosive tectonics" [18]). 


\section{Concluding Remarks}

The new data analysis methods and tools developed in the GIS-ENDDB system environment provide wider studies for enriching our knowledge about the structure and dynamics of the geological-geophysical environment based on geophysical evidences, the digital topographic and geophysical fields, as well as on geological data. For example, the results comparison of formalized calculation of seismolineaments with the maps of real geophysical manifestations and a more detailed study of the seismolineaments dynamics in anomalous geophysical zones allow the identification of objective characteristics of seismic and geodynamic regime of the territories. Such studies can help to put forward dynamic models of global tectonic processes and to give a wealth of prognostic information for seismologists (for example, about the earthquakes preparation, confined to the linear and ring tectonic structures), i.e., to solve fundamental and applied geodynamics problems. This has been demonstrated on the example of global seismolineament structures of seismicity passing through the PHKS zone and affecting on crust seismicity of Altay region. The presented examples are supported by newer methods included in the GIS-ENDDB complex research: the new GC algorithm for detecting linear structures, methods of $M_{\max }$-contours (maximum earthquake magnitudes), and of Slip 12 distribution (the averaging characteristic of earthquake source mechanism).

\section{References}

[1] Mikheeva, A. V., An. G. Marchuk, and P. G. Dyadkov. 2014. Geoinformation systems for studying seismicity and impact cratering using remote sensing data. Geographic information systems (GIS): Techniques, applications and technologies. Ed. D. Nielson. Engineering tools, techniques and tables ser. Nova Science Publishers. Ch. 7. 151-216. Available at: http://www .novapublishers . com/catalog/product_info.php?products_id=50334\&osCsid (accessed December 29, 2017).

[2] Mikheeva, A. V. 2016. Geostrukturnye elementy, vyyavlyaemye matematicheskimi algoritmami i tsifrovymi modelyami geoinformatsionno-vychislitel'noy sistemy GIS-ENDDB [Geostructural elements detected by mathematical algorithms and numerical models of the geoinformationcomputer system GIS-ENDDB]. Novosibirsk: Omega Print. 300 p. Available at: http:// elibrary.ru/item.asp?id=27622389 (accessed December 29, 2017).

[3] Gitis, V.G., and B. V. Ermakov. 2004. Osnovy prostranstvenno-vremennogo prognozirovaniya $\checkmark$ geoinformatike [Fundamentals of spatial-temporal forecasting in geoinformatics]. Moscow: FIZMATLIT. 256 p. Available at: http://www.rfbr.ru/rffi/ru/books/o_65375 (accessed December 29, 2017).

[4] Mikheeva, A. V., P. G. Dyadkov, An. G. Marchuk, and A. A. Egorov. 2016. Geoinformatsionnye tekhnologii ekspertnoy sistemy GIS-ENDDB ("Bazy dannykh prirodnykh katastrof Zemli") [Information technologies of the expert system GIS-ENDDB ("The Earth's Natural Disasters Databases")]. Vestnik NSU, Ser. Information Technologies 14(3):49-60. Available at: http: //jit.nsu.ru/article.php?11567+en_EN+10229 (accessed December 29, 2017).

[5] Vazhenin, A., A. Mikheeva, P. Dyadkov, and A. Marchuk. 2017. The software using digital databases and gis interface for detecting geodynamic structures. New trends in intelligent software methodologies, tools and techniques. Eds. H. Fujita, A. Selamat, and S. Omatu. Frontiers in artificial intelligence and applications ser. IOS Press. 297:576-592. doi: 10.3233/978-1-61499800-6-576.

[6] Schaeffer, A. J., and S. L. Lebedev. 2013. Global shear speed structure of the upper mantle and transition zone. Geophys. J. Int. 194:417-449. doi: 10.1093/gji/ggt095. 
[7] Dyadkov, P. G., and A. V. Mikheeva. 2010. The EEDB — Expert Earthquake Database for seismic-geodynamic research. Bull. NCC. Ser. Math. Model. Geophys. 13:15-30. Available at: http://bulletin.iis.nsk.su/article/803 (accessed December 29, 2017).

[8] Dyadkov, P.G., and A.V. Mikheeva. 2011. Metody vyyavleniya prostranstvennogo gruppirovaniya zemletryaseniy $\mathrm{v}$ seismogeodynamicheskom issledovanii rayonov Tsentral'noy Azii [Methods for detection of spatial clustering of earthquakes in seismogeodynamic study areas of Central Asia]. 15th Conference "Mathematical Methods of Pattern Recognition" Procceedings. Moscow: MAKS Press. 560-563.

[9] Nikolaev, N. I. 1988. Noveyshaya tektonika i geodynamika litosfery [The newest tectonics and geodynamics of the lithosphere]. Moscow: Nedra. 491 p. Available at: http://www.geokniga. org/bookfiles/geokniga-noveyshaya-tektonika-i-geodinamika-litosfery.pdf (accessed December 29, 2017).

[10] Oparin, V.N., and M. A. Guzev. 2008. Zonal'naya dezintegratsiya gornykh porod i ustoichivost' podzemnykh vyrabotok [The zonal disintegration of rocks and stability of underground workings]. Novosibirsk: SB RAS Publs. 278 p. Available at: http://elibrary.ru/item.asp?id=19602004 (accessed December 29, 2017).

[11] Ustyantsev, V. N. 2013. O edinom mekhanizme structuroobrazovaniya sistemy Zemli [On a single mechanism of structure formation of the Earth system]. LAP LAMBERT Academic Publishing. $620 \mathrm{p}$.

[12] Kalinnikov, I. I., and A. V. Mikheeva. 2016. Algorithms of building lineaments in the program GIS-ENDDB. Bull. NCC. Ser. Math. Model. Geophys. 19:1-9. Available at: http://bulletin . iis.nsk.su/article/1563 (accessed December 29, 2017).

[13] Mikheeva, A. V., and An. G. Marchuk. 2016. Geographical information system "The Earth's natural disasters Database" (ENDDB) as a tool for studying complex geotectonic structures. Bull. NCC. Ser. Comput. Sci. 39:25-36. Available at: http://bulletin.iis.nsk.su/article/1556 (accessed December 29, 2017).

[14] Mikheeva, A. V. 2008. The new data of "Catalogue of the Earth's impact structures". Geochim. Cosmochim. Ac. 72(12, Suppl. 1):A627. doi: 10.1016/j.gca.2008.05.016.

[15] Vadkovsky, V.N. 2012. Subvertikal'nye skopleniya gipotsentrov zemletryaseniy — seysmicheskie "gvozdi" [Subvertical accumulation of earthquake hypocenters — seismic "nails"]. Vestnik ONZ RAS 4:NZ1001. Available at: http://onznews.wdcb.ru/publications/v04/2012NZ000110/ 2012NZ000110.pdf (accessed December 29, 2017).

[16] Shevchenko, V.I., I. P. Dobrovolsky, and A. A. Lukk. 2010. Deformatsii odnoosnogo udlineniya i anomal'nye mekhanizmy ochagov zemletryaseniy v zemnoy kore Tadzhikskoy depressii [Seismotectonic deformation of the uniaxial elongation and anomalous mechanisms of earthquakes in the Earth's crust of Tajik depression]. Geofizicheskiye issledovaniya [Geoph. Res.] 11(1):15-26. Available at: http://elibrary.ru/item.asp?id=13860879 (accessed December 29, 2017).

[17] Barenbaum, A.A. 2009. Galaktotsentricheskaya paradigma i ee sledstviya [Galactocentric paradigm in geology and astronomy]. Moscow: LIBROKOM. $547 \mathrm{p}$.

[18] Zeilik, B.S. 1991. Udarno-vzryvnaya tektonika i kratkiy ocherk tektoniki plit [Shock-explosive tectonics and a plate tectonic synopsis]. Alma-Ata: Gylym. 120 p.

Received February 20, 2017 


\title{
Алгоритмы и методы геоинформационно-экспертного анализа данных в ГИС ENDDB*
}

\author{
А. В. Михеева ${ }^{1}$ И. И. Калинников ${ }^{2}$ \\ anna@omzg.sscc.ru
}

${ }^{1}$ Институт вычислительной математики и математической геофизики СО РАН, Россия, г. Новосибирск, пр. акад. Лаврентьева, 6

${ }^{2}$ Институт физики Земли им. О. Ю. Шмидта РАН, Россия, г. Москва, ул. Б. Грузинская, 10/1

Геоинформационная программная система изучения природных катастроф Земли GISENDDB ориентирована на изучение причинно-следственных связей катастрофических событий в истории нашей планеты. Она содержит данные о сейсмической активности планеты, тепловом потоке, детальном рельефе, аномалиях гравитационного поля и распределении космогенных структур Земли. Постоянно развиваются методы анализа этих данных. В числе последних обновлений в подсистемах информационного и математического обеспечения GIS-ENDDB: алгоритм построения глобальных линеаментов сейсмичности по большим кругам Земли; расчет изолиний максимальных магнитуд землетрясений и осредненного механизма землетрясений на единицу площади; функции визуализации и трансформации геофизических полей, функции распределения в разрезе различных характеристик сейсмичности и данных томографии. Все это помогает расширить классические методы геотектонического исследования комплексным научно-экспериментальным подходом, позволяющим выделять современные тектонически активные границы и разломы, изучать пространственную взаимосвязь сейсмичности и космогенных палеоструктур (связанных с историческим прошлым Земли) и, в конечном итоге, интерпретировать данные с точки зрения построения сейсмогеодинамических моделей литосферы.

Ключевые слова: каталог импактных структур; каталоги землетрясений; геотектонические морфоструктурные элементы; геофизические аномалии; экспертно-геоинформачионный подход

DOI: $10.21469 / 22233792.3 .1 .03$

\section{Литература}

[1] Mikheeva A. V., Marchuk An. G., Dyadkov P. G. Geoinformation systems for studying seismicity and impact cratering using remote sensing data // Geographic information systems (GIS): Techniques, applications and technologies / Ed. D. Nielson. - Engineering tools, techniques and tables ser. - Nova Science Publishers, 2014. Ch. 7. P. 151-216. http://www. novapublishers. com/catalog/product_info.php?products_id=50334\&osCsid.

[2] Михеева A.В. Геоструктурные элементы, выявляемые математическими алгоритмами и цифровыми моделями геоинформационно-вычислительной системы GIS-ENDDB. - Hовосибирск: Омега Принт, 2016. 300 c. http://elibrary.ru/item.asp?id=27622389.

[3] Гитис В. Г., Ермаков Б. В. Основы пространственно-временного прогнозирования в геоинформатике. - М.: Физматлит, 2004. 256 c. http://www.rfbr.ru/rffi/ru/books/o_65375.

[4] Михеева А.В., Дядъков П. Г., Марчук Ан. Г., Егоров А.А. Геоинформационные технологии экспертной системы GIS-ENDDB («Базы данных природных катастроф Земли») // Вестн. НГУ. Сер. Информационные технологии, 2016. Т. 14. №3. С. 49-60. http://jit.nsu.ru/ article.php?11567+en_EN+10229.

*Работа выполнена при финансовой поддержке РФФИ, проект №17-05-01234. 
[5] Vazhenin A., Mikheeva A., Dyadkov P., Marchuk A. The software using digital databases and gis interface for detecting geodynamic structures // New trends in intelligent software methodologies, tools and techniques / Eds. H. Fujita, A. Selamat, S. Omatu. - Frontiers in artificial intelligence and applications ser. - IOS Press, 2017. Vol. 297. P. 576-592. doi: 10.3233/978-1-61499-800-6-576.

[6] Schaeffer A.J., Lebedev S.L. Global shear speed structure of the upper mantle and transition zone // Geophys. J. Int., 2013. Vol. 194. P. 417-449. doi: 10.1093/gji/ggt095.

[7] Dyadkov P. G., Mikheeva A. V. The EEDB - Expert Earthquake Database for seismic-geodynamic research // Bull. NCC. Ser. Math. Model. Geophys., 2010. Vol. 13. P. 15-30. http://bulletin. iis.nsk.su/article/803.

[8] Дядъков П. Г., Михеева А.В. Методы выявления пространственного группирования землетрясений в сейсмогеодинамическом исследовании районов Центральной Азии // Математические методы распознавания образов: 15-я Всеросс. конф. - М: MAKC Пресс, 2011. С. 560563.

[9] Николаев Н. И. Новейшая тектоника и геодинамика литосферы. - М.: Недра, 1988. 491 с. http://www.geokniga.org/bookfiles/geokniga-noveyshaya-tektonika-i-geodinamikalitosfery.pdf.

[10] Опарин B. Н., Гузев M. А. Зональная дезинтеграция горных пород и устойчивость подземных выработок. - Новосибирск: Изд-во СО РАН, 2008. 278 c. http://elibrary.ru/item.asp?id= 19602004.

[11] Устъянцев В.H. О едином механизме структурообразования системы Земля. LAP LAMBERT Academic Publishing, 2013. 620 c.

[12] Kalinnikov I. I., Mikheeva A. V. Algorithms of building lineaments in the program GIS-ENDDB // Bull. NCC. Ser. Math. Model. Geophys., 2016. Vol. 19. P. 1-9. http://bulletin.iis.nsk.su/ article/1563.

[13] Mikheeva A. V., Marchuk An. G. Geographical information system "The Earth's natural disasters Database" (ENDDB) as a tool for studying complex geotectonic structures // Bull. NCC. Ser. Comp. Sci., 2016. Vol. 39. P. 25-36. http://bulletin.iis.nsk.su/article/1556.

[14] Mikheeva A. V. The new data of "Catalogue of the Earth's impact structures" // Geochim. Cosmochim. Ac., 2008. Vol. 72. No. 12. Suppl. 1. P. A627. doi: 10.1016/j.gca.2008.05.016.

[15] Ваджовский В.Н. Субвертикальные скопления гипоцентров землетрясений - сейсмические «гвозди»// Вестн. ОНЗ РАН, 2012. № 4. C. NZ1001. http://onznews.wdcb.ru/publications/ v04/2012NZ000110/2012NZ000110.pdf.

[16] Шевченко В. И., Добровольский И. П., Лукк А. А. Деформация одноосного удлинения и аномальные механизмы очагов землетрясений в земной коре Таджикской депрессии // Геофизические исследования, 2010. Т. 11. № 1. С. 15-26. http://elibrary.ru/item. asp?id=13860879.

[17] Баренбаум A. А. Галактоцентрическая парадигма в геологии и астрономии. - М.: ЛИБКОPOM, 2009. 547 c.

[18] Зейлик Б. С. Ударно-взрывная тектоника и краткий очерк тектоники плит. - Алма-Ата: Гылым, 1991. 120 с. 


\title{
Обусловленность матриц парных сравнений при коррекции метрических нарушений*
}

\author{
С. Д. Двоенко, Д. О. Пиеничный \\ sergedv@yandex.ru; denispshenichny@yandex.ru \\ Тульский государственный университет, Россия, г. Тула, пр. Ленина, 92
}

\begin{abstract}
В интеллектуальном анализе данных результаты исследований часто представлены в виде парных сравнений сходства или различия объектов. Для корректного применения алгоритмов машинного обучения результаты парных сравнений необходимо погрузить в метрическое пространство. Одним из условий корректного погружения является неотрицательная определенность матрицы парных близостей элементов множества друг с другом. В этом случае неотрицательные близости интерпретируются как скалярные произведения векторов в положительном квадранте гипотетического признакового пространства, а соответствующие различия представляют собой расстояния. На практике применяют различные способы оценки сходства или различия элементов множества. Во многих случаях такие функции сравнения не обладают свойствами функций близостей или расстояний, поэтому возникает необходимость в метрической коррекции произвольных экспериментальных матриц парных сравнений для обеспечения положительной определенности соответствующих им нормированных матриц скалярных произведений. Но естественное требование минимизации отклонений значений скорректированных матриц от их исходных значений обычно приводит к плохо обусловленным матрицам скалярных произведений с большим числом обусловленности. В данной работе исследуется обусловленность скорректированных матриц скалярных произведений.
\end{abstract}

Ключевые слова: метрика; детерминант; собственное число; собственный вектор; скалярное произведение; парные сравнения

DOI: $10.21469 / 22233792.3 .1 .04$

\section{1 Задача коррекции метрических нарушений}

Рассмотрим нормированную матрицу скалярных произведений $S(n, n)$, для элементов которой выполняются условия: $s_{i i}=1, i=1, \ldots, n ; s_{i j}=s_{j i},\left|s_{i j}\right| \leqslant 1, i, j=1, \ldots, n$, где $n$ - число элементов множества. Такая матрица может быть получена по теореме косинусов из матрицы расстояний $D(n, n)$ между элементами множества относительно некоторого начала координат.

Непосредственно оценивая сходство элементов множества между собой, обычно применяют различные функции сходства, получая матрицы парных близостей $S(n, n)$ с неотрицательными элементами $s_{i j} \geqslant 0$. Неотрицательные значения $s_{i j} \geqslant 0$ рассматриваются как скалярные произведения элементов множества, представленных векторами в положительном квадранте соответствующего неизвестного нам гипотетического признакового пространства.

Одним из условий отсутствия метрических нарушений в конфигурации множества элементов, помещенных в некоторое пространство, является неотрицательная определенность матрицы их взвешенных скалярных произведений. Если такими свойствами обладает произвольная матрица близостей $S(n, n)$, то считается, что элементы данного множества корректно погружены в метрическое пространство, размерность которого не превышает $n$.

*Работа выполнена при финансовой поддержке РФФИ, проект № 17-07-00319. 
В этом случае совершенно необязательно иметь признаковое пространство в явном виде как набор измерений соответствующих характеристик, чтобы применить алгоритмы машинного обучения, кластер-анализа и т. д.

Но часто оказывается, что экспериментальная матрица сходства элементов множества между собой неположительно определена. Это не позволяет считать, что соответствующее множество элементов может быть представлено точками в некотором неизвестном нам признаковом пространстве. Для математически корректной обработки таких наблюдений в виде близостей необходимо скорректировать некоторые парные близости, чтобы все множество элементов оказалось погруженным в метрическое пространство. Только в этом случае мы можем быть уверены, что при «внезапном» появлении признакового пространства результаты обработки не изменятся.

В итоге, для заданной матрицы парных сравнений сходства или различия, для которой соответствующая матрица нормированных скалярных произведений неположительно определена, требуется так скорректировать значения скалярных произведений, чтобы восстановить ее положительную определенность при минимальных в некотором смысле отклонениях скорректированных значений ряда ее элементов от исходных.

Проблемы преобразования произвольных матриц парных сравнений к нормированному виду и некоторые вопросы их коррекции были ранее рассмотрены в [1-3]. Разработка алгоритмов классификации по матрицам парных сравнений была рассмотрена в $[4,5]$.

В [6] была сформулирована общая постановка задачи оптимальной коррекции значений нормированной матрицы скалярных произведений для элемента, нарушающего метричность конфигурации, при условии минимизации суммы квадратов отклонений скорректированных сравнений данного элемента с остальными от исходных сравнений.

K сожалению, такое естественное требование приводит к нулевому детерминанту скорректированной матрицы, что, как минимум, говорит о некорректной вложенности множества в гипотетическое пространство избыточной размерности, поэтому необходимо обеспечить некоторое небольшое, но положительное значение детерминанта скорректированной матрицы. Вопрос его выбора немедленно приводит к проблеме обусловленности матрицы парных сравнений сходства.

В данной работе рассматривается проблема определения оптимального числа обусловленности матрицы нормированных скалярных произведений при решении задачи ее метрической коррекции.

\section{2 Обусловленность матрицы парных сравнений}

Известно, что число обусловленности квадратной матрицы показывает степень ее вырожденности. Если квадратная матрица $A$ является матрицей коэффициентов некоторой системы линейных уравнений $A \mathbf{x}=\mathbf{b}$ и почти вырождена, то малые изменения $A$ и $\mathbf{b}$ вызовут большие изменения в решении $\mathbf{x}$. Если матрица коэффициентов невырождена (например, близка к единичной), то малые изменения $A$ и $\mathbf{b}$ повлекут только малые изменения в решении х. Невырожденная квадратная матрица характеризуется небольшим числом обусловленности.

Рассмотрим квадратную матрицу $S$. Известно, что ее число обусловленности может быть определено как произведение норм ее и обратной ей матриц Cond $(S)=\|S\| \cdot\left\|S^{-1}\right\|$. Норма матрицы может быть определена различными способами, например как максимальное по модулю собственное число ||$S||=\max |\lambda|$. Норма обратной матрицы окажется $\| S^{-1}||=1 / \min |\lambda|$, так как собственные числа обратной матрицы обратны собственным числам исходной матрицы. 
Для положительно определенной матрицы $S(n, n)$ ее число обусловленности Cond $(S(n, n))=\lambda_{1} / \lambda_{n}$, где $\lambda_{\max }=\lambda_{1}>\cdots>\lambda_{n}=\lambda_{\min }>0$. Заметим, что метрические нарушения приводят к появлению отрицательных собственных чисел, а коррекция их устраняет. Поэтому такое определение числа обусловленности является приемлемым в задаче коррекции.

В то же время, другие возможные определения норм матрицы могут и не подойти, например $\max \left|s_{i j}\right|$, так как здесь данный элемент может вообще не измениться при коррекции. Такая коррекция никак не отразится на числе обусловленности.

$\mathrm{K}$ сожалению, для скорректированной матрицы $S(n, n)$ ее число обусловленности Cond $(S(n, n))$ никак не связано явно со значением ее детерминанта $S_{n}=\operatorname{det} S(n, n)$, хотя известно, что $S_{n}=\prod_{i=1}^{n} \lambda_{i}$. Действительно, из условия $n=\sum_{i=1}^{n} \lambda_{i}$ можно лишь утверждать, что $\lambda_{\max }=\lambda_{1}>0$ уменьшится, если остальные собственные числа не изменятся при возрастании $\lambda_{\min }$, когда оно станет положительным: $\lambda_{\min }=\lambda_{n}>0$. Отсюда число обусловленности Cond $(S(n, n))=\lambda_{1} / \lambda_{n}$ снизится, а обусловленность матрицы $S(n, n)$ улучшится.

Очевидно, что наилучшее решение задачи коррекции, доставляющее минимум отклонения от $S_{n}<0$, определяет значение $S_{n}=0$. Также очевидно, что такое решение неприемлемо, так как $\lambda_{\min }=\lambda_{n}=0$, a Cond $(S(n, n))=\infty$. Как было отмечено выше, указанное противоречие необходимо разрешить, позволив сильнее скорректировать элементы последней строки и столбца матрицы $S(n, n)$.

С другой стороны, значение $S_{n}$ детерминанта скорректированной матрицы $S(n, n)$ не может превысить значения предыдущего минора $S_{n} \leqslant S_{n-1}$. Если же результат коррекции $S_{n}=S_{n-1}$, то по правилу вычисления детерминанта как разложения по элементам последней строки следует, что эта строка должна быть нулевой, как и последний столбец, в силу симметричности $s_{n i}=s_{i n}=0, i=1, \ldots, n$. В этом случае число обусловленности минимально Cond $(S(n, n))=$ Cond $(S(n-1, n-1))$ для данной матрицы. Но также очевидно, что такая коррекция неприемлема из-за недопустимо большого расхождения между исходными и новыми значениями элементов скорректированной матрицы $S(n, n)$.

\section{3 Оптимальная коррекция парных сравнений}

Рассмотрим последовательность главных миноров $S(1,1)=1, S(2,2), \ldots, S(k, k), \ldots$ $\ldots, S(n, n)$ нормированной матрицы скалярных произведений $S(n, n)$. Их значения $S_{1}=1, \ldots, S_{k}=\operatorname{det} S(k, k), \ldots, S_{n}=\operatorname{det} S(n, n)$ убывают, оставаясь положительными при добавлении очередного элемента множества, не нарушающего метрическую конфигурацию. Если имеются метрические нарушения, то такая последовательность миноров оказывается знакопеременной с уменьшающимися по модулю значениями. Тогда отрицательность значения $S_{k}<0$ минора $S(k, k)$ означает, что очередной добавленный элемент, представленный своими парными сравнениями $s_{k i}=s_{i k}, i=1, \ldots, k$, внес метрическое нарушение, которое требуется исправить так, чтобы получить $S_{k}>0$.

Вычислим значение $S_{k}$ минора $S(k, k)$. Для этого разложим его по элементам последней строки:

$$
S_{k}=\sum_{i=1}^{k}(-1)^{k+i} s_{k i}\left(S_{k}\right)_{i}^{k}=\sum_{i=1}^{k-1}(-1)^{k+i} s_{k i}\left(S_{k}\right)_{i}^{k}+S_{k-1}
$$


где $\left(S_{k}\right)_{i}^{k}$ - значение минора $(S(k, k))_{i}^{k}$, полученного из минора $S(k, k)$ удалением строки $k$ и столбца $i$. Далее разложим минор $(S(k, k))_{i}^{k}$ по последнему столбцу и вычислим его:

$$
\left(S_{k}\right)_{i}^{k}=\sum_{j=1}^{k-1}(-1)^{j+k-1} s_{j k}\left(\left(S_{k}\right)_{i}^{k}\right)_{k}^{j}
$$

После подстановки этого разложения с учетом $(-1)^{2 k-1}=-1$ получим:

$$
S_{k}=\sum_{i=1}^{k-1} \sum_{j=1}^{k-1}(-1)^{k+i} s_{k i}(-1)^{j+k-1} s_{j k}\left(S_{k-1}\right)_{i}^{j}+S_{k-1}=S_{k-1}-\sum_{i=1}^{k-1} \sum_{j=1}^{k-1} s_{k i} s_{j k}(-1)^{i+j}\left(S_{k-1}\right)_{i}^{j} .
$$

Если рассмотреть матрицу $S(k-1, k-1)$ и обратную ей $R=S^{-1}(k-1, k-1)$, то для матрицы $R(k-1, k-1)$ вычисление ее элементов дает значения $r_{i j}=(-1)^{i+j}\left(S_{k-1}\right)_{i}^{j} / S_{k-1}$. Отсюда окончательно получим:

$$
S_{k}=S_{k-1}-\sum_{i=1}^{k-1} \sum_{j=1}^{k-1} s_{k i} s_{j k} S_{k-1} r_{i j}=S_{k-1}\left(1-\sum_{i=1}^{k-1} \sum_{j=1}^{k-1} s_{k i} s_{j k} r_{i j}\right) .
$$

Пусть $S_{k}<0$ при $S_{i}>0, i=1, \ldots, k-1$. Скорректируем некоторые элементы последних строки $k$ и столбца $k$ текущего минора, индексы которых образуют множество $I \subseteq\{1, \ldots, k-1\}$. Пусть после коррекции $S_{k}=\tilde{C}$, где $0<\tilde{C}<S_{k-1}$. Обозначим элементы $s_{k i}=s_{i k}$ скорректированной матрицы $S(k, k)$ как переменные $x_{i}, i=1, \ldots, k-1$, и, согласно (1), получим ограничения на их значения:

$$
\sum_{i=1}^{k-1} \sum_{j=1}^{k-1} x_{i} x_{j} r_{i j}=C, \quad C=1-\frac{\tilde{C}}{S_{k-1}}
$$

где для индексов $i \notin I$ элементы $x_{i}=s_{k i}=s_{i k}$ остаются неизменными.

Минимизация отклонений скорректированных элементов при заданном ограничении (2) приводит к следующей задаче оптимизации:

$$
\sum_{i=1}^{k-1}\left(s_{i k}-x_{i}\right)^{2} \rightarrow \min ; \sum_{i=1}^{k-1} \sum_{j=1}^{k-1} x_{i} x_{j} r_{i j}=C .
$$

Для задачи (3) по методу множителей Лагранжа получим систему уравнений:

$$
\left.\begin{array}{c}
\lambda \sum_{i \in I} x_{i} r_{i p}+\sum_{i \notin I} s_{k i} r_{i p}=s_{k p}-x_{p}, \quad p \in I \\
\sum_{i \in I} \sum_{j \in I} x_{i} x_{j} r_{i j}+\sum_{i \in I} \sum_{j \notin I} x_{i} s_{j k} r_{i j}+\sum_{i \notin I} \sum_{j \in I} s_{k i} x_{j} r_{i j}+\sum_{i \notin I} \sum_{j \notin I} s_{k i} s_{j k} r_{i j}=C .
\end{array}\right\}
$$

Решая данную систему численным методом, получим оптимально скорректированные строку и столбец данного минора. Количество уравнений в системе (4) зависит от индексов $p \in I$, т. е. от количества и состава корректируемых элементов.

Таким образом, величина $C$ является параметром задачи оптимизации (3), который неявно связан с числом обусловленности. 
Для согласования двух противоречивых требований (минимизации отклонений и минимизации числа обусловленности) предлагается эвристическая процедура построения с некоторым шагом из интервала $0<\alpha<1$ графиков изменения двух величин $\operatorname{Cond}_{\alpha}(S(k, k))$ и $D_{\alpha}=\sum_{i=1}^{k-1}\left(s_{i k}-x_{i}\right)^{2}$ для параметра $C=1-\alpha$ в задаче оптимизации $(3)$, где $\tilde{C}=\alpha S_{k-1}, \alpha-$ доля значения минора $S_{k-1}$.

Для поиска оптимального числа обусловленности применим популярный эвристический способ совместного анализа графиков противоположно изменяющихся величин, приведенных к единому масштабу. Очевидно, что точка пересечения таких графиков претендует на оптимальность в эвристическом смысле. С другой стороны, формально численный поиск точки пересечения двух плавно изменяющихся функций осуществляется каким-либо из известных итерационных численных методов решения систем нелинейных уравнений [7].

\section{4 Эксперименты на реальных данных}

Рассмотрим корреляционную матрицу $S(11,11)$ статистических взаимосвязей между энергетическими свойствами биоритмов головного мозга для 11 частот (альфа-, бетаи тета-ритмы электроэнцефалограммы головного мозга), полученных В. Д. Небылицыным в его исследованиях по эффекту навязывания ритма светослуховыми ощущениями [8]:

$\left(\begin{array}{ccccccccrrr}1 & 0,562 & 0,568 & 0,152 & 0,347 & 0,250 & 0,264 & -0,020 & -0,212 & -0,086 & -0,076 \\ 0,562 & 1 & 0,784 & 0,057 & 0,196 & 0,218 & 0,009 & -0,017 & -0,002 & 0,163 & 0,284 \\ 0,568 & 0,784 & 1 & 0,288 & 0,475 & 0,264 & 0,066 & 0,144 & 0,114 & 0,228 & 0,151 \\ 0,152 & 0,057 & 0,288 & 1 & 0,686 & 0,293 & 0,034 & 0,048 & -0,069 & -0,064 & 0,175 \\ 0,347 & 0,196 & 0,475 & 0,686 & 1 & 0,429 & 0,070 & 0,152 & 0,036 & 0,028 & 0,216 \\ 0,250 & 0,218 & 0,264 & 0,293 & 0,429 & 1 & 0,788 & 0,197 & 0,154 & 0,109 & 0,035 \\ 0,264 & 0,009 & 0,066 & 0,034 & 0,070 & 0,788 & 1 & 0,109 & 0,054 & -0,002 & -0,018 \\ -0,020 & -0,017 & 0,144 & 0,048 & 0,152 & 0,197 & 0,109 & 1 & 0,807 & 0,830 & 0,699 \\ -0,212 & -0,002 & 0,114 & -0,069 & 0,036 & 0,154 & 0,054 & 0,807 & 1 & 0,904 & 0,728 \\ -0,086 & 0,163 & 0,228 & -0,064 & 0,028 & 0,109 & -0,002 & 0,830 & 0,904 & 1 & 0,768 \\ -0,076 & 0,284 & 0,151 & 0,175 & 0,216 & 0,035 & -0,018 & 0,699 & 0,728 & 0,768 & 1\end{array}\right)$.

Данная матрица содержит 10 положительных и одно отрицательное собственное число. Опыт показывает, что просмотр главных миноров в исходном порядке перечисления элементов множества обычно приводит к необходимости корректировать большое число строк (и одновременно таких же столбцов) матрицы. Это было названо нами эффектом шлейфа после коррекции [1-3]. Поэтому ранее было предложено найти такую ранжировку элементов множества, чтобы первый отрицательный главный минор матрицы близостей в соответствующей ранжировке элементов множества находился бы как можно ближе к концу последовательности миноров [2,3].

Оптимальная ранжировка элементов дает следующую перестановку элементов: 7, 4, $8,1,3,11,5,9,6,10,2$. Главные миноры в данной ранжировке имеют следующие значения: $1,000000,0,998844,0,985015,0,893156,0,539420,0,255770,0,108704,0,024602,0,004752$, $0,000481,-0,000057$.

Таким образом, в данной перестановке последний элемент вносит метрическое нарушение. Это второй элемент в исходном порядке элементов множества. Ранее в [6] была получена корректировка полной строкой, согласно методу коррекции, описанному здесь выше (скорректированные элементы показаны жирным шрифтом): 


$\left(\begin{array}{ccccccccrrr}1 & \mathbf{0 , 5 5 2} & 0,568 & 0,152 & 0,347 & 0,250 & 0,264 & -0,020 & -0,212 & -0,086 & -0,076 \\ \mathbf{0 , 5 5 2} & 1 & \mathbf{0 , 7 5 9} & \mathbf{0 , 0 6 5} & \mathbf{0 , 2 1 3} & \mathbf{0 , 1 9 1} & \mathbf{0 , 0 3 0} & -\mathbf{0 , 0 0 6} & \mathbf{0 , 0 0 9} & \mathbf{0 , 1 6 9} & \mathbf{0 , 2 5 4} \\ 0,568 & \mathbf{0 , 7 5 9} & 1 & 0,288 & 0,475 & 0,264 & 0,066 & 0,144 & 0,114 & 0,228 & 0,151 \\ 0,152 & \mathbf{0 , 0 6 5} & 0,288 & 1 & 0,686 & 0,293 & 0,034 & 0,048 & -0,069 & -0,064 & 0,175 \\ 0,347 & \mathbf{0 , 2 1 3} & 0,475 & 0,686 & 1 & 0,429 & 0,070 & 0,152 & 0,036 & 0,028 & 0,216 \\ 0,250 & \mathbf{0 , 1 9 1} & 0,264 & 0,293 & 0,429 & 1 & 0,788 & 0,197 & 0,154 & 0,109 & 0,035 \\ 0,264 & \mathbf{0 , 0 3 0} & 0,066 & 0,034 & 0,070 & 0,788 & 1 & 0,109 & 0,054 & -0,002 & -0,018 \\ -0,020 & \mathbf{- 0 , 0 0 6} & 0,144 & 0,048 & 0,152 & 0,197 & 0,109 & 1 & 0,807 & 0,830 & 0,699 \\ -0,212 & \mathbf{0 , 0 0 9} & 0,114 & -0,069 & 0,036 & 0,154 & 0,054 & 0,807 & 1 & 0,904 & 0,728 \\ -0,086 & \mathbf{0 , 1 6 9} & 0,228 & -0,064 & 0,028 & 0,109 & -0,002 & 0,830 & 0,904 & 1 & 0,768 \\ -0,076 & \mathbf{0 , 2 5 4} & 0,151 & 0,175 & 0,216 & 0,035 & -0,018 & 0,699 & 0,728 & 0,768 & 1\end{array}\right)$

Легко заметить, что скорректированные значения воспринимаются вполне естественно. Задача была решена при $\tilde{C}=0,1 S_{10}=0,1 \cdot 0,000481 \approx 0,00005$, где была получена величина отклонения 0,058 .

Проверим оптимальность полученного ранее решения, исследуя обусловленность скорректированной матрицы $S(11,11)$. Построим сначала графики изменения величин $\mathrm{Cond}_{\alpha}$ и $D_{\alpha}$ на всем диапазоне $0<\alpha<1$ при корректировке полной строкой по уравнениям (4), так как в этом случае можно получить предельное скорректированное значение минора $S_{k}=S_{k-1}$ при $\alpha=1$ (рис. 1).

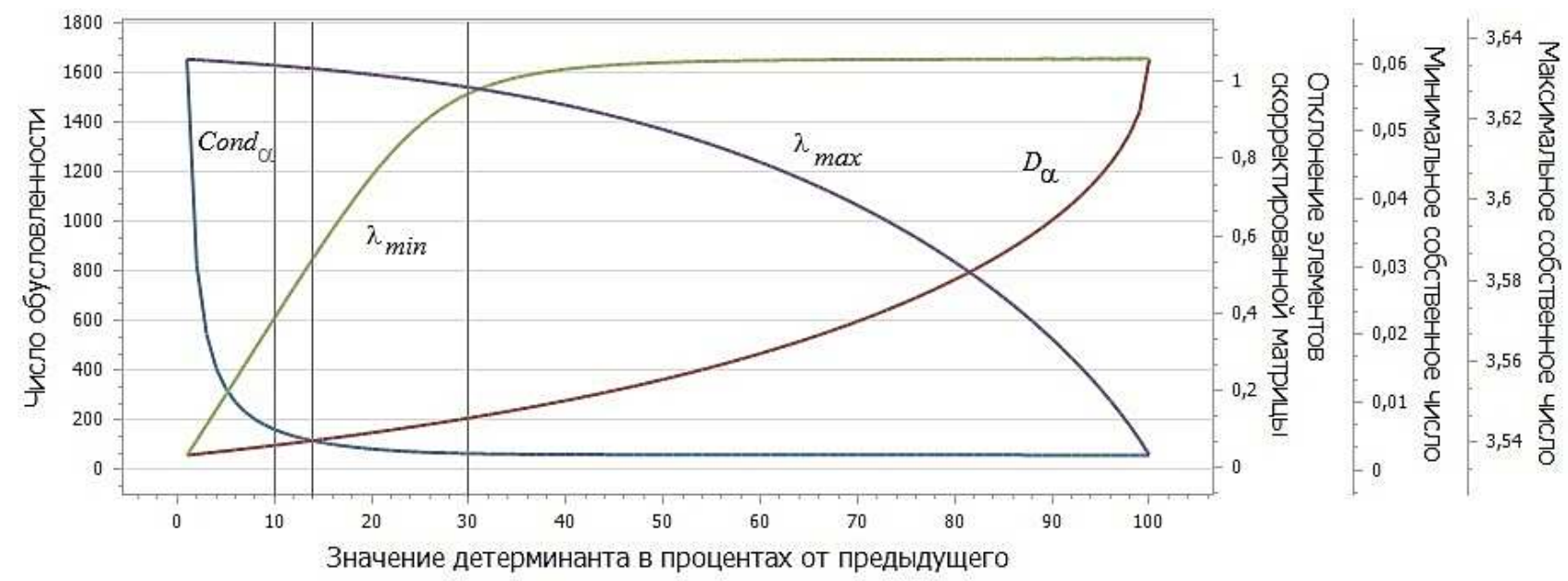

Рис. 1 Изменение числа обусловленности $\left(\operatorname{Cond}_{\alpha}\right)$, отклонения $\left(D_{\alpha}\right)$, максимального $\left(\lambda_{\max }\right)$ и минимального $\left(\lambda_{\min }\right)$ собственных чисел скорректированной матрицы $S(11,11)$ при изменении доли $\alpha$ значения ее детерминанта $S_{11}$ от значения детерминанта $S_{10}=0,000481$ минора $S(10,10)$

Легко увидеть, что при доле $\alpha=0,1$ число обусловленности уже значительно снижено до 162 с величины 1652,8 при $\alpha=0,01$. Тем не менее, совместный анализ противоположно изменяющихся графиков $\operatorname{Cond}_{\alpha}$ и $D_{\alpha}$, приведенных к одному масштабу, указывает на другую эвристически оптимальную долю $\alpha=0,14$ для числа обусловленности 116. И, наконец, по-видимому, вполне допустимо взять также долю вплоть до $\alpha=0,3$, так как на этом интервале собственное число $\lambda_{\min }$ интенсивно нарастает. В то же время собственное число $\lambda_{\text {max }}$ изменяется значительно медленнее, что и определяет монотонное уменьшение числа обусловленности еще почти в 2 раза до значения 65,26 (табл. 1).

Также сравним исходные и скорректированные значения во второй строке матрицы $S(11,11)$, которые показаны в табл. 2. Становится очевидным, что практически со всеми скорректированными значениями можно согласиться, по-видимому, даже включая значе- 
Таблица 1 Характеристики матрицы $S(11,11)$ после коррекции при разных $\alpha$

\begin{tabular}{|c|c|c|c|c|}
\hline$\alpha$ & Cond & $D$ & $\lambda_{\max }$ & $\lambda_{\min }$ \\
\hline 0,01 & 1652,78 & 0,032 & 3,6348 & 0,002199 \\
0,10 & 162 & 0,058 & 3,633299 & 0,022427 \\
0,14 & 116 & 0,070 & 3,632479 & 0,031307 \\
0,30 & 65,26 & 0,128 & 3,627854 & 0,055590 \\
\hline
\end{tabular}

Таблица 2 Значения элементов второй строки в матрице $S(11,11)$

\begin{tabular}{|c|r|r|r|r|r|r|r|r|r|r|r|}
\hline Исходное & 0,562 & 1 & 0,784 & 0,057 & 0,196 & 0,218 & 0,009 & $-0,017$ & $-0,002$ & 0,163 & 0,284 \\
\hline$\alpha=0,10$ & 0,552 & 1 & 0,759 & 0,065 & 0,213 & 0,191 & 0,030 & $-0,006$ & 0,009 & 0,169 & 0,254 \\
$\alpha=0,14$ & 0,549 & 1 & 0,752 & 0,067 & 0,216 & 0,187 & 0,033 & $-0,003$ & 0,011 & 0,169 & 0,248 \\
$\alpha=0,30$ & 0,534 & 1 & 0,715 & 0,076 & 0,228 & 0,169 & 0,046 & 0,013 & 0,023 & 0,167 & 0,219 \\
\hline
\end{tabular}

ния, где меняется знак. Конечно, здесь нужна более строгая (статистическая) проверка значимости отклонений скорректированных значений от исходных.

Ввиду того что в общем случае с некоторыми корректировками исследователь может и не согласиться, рассмотрим также возможность корректировки не всех элементов в строке матрицы парных сравнения для объекта, внесшего метрическое нарушение. Будем считать, например, что поочередно один из элементов второй строки не корректируется.

На рис. 2 представлены графики изменения характеристик матрицы $S(11,11)$ при изменении доли $\alpha$. Сразу следует отметить, что корректировка неполной строкой приводит к невозможности изменения доли $\alpha$ во всем диапазоне $0<\alpha<1$, так как предельное скорректированное значение минора $S_{11}=S_{10}$ при $\alpha=1$ не удается получить из-за ненулевой скорректированной строки.

Таким образом, при изменении доли $\alpha$ возникает порог, когда система уравнений (4) оказывается несовместной (табл. 3). Также можно убедиться, что достигнутые значения числа обусловленности сопоставимы со значением числа обусловленности при корректировке полным вектором. Это показывает, что действительно корректировать в матрице парных сравнений можно меньшее число элементов.

Анализ табл. 3 показывает, что во многих случаях когда неизменяемый элемент оказывается почти нулевым, то это фактически соответствует случаю корректировки полной строкой, позволяя просмотреть весь интервал $0<\alpha<1$ изменения доли корректируемого детерминанта $S_{11}$ относительно предыдущего значения $S_{10}$ (элементы $s_{24}, s_{27}, s_{28}$ и $s_{29}$ ).

Небольшое значение неизменяемого элемента, но не позволяющее считать его нулевым, также определяет почти весь интервал изменения доли $\alpha$ (элементы $s_{25}, s_{26}, s_{2,10}$ и $s_{2,11}$ ).

Наконец, большое по модулю значение неизменяемого элемента значительно сокращает интервал изменения доли $\alpha\left(s_{21}\right.$ и $\left.s_{23}\right)$. Можно показать, что увеличение числа неизменяемых элементов, если их значения сильно отличаются от нулевых, радикально сужает интервал изменения доли $\alpha$. В этом случае может оказаться, что при ограниченном числе корректируемых элементов мы не сможем обеспечить требуемый уровень коррекции, задаваемый параметром $\alpha$. В частности, такая ситуация обычно наблюдается при попытке коррекции одиночным элементом.

В общем случае, чем меньше число корректируемых элементов, тем сильнее их отклонения от исходных значений. 


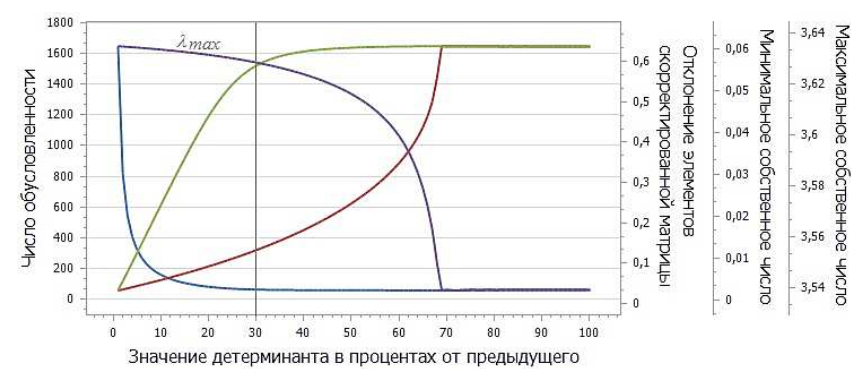

(a) $s_{21}=0,562$, порог $\alpha=0,7$

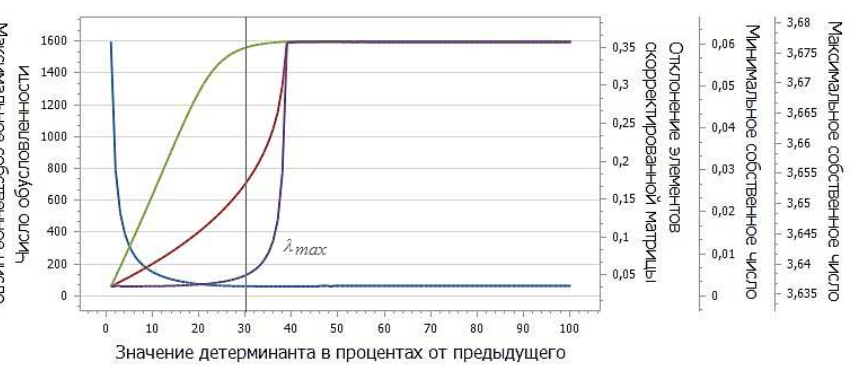

(б) $s_{23}=0,784$, порог $\alpha=0,39$

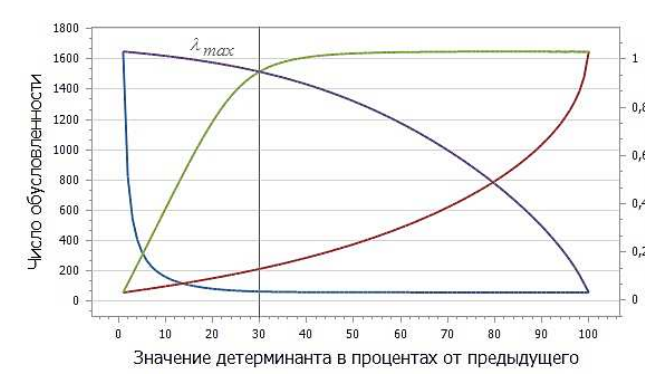

(в) $s_{24}=0,057$, порог $\alpha=1$

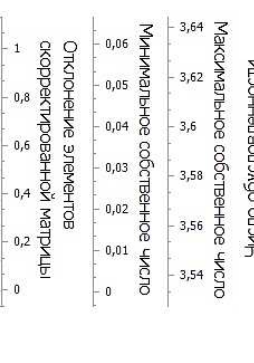

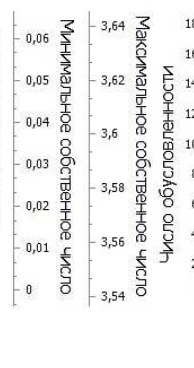

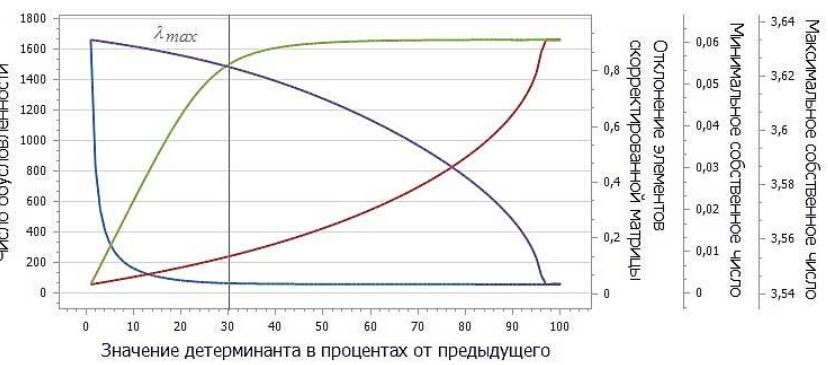

(2) $s_{25}=0,196$, порог $\alpha=0,97$ (d) $s_{26}=0,218$, порог $\alpha=0,96$
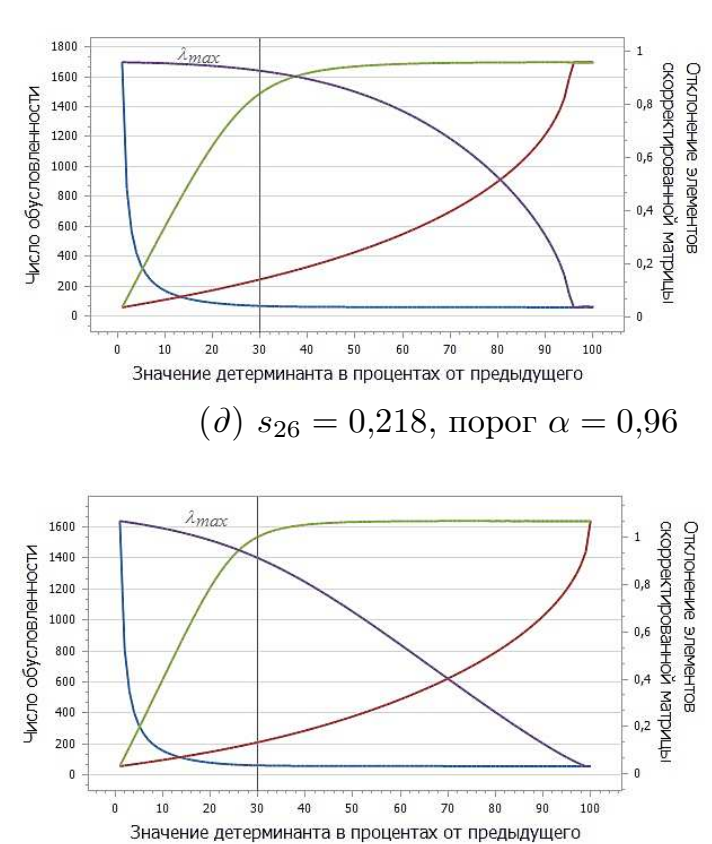

(ж) $s_{28}=-0,017$, порог $\alpha=1$

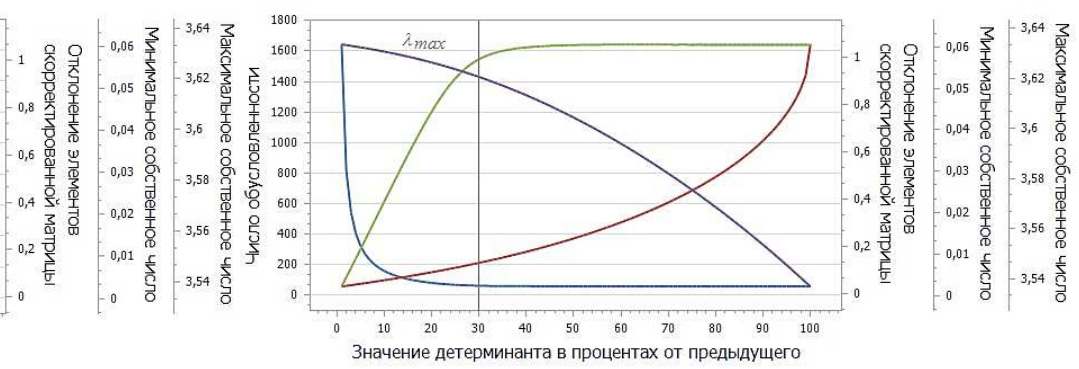

(3) $s_{29}=-0,002$, порог $\alpha=1$

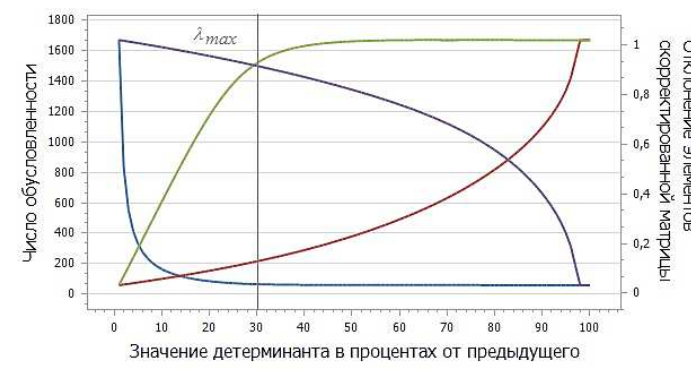

(u) $s_{2,10}=0,163$, порог $\alpha=0,98$

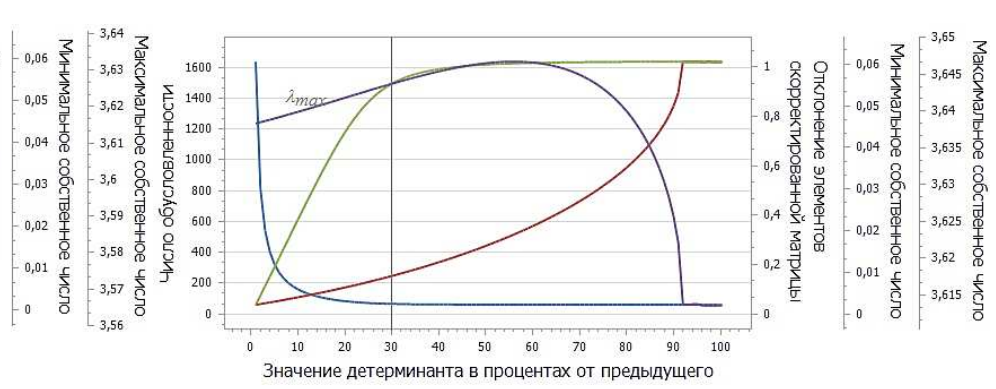

(火) $s_{2,11}=0,284$, порог $\alpha=0,92$

Рис. 2 Изменение характеристик матрицы $S(11,11)$ при изменении доли $0<\alpha<1$ (в процентах) 
Таблица 3 Характеристики матрицы $S(11,11)$ после коррекции при $\alpha=0,3$ неполным вектором

\begin{tabular}{|l|l|l|l|l|l|}
\hline Өлемент & Cond & $D$ & $\lambda_{\max }$ & $\lambda_{\min }$ & Порог $\alpha$ \\
\hline$s_{21}=0,562$ & 64,869381 & 0,132 & 3,6286 & 0,055937 & 0,70 \\
$s_{23}=0,784$ & 61,5059 & 0,170 & 3,638119 & 0,059151 & 0,39 \\
$s_{24}=0,057$ & 65,05 & 0,130 & 3,626335 & 0,055747 & 1 \\
$s_{25}=0,196$ & 66,289948 & 0,133 & 3,623685 & 0,054664 & 0,97 \\
$s_{26}=0,218$ & 68,308514 & 0,142 & 3,633191 & 0,053188 & 0,96 \\
$s_{27}=0,009$ & 67,19 & 0,136 & 3,624918 & 0,053947 & 1 \\
$s_{28}=-0,017$ & 63,66 & 0,134 & 3,61919 & 0,056852 & 1 \\
$s_{29}=-0,002$ & 63,470246 & 0,132 & 3,620596 & 0,057044 & 1 \\
$s_{2,10}=0,163$ & 65,78159 & 0,128 & 3,626781 & 0,055134 & 0,98 \\
$s_{2,11}=0,284$ & 65,87692 & 0,154 & 3,643714 & 0,055311 & 0,92 \\
\hline
\end{tabular}

\section{5 Заключение}

В работе рассмотрен алгоритм оптимальной коррекции неположительно определенных матриц парных близостей. Алгоритм позволяет определить, какие элементы множества вносят метрические искажения и скорректировать их парные сравнения. Предложенный алгоритм позволяет регулировать степень коррекции парных сравнений элемента множества, опираясь на заранее заданный параметр коррекции.

В работе показано, что естественное требование минимизации отклонений скорректированных значений от исходных с неизбежностью приводит к (почти) нулевому детерминанту скорректированного минора, что недопустимо, так как соответствующая нормированная матрица близостей элементов множества оказывается плохо определенной с (почти) бесконечным числом обусловленности.

В работе поставлена и решена задача поиска оптимальной коррекции, позволяющей получить приемлемое значение числа обусловленности скорректированной матрицы. К сожалению, оказалось, что параметр задачи оптимизации связан с числом обусловленности лишь неявно, что пока не позволило сформулировать на данном этапе исследований математически корректную задачу поиска оптимального числа обусловленности.

Тем не менее, в работе предложен эмпирический способ определения диапазона подходящих значений числа обусловленности. В совокупности с ранее полученными результатами [1-6] определены рекомендации для применения практической технологии метрической коррекции произвольных матриц парных сравнений.

\section{Литература}

[1] Двоенко С.Д., Пшеничный Д. О. Устранение метрических нарушений в матрицах парных сравнений // Изв. ТулГУ. Технические науки, 2013. № 2. С. 96-104.

[2] Двоенко С.Д., Пшеничный Д.О. О локализации отрицательных собственных значений в матрицах парных сравнений // Изв. ТулГУ. Технические науки, 2013. № 9. Вып. 2. С. 94102.

[3] Двоенко С.Д., Пшеничный Д. О. О метрической коррекции матриц парных сравнений // Машинное обучение и анализ данных, 2013. Т. 1. № 5. С. 606-620.

[4] Dvoenko S.D. Clustering and separating of a set of members in terms of mutual distances and similarities // Trans. Machine Learning Data Mining, 2009. Vol. 2. No. 2. P. 80-99.

[5] Двоенко С.Д. Двухкомпонентная функция качества кластеризации множества элементов, представленных парными сравнениями // Машинное обучение и анализ данных, 2014. Т. 1. № 9. C. 1141-1153. 
[6] Двоенко С.Д., Пшеничный Д. О. Оптимальная коррекция метрических нарушений в матрицах парных сравнений // Машинное обучение и анализ данных, 2014. Т. 1. №7. С. 885-890.

[7] Демидович Б. П., Марон И. А. Основы вычислительной математики. - М.: Наука, 1966. 664 с.

[8] Небыличын В. Д. Избранные психологические труды. - М.: Педагогика, 1990. 408 с.

Поступила в редакиию 29.08.2017

\title{
The conditionality of matrices of pairwise comparisons after metric corrections*
}

\author{
S.D. Dvoenko and D. O. Pshenichny \\ sergedv@yandex.ru; denispshenichny@yandex.ru \\ Tula State University, 92 Lenina pr., Tula, Russia
}

In modern intelligent data analysis and data mining, results of investigations are usually represented by mutual pairwise comparisons of similarity or dissimilarity of objects. It needs to immerse results of pairwise comparisons into some metric space for correct using of machine learning algorithms. One of the conditions of the correct immersion is the nonnegative definite matrix of pairwise similarities of set elements. In this case, nonnegative similarities represent scalar products of vectors in the positive quadrant of an imaginary feature space and corresponding dissimilarities represent distances. Various similarity and dissimilarity measurements are used in practice. Nevertheless, not all of them are correct as metric functions. Therefore, it needs to use metric corrections of real experimental matrices of pairwise comparisons to reach the positive definiteness of the corresponding matrices of standard scalar products. Unfortunately, the natural best limit to minimize deviations of corrected values from initial ones leads to ill-conditioned matrices of scalar products with the large condition number. A way to improve the conditionality of matrices of pairwise comparisons is investigated.

Background: Experimental data are usually represented by mutual pairwise comparisons of similarity or dissimilarity of objects. If data are immersed into some metric space, the nonnegative definite matrix of pairwise similarities of set elements represents data. The problem consists in various similarity and dissimilarity measurements used in practice. However, not all of them are correct as metric functions and give nonpositive definite matrix of pairwise similarities. Therefore, measurement results need to be corrected.

Methods: The novelty of the proposed method consists in detecting objects, which contribute violations in metrics. Pairwise comparisons of such objects with others are optimally corrected to provide the minimal deviation of new values from the initial ones. In contrast to traditional approach based on the Karhunen-Loeve decomposition, the proposed method allows to correct only some of the matrix elements. From other side, the proposed method allows to reach a suitable value of a condition number of a resulted matrix.

Results: The proposed method appears to be the basis of the improved technique for metric corrections of any experimental matrix of pairwise comparisons. Experimental results on real data show the significant reducing of condition numbers of the corrected matrices.

Concluding Remarks: In contrast to traditional approaches, the proposed method is able to optimally correct only some elements of a matrix of pairwise comparisons and provide the optimal and not so big condition number.

Keywords: metrics; determinant; eigenvalue; eigenvector; scalar product; pairwise comparisons

DOI: $10.21469 / 22233792.3 .1 .04$

*The research was supported by the Russian Foundation for Basic Research (grant 17-07-00319). 


\section{References}

[1] Dvoenko, S. D., and D. O. Pshenichny. 2013. Ustranenie metricheskikh narusheniy v matritsakh parnykh sravneniy [The removing of metric violations in matrixes of pair comparisons]. Izv. TulGU. Tekhnicheskie nauki [Proceedings of Tula State University. Technical sciences] 2:96-104.

[2] Dvoenko, S. D., and D. O. Pshenichny. 2013. O lokalizatsii otritsatel'nykh sobstvennykh znacheniy $\mathrm{v}$ matritsakh parnukh sravnrniy [On localization of the negative eiegnvalues for matrices of pairwise comparisons]. Izv. TulGU. Tekhnicheskie nauki [Proceedings of Tula State University. Technical sciences] 9(2):94-102.

[3] Dvoenko, S.D., and D. O. Pshenichny. 2013. O metricheskoy korrektsii matrits parnykh sravneniy [On metric correction of matrices of pairwise comparisons]. Machine Learning Data Anal. $1(5): 606-620$.

[4] Dvoenko, S. D. 2009. Clustering and separating of a set of members in terms of mutual distances and similarities Trans. Machine Learning Data Mining 2(2):80-99.

[5] Dvoenko, S. D. 2014. Dvukhkomponentnaya funktsiya kachestva klasterizatsii mnozhestva elementov, predstavlennykh parnymi sravneniyami [Bi-partrial objective function for clustering a set elements in terms of pairwise comparisons]. Machine Learning Data Anal. 1(9):1141-1153.

[6] Dvoenko, S. D., and D. O. Pshenichny. 2014. Optimal'naya korretsiya metricheskikh narusheniy $\mathrm{v}$ matritsakh parnykh sravneniy [Optimal correction of metrical violations in matrices of pairwise comparisons]. Machine Learning Data Anal. 1(7):885-890.

[7] Hamming, R. W. 1962. Numerical methods for scientists and engineers. McGraw-Hill. 411 p.

[8] Nebylitsyn, V.D. 1990. Izbrannye psihologicheskie trudy [Selected psychological proceedings]. Moscow: Pedagogika. 408 p. 


\title{
Применение гауссовых вращений для защиты графической информации*
}

\author{
А.Н. Каркищенко, В.Б. Мнухин \\ karkishalex@gmail.com; mnukhin.valeriy@mail.ru \\ Южный федеральный университет, Россия, г. Ростов-на-Дону, ул. Большая Садовая, 105/42 \\ Рассматриваются цифровые изображения над «конечными комплексными полями». \\ Вводится преобразование гауссова вращения таких изображений и доказывается, что при \\ определенных условиях его результат напоминает несколько уменьшенных и повернутых \\ копий оригинала, несмотря на то что эти «копии» образованы различными пикселями. \\ Рассмотрена возможность создания на основе гауссовых вращений защитных фонов и тек- \\ стур для предотвращения несанкционированного изменения документов. Приведен метод \\ верификации защищенных таким образом документов.
}

Ключевые слова: иифровое изображение; конечные поля; гауссовы целые; вращение; защита документов; стеганография

DOI: $10.21469 / 22233792.3 .1 .05$

\section{1 Введение}

Интенсивно происходящий во всем мире процесс построения «информационного общества» делает актуальными задачи разработки и исследования новых методов работы с дискретной информацией, в частности методов решения задач обработки, распознавания и классификации цифровых изображений. В настоящее время такие задачи, как правило, решаются в предположении непрерывности заданного изображения, что позволяет применять мощный аппарат классического математического анализа и интегральных преобразований. Однако на практике применение подобных методов неизбежно приводит к появлению систематических ошибок, связанных с дискретностью реальных изображений и невозможностью адекватного переноса на дискретный случай многих понятий непрерывной математики.

В качестве примера укажем на такие понятия, как вращение и полярная система координат на плоскости. Будучи естественными и элементарными в непрерывном случае $\mathbb{R}^{2}$, они утрачивают эти качества на дискретной плоскости $\mathbb{Z}^{2}[1$, с. 568]. Традиционные методы вращения цифровых изображений основаны, как правило [2, с. 390], на формальном округлении результатов непрерывных вращений; ряд работ посвящен альтернативным методам, основанным на преобразовании Фурье, функциях Эрмита и пр. [3-7].

В связи с этим возникает задача разработки методов, изначально ориентированных на цифровые изображения и опирающихся на аппарат алгебры и теории чисел. В частности, использование различных теоретико-числовых преобразований над конечными полями позволяет проводить быстрые и безошибочные вычисления на основе модулярной арифметики [8-11].

Рассматриваемый в данной работе метод основан на использовании конечых полей, обладающих свойствами, до некоторой степени аналогичными свойствам непрерывного комплексного поля. Такие «конечные комплексные плоскости» имеют характеристику $p=$ $=4 k+3 \geqslant 3$ и могут рассматриваться как дискретные торы $\mathbb{Z}_{p} \times \mathbb{Z}_{p}$, а функции на

\footnotetext{
*Работа выполнена при поддержке РФФИ, проекты № 16-07-00648-а и №17-20-02017-офи_м_РЖД.
} 
них - как цифровые изображения. Идея построения таких полей восходит, по-видимому, к работе [12] и затем развивалась в работах [13-19] и др. Учитывая связь этих полей с целыми гауссовыми числами [20], будем называть их конечными гауссовыми полями

Как известно, вращения на непрерывной комплексной плоскости $\mathbb{C}$ сводятся к умножению на числа $w \in \mathbb{C}$ с единичным модулем, $|w|=1$. Естественно возникающая идея рассмотреть преобразование $f(z) \rightarrow f(w z)$ над гауссовыми полями послужила мотивацией данной работы. Как оказалось, такие гауссовы вращения в некоторых случаях действительно напоминают непрерывные. Точнее говоря, для больших $p$ и при определенных $w$ результат гауссова вращения изображения напоминает несколько уменьшенных и повернутых копий оригинала, несмотря на то что эти «копии» образованы различными пикселями. В других случаях гауссовы вращения приводят к существенным искажениям.

Основным результатом работы является строгое доказательство упомянутых выше свойств гауссовых вращений (ранее в [14-17] эти свойства обсуждались без корректных доказательств). Рассмотрена возможность создания на основе гауссовых вращений защитных фонов и текстур для предотвращения несанкционированного изменения документов. Предложен метод верификации защищенных таким образом документов.

\section{2 Конечные поля целых гауссовых чисел}

Как обычно, далее $\mathbb{Z}$ и $\mathbb{C}$ обозначают соответственно кольцо целых и поле комплексных чисел. Кольцо классов вычетов по модулю целого $n>1$ условимся обозначать как $\mathbb{Z}_{n}=$ $=\mathbb{Z} / n \mathbb{Z}$, а конечное поле из $p^{m}$ элементов - как $\mathbb{G F}\left(p^{m}\right)$, где $p$ - простое и $m>0$.

Напомним, что в теории чисел [20, Ch. 1.4] гауссовыми иелыми называются комплексные числа $z=a+b i \in \mathbb{C}$ с целыми $a$ и $b$. Множество $\mathbb{Z}[i]$ таких чисел замкнуто относительно сложения и умножения, но деление в $\mathbb{Z}[i]$, вообще говоря, не определено. Заметим, что $\mathbb{Z}[i]$ можно рассматривать как квадратную решетку на комплексной плоскости. Это позволяет сопоставлять пикселям цифрового изображения гауссовы целые и рассматривать преобразования изображений, соответствующие операциям в кольце $\mathbb{Z}[i]$. Подобный подход был предложен Г. Бейкером [21] в 1993 г., однако отсутствие деления в $\mathbb{Z}[i]$ существенно ограничивает применимость метода. Естественно возникает мысль об использовании для обработки изображений конечных полей, аналогичных, в каком-то смысле, полю $\mathbb{C}$.

Для построения таких полей заметим, что если для целого $k \geqslant 0$ число $p=4 k+3$ оказывается простым, то над полем $\mathbb{Z}_{p}$ многочлен $x^{2}+1$ будет неприводимым [22]. Вспоминая алгебраический метод построения поля комплексных чисел, приходим к следующему определению.

Определение 1. Пусть простое $p \geqslant 3$ удовлетворяет условию $p \equiv 3(\bmod 4)$. Тогда конечное поле

$$
\mathbb{C}(p) \stackrel{\text { def }}{=} \mathbb{Z}_{p}[x] /\left(x^{2}+1\right) \simeq \mathbb{G} \mathbb{F}\left(p^{2}\right)
$$

будем называть гауссовым полем.

Таким образом, конечные гауссовы поля имеют $p^{2}$ элементов, где $p=3,7,11,19,23$, $31,43,47,59,67,71,79,83,103, \ldots$; всего для $3 \leqslant p<1000$ существует 87 полей $\mathbb{C}(p)$. Каждому $z=a+i b \in \mathbb{Z}[i]$ отвечает единственный элемент $\bar{z}=\bar{a}+\iota \bar{b}$ поля $\mathbb{C}(p)$, где $\bar{a}, \bar{b} \in \mathbb{Z}_{p}$ есть классы вычетов $a, b \in \mathbb{Z}$ по модулю $p$, а $\iota-$ класс вычетов $x$ по модулю идеала $\left(x^{2}+1\right)$, так что $\iota^{2}=\overline{-1} \in \mathbb{Z}_{p}$.

Условимся далее там, где это не может привести к недопониманию, отождествлять $\iota$ с $i$, а классы вычетов - с их представителями, обозначая элементы поля $\mathbb{C}(p)$ точно так 
же, как и гауссовы целые, например $1+2 i \in \mathbb{C}(p)$. Учитывая аналогию $\mathbb{C}(p)$ с комплексным полем $\mathbb{C}$ и кольцом $\mathbb{Z}[i]$, будем называть элементы поля $\mathbb{C}_{p}$ дискретными гауссовыми или дискретными комплексными числами и использовать при работе с ними стандартную терминологию комплексного анализа. В частности, величину $N(z)=a^{2}+b^{2}$ будем называть нормой.

\section{3 Вращения изображений над гауссовыми полями}

Пусть $f(z): \mathbb{C}(p) \rightarrow \mathbb{R}^{+}$- ограниченная действительнозначная функция, определенная на некотором гауссовом поле $\mathbb{C}(p)$ и принимающая только неотрицательные значения. Вспоминая интерпретацию элементов поля $\mathbb{C}(p)$ как пикселей, будем называть $f(z)$ nолутоновым иибровым изображением над полем $\mathbb{C}(p)$. Такие изображения имеют размер $p \times p$, где $p \equiv 3(\bmod 4)$. (Поскольку на практике всякое изображение можно вложить в бо́льшее требуемого размера, последнее условие не является ограничением.) Условимся рассматривать изображения над $\mathbb{C}(p)$ как совокупность квадратных пикселей на дискретном торе $\mathbb{Z}_{p} \times \mathbb{Z}_{p}$. Будем называть подмножество $D \subseteq \mathbb{C}(p)$ связным, если пиксели, отвечающие элементам $D$, образуют на торе односвязную область.

Заметим, что операции поля $\mathbb{C}(p)$ порождают преобразования изображений. Например, сложению следующим образом отвечает циклический сдвиг: для каждого $w=a+b i \in \mathbb{C}(p)$ рассмотрим преобразование $\mathcal{T}_{w}: f(z) \rightarrow f(z+w)$. Тогда изображение $\mathcal{T}_{w}[f]$ есть исходный образ $f(z)$, сдвинутый циклически на $a$ единиц вдоль «действительной» оси и на $b$ единиц вдоль «мнимой» оси. Будем называть $\mathcal{T}_{w}[f]$ сдвигом изображения $f$ н $w$. Как очевидно, сдвиги обратимы: $\mathcal{T}_{w}^{-1}=\mathcal{T}_{-w}$.

В этой работе нас будет интересовать преобразование $f(z) \rightarrow f(w z)$, порождаемое умножением в поле $\mathbb{C}(p)$. Известно, что для непрерывного изображения на комплексной плоскости $\mathbb{C}$ подобное преобразование при $0 \neq w=r e^{i \alpha} \in \mathbb{C}$ является композицией вра-

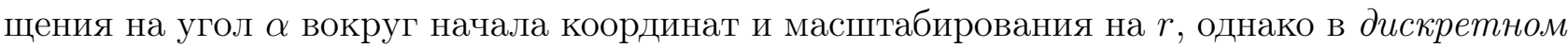
случае корректное определение вращения и масштабирования оказывается нетривиальным [7, p. 377]. Тем не менее сходство между $\mathbb{C}$ и $\mathbb{C}(p)$ наводит на мысль, что некоторые свойства преобразования $f(z) \rightarrow f(w z)$ могут оказаться аналогичными вращениям и в дискретном случае.

Определение 2. Пусть $f(z)$ - цифровое изображение на гауссовом поле $\mathbb{C}(p)$ и пусть $w$ - ненулевой элемент этого поля. Преобразование $\mathscr{R}_{w}: f(z) \rightarrow f(w z)$ изображения $f(z)$ будем называть его гауссовым вращением на $0 \neq w \in \mathbb{C}(p)$.

Непосредственно из определения вытекает обратимость гауссовых вращений:

$$
\mathscr{R}_{w}^{-1}=\mathscr{R}_{w^{-1}} \quad \text { для } 0 \neq w \in \mathbb{C}(p) .
$$

Таким образом, изображение $\mathscr{R}_{w}[f]$ полностью сохраняет всю информацию об оригинале и является просто перестановкой его пикселов.

Рассмотрим примеры гауссовых вращений. На рис. 1 показаны изображение креста на поле $\mathbb{C}(71)$ и его образ при вращении на $w=1+2 i \in \mathbb{C}(71)$. Вполне предсказуемо по аналогии с непрерывным случаем результат можно рассматривать как непрерывное вращение на угол $\operatorname{arctg} 2$, совмещенное с пятикратным увеличением площади. Однако конечность $\mathbb{C}(p)$ приводит, как правило, к значительным искажениям при гауссовых вращениях. Это демонстрируется на рис. 2, где оригинал показан на рис. 2, a. (Важно отметить, что, поскольку изображения заданы на дискретном торе $\mathbb{Z}_{251} \times \mathbb{Z}_{251}$, их противоположные края следует считать склеенными.) На рис. 2, б показан результат вращения изображения 

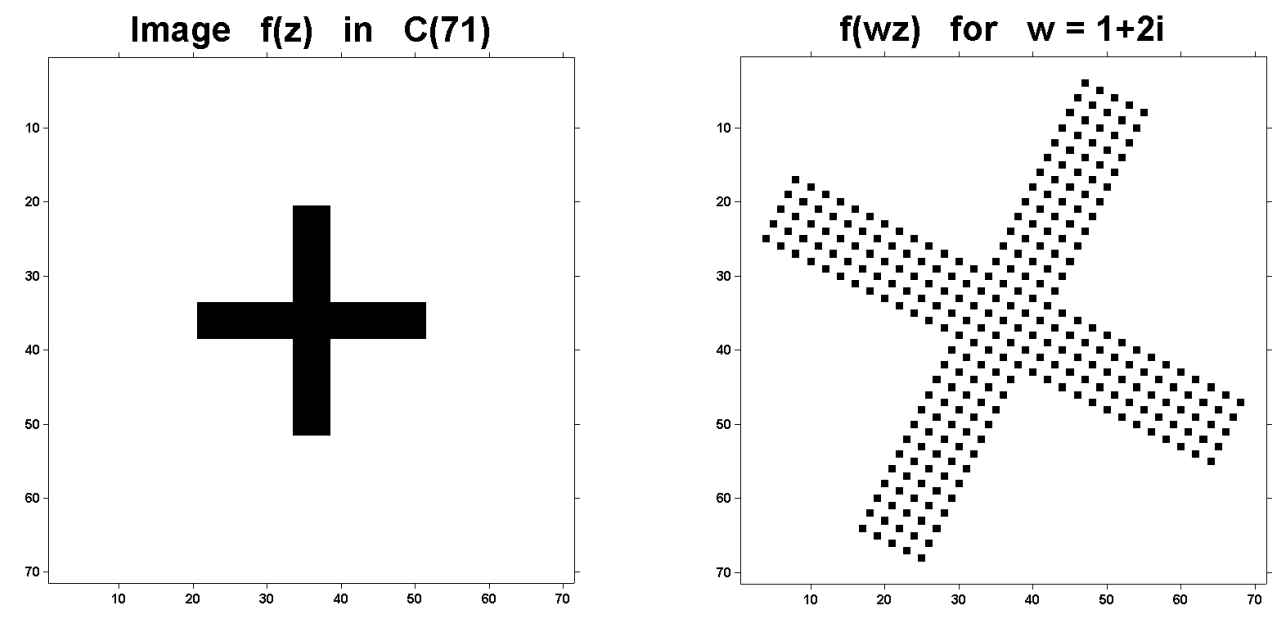

Рис. 1 Пример гауссова вращения над полем $\mathbb{C}(71)$

Ленны на $w=1+i$. При этом оригинал поворачивается на $45^{\circ}$ и «увеличивается» в $\sqrt{2}$ раз, однако конечность тора приводит к взаимопроникновению частей изображения, вызывая его визуальные искажения. (Увеличенный фрагмент исходного изображения различим в левом нижнем углу рис. 2,6 .) Изображение на рис. 2 , г соответствует $w=9+13 i$, когда искажения оказываются настолько значительными, что результат вращения теряет всякое сходство с оригиналом и выглядит как экзотический орнамент.

На фоне предыдущих примеров несколько парадоксальным выглядит результат вращения на $w=-50+100 i=(1+2 i)^{-1} \in \mathbb{C}(251)$, показанный на рис. 2 , в. Визуально он состоит из четырех уменьшенных версий исходного изображения и ряда фрагментов, в совокупности на торе составляющих пятую. Заметим, что эти части изображения, выглядящие одинаковыми, составлены из различных пикселей оригинала. Более того, поскольку общее число пикселей равно $p^{2}$, части не могут содержать одно и то же число пикселей.

Следующая теорема объясняет предыдущий пример и демонстрирует его общность.

Теорема 1. Пусть дано конечное гауссово поле $\mathbb{C}(p)$ и изображение $f$ на нем. Пусть $u=c+d i \in \mathbb{Z}[i]-$ гауссово целое такое, что $0<c, d<p$ и $\operatorname{gcd}(c, d)=1$. Пусть $\bar{u} \in$ $\in \mathbb{C}(p)$ - отвечающий элемент поля $\mathbb{C}(p)$, а $w=1 / \bar{u} \in \mathbb{C}(p)$ - обратный к $\bar{u}$ элемент. Тогда если норма $u$ равна $N \in \mathbb{Z}$, то изображение $\mathscr{R}_{w}[f]$ на торе $\mathbb{Z}_{p} \times \mathbb{Z}_{p}$ состоит из $N$ связных непересекающихся частей таких, что пиксели, смежные в одной части, в исходном изображении $f$ находятся на манхэттенском расстоянии $c+d$ друг от друга.

$B$ случае $p \gg 1$ и $N \ll p$ эти части визуально представляются копиями изображения $f$, повернутого на угол $\operatorname{arctg}(d / c)$ и уменьшенного в $\sqrt{N}$ раз.

Доказательству теоремы посвящен следующий раздел, при первом чтении его можно пропустить. Отметим, что аналоги гауссовых вращений можно ввести и в конечных полях целых Эйзенштейна. Такие эйзенштейновские вращения гексагональных изображений рассматривались в $[23,24]$.

\section{4 Доказательство теоремы}

Пусть

$$
\Gamma \stackrel{\text { def }}{=}\{a+i b: a, b \in \mathbb{Z}, 0 \leqslant a, b<p\} \subset \mathbb{C}
$$




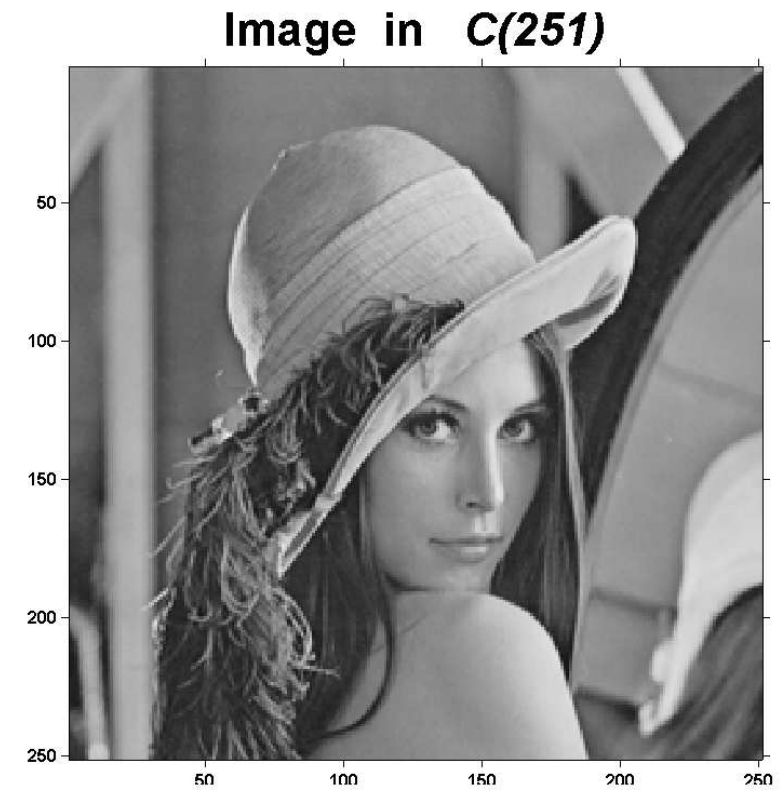

(a)

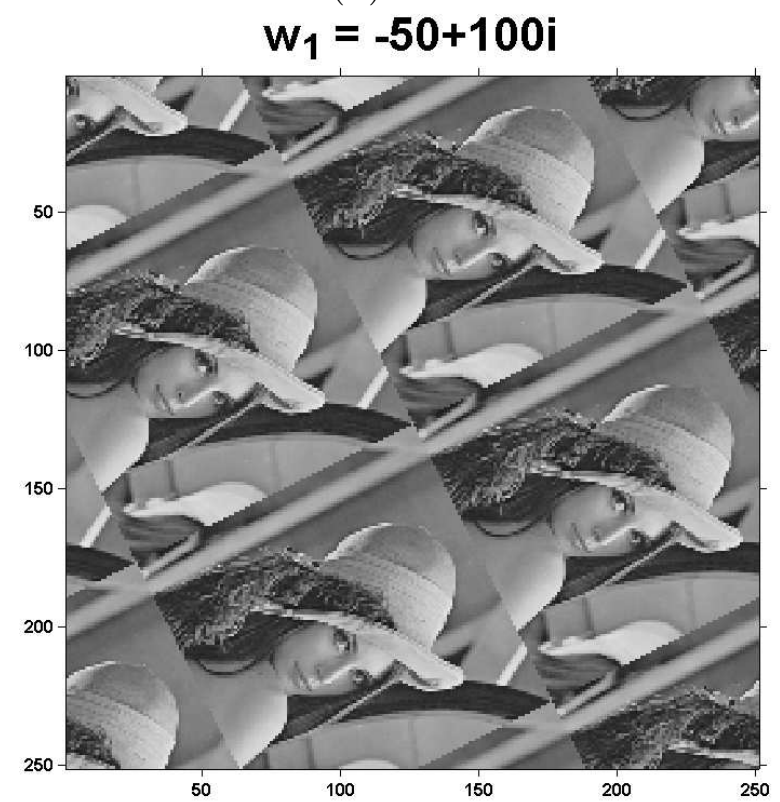

(8)

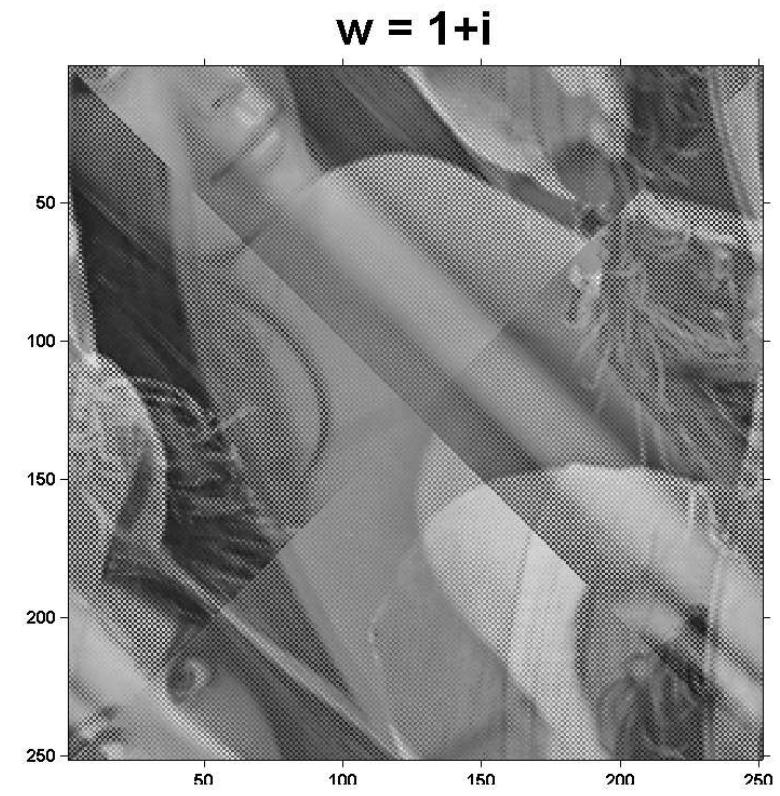

$(6)$

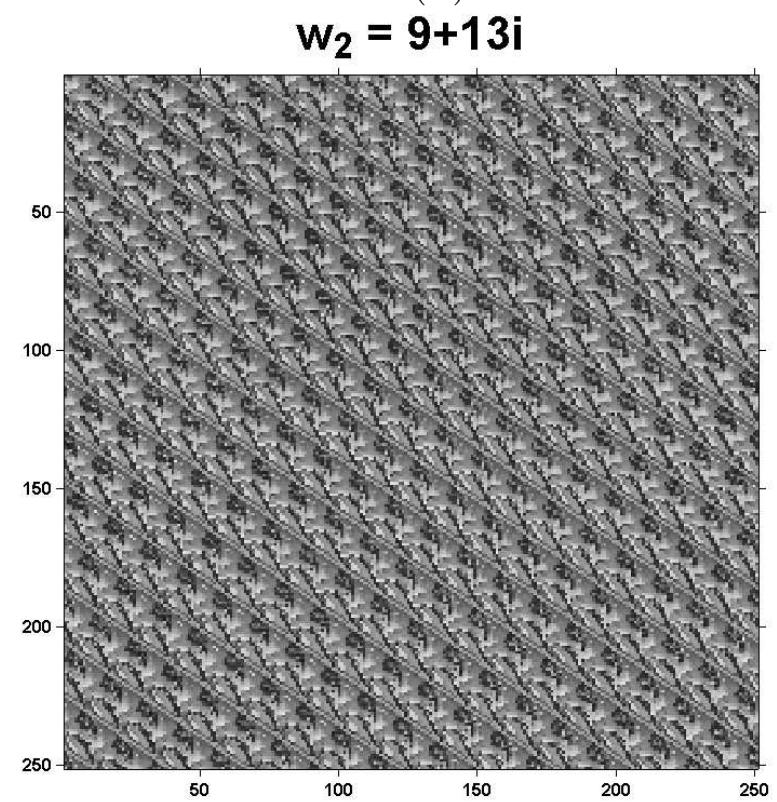

( (2)

Рис. 2 Гауссовы вращения на $\mathbb{C}(251)$

есть множество гауссовых целых в области $[0, p-1] \times[0, p-1]$ на комплексной плоскости. Будем рассматривать эту квадратную область как развертку дискретного тора $\mathbb{Z}_{p} \times \mathbb{Z}_{p}$. Понятно, что между $Г$ и $\mathbb{C}(p)$ существует взаимно-однозначное соответствие.

На первом этапе доказательства будет построено разбиение множества $\mathbb{Z}[i]$ на $N$ классов, после чего эти классы будут ограничены на $Г$ и тем самым перенесены на гауссово поле $\mathbb{C}(p)$. Для построения разбиения напомним [25, гл. 1.1], что множество $L$ точек на плоскости $\mathbb{R}^{2}$ называется иелочисленной решеткой, если найдутся два линейно независимых вектора $\boldsymbol{v}_{1}, \boldsymbol{v}_{2} \in \mathbb{R}^{2}$ таких, что 


$$
L=\left\{a \boldsymbol{v}_{1}+b \boldsymbol{v}_{2}: a, b \in \mathbb{Z}\right\} \subset \mathbb{R}^{2} .
$$

Упорядоченная пара $\mathscr{B}=\left\langle\boldsymbol{v}_{1}, \boldsymbol{v}_{2}\right\rangle$ называется базисом решетки $L$, а область $\Phi_{\mathscr{B}}=$ $=\left\{\alpha_{1} \boldsymbol{v}_{1}+\alpha_{2} \boldsymbol{v}_{2}: 0 \leqslant \alpha_{1}, \alpha_{2}<1\right\} \subset \mathbb{R}^{2}-$ ее фундаментальным параллелограммом. Хотя решетка может порождаться различными базисами и иметь разные фундаментальные параллелограммы, их площадь остается постоянной. Элементы из $L$ называют узлами решетки. В частности, $\mathbb{Z}[i]$ можно рассматривать как решетку с базисом $\mathbf{1}=(1,0)$ и $\boldsymbol{i}=(0,1)$. Ее фундаментальным параллелограммом является единичный квадрат с вершиной в $(0,0)$.

Рассмотрим менее тривиальный пример. Для этого с ненулевым гауссовым числом $u=$ $=c+d i \in \mathbb{Z}[i]$ свяжем два ортогональных вектора $\boldsymbol{v}_{1}=(c, d)$ и $\boldsymbol{v}_{2}=(-d, c)$ и рассмотрим решетку $\Lambda(u) \subset \mathbb{Z}[i]$ с базисом $\mathscr{B}=\left\langle\boldsymbol{v}_{1}, \boldsymbol{v}_{2}\right\rangle$.

Лемма 1. $Е с л и \operatorname{gcd}(c, d)=1$, то внутри фундаментального параллелограмма $\Phi_{\mathscr{B}}$ решетки $\Lambda(u)$ находится ровно $N-1$ узлов решетки $\mathbb{Z}[i]$.

Доказательство. Понятно, что $\Phi_{\mathscr{B}}$ представляет собой квадрат со сторонами $\boldsymbol{v}_{1}$ и $\boldsymbol{v}_{2}$, имеющий площадь

$$
\left|\left[\boldsymbol{v}_{1}, \boldsymbol{v}_{2}\right]\right|=\left|\begin{array}{rr}
c & -d \\
d & c
\end{array}\right|=c^{2}+d^{2}=N(u)=N
$$

Тогда, согласно формуле Пика [26],

$$
N=r+\frac{s}{2}-1
$$

где $r$ - число узлов решетки внутри $\Phi_{\mathscr{B}} ; s-$ число узлов на его границе. Взаимная простота чисел $c$ и $d$ означает, что единственными точками на границах фундаментального параллелограмма являются его вершины, так что $s=4$. Следовательно, $r=N-1$, что завершает доказательство леммы.

Далее будем считать узлы решеток целыми гауссовыми числами. Тогда $\mathbb{Z}[i]$ является абелевой группой относительно сложения, а $\Lambda(u)$ - ее подгруппой. Нетрудно заметить, что индекс $\Lambda(u)$ в $\mathbb{Z}[i]$ равен $N(u)$ :

$$
|\mathbb{Z}[i] / \Lambda(u)|=N(u)
$$

причем классы смежности имеют вид:

$$
\Lambda_{k}(u)=h_{k}+\Lambda(u), \quad k=0, \ldots, N(u)-1,
$$

где $h_{0}=0$, а числа $h_{k}$ при $k \geqslant 1$ соответствуют внутренним узлам фундаментального параллелограмма $\Phi_{\mathscr{B}}$.

Каждый класс смежности $\Lambda_{k}(u)$ содержит бесконечное число узлов решетки $\mathbb{Z}[i]$. Ограничим классы на множество Г, оставляя в каждом классе только узлы, лежащие внутри квадрата $[0, p-1] \times[0, p-1]$. Поскольку между $\Gamma$ и $\mathbb{C}(p)$ существует естественное взаимнооднозначное соответствие, каждый ограниченный класс $\Lambda_{k}(u) \cap \Gamma$ определяет множество $\Theta_{k}(u) \subset \mathbb{C}(p)$. Тем самым получаем разбиение поля $C(p)$ на непересекающиеся классы:

$$
\mathbb{C}(p)=\bigcup_{k=0}^{N-1} \Theta_{k}(u), \quad \Theta_{k}(u) \cap \Theta_{l}(u)=\varnothing \quad \text { при } k \neq l .
$$




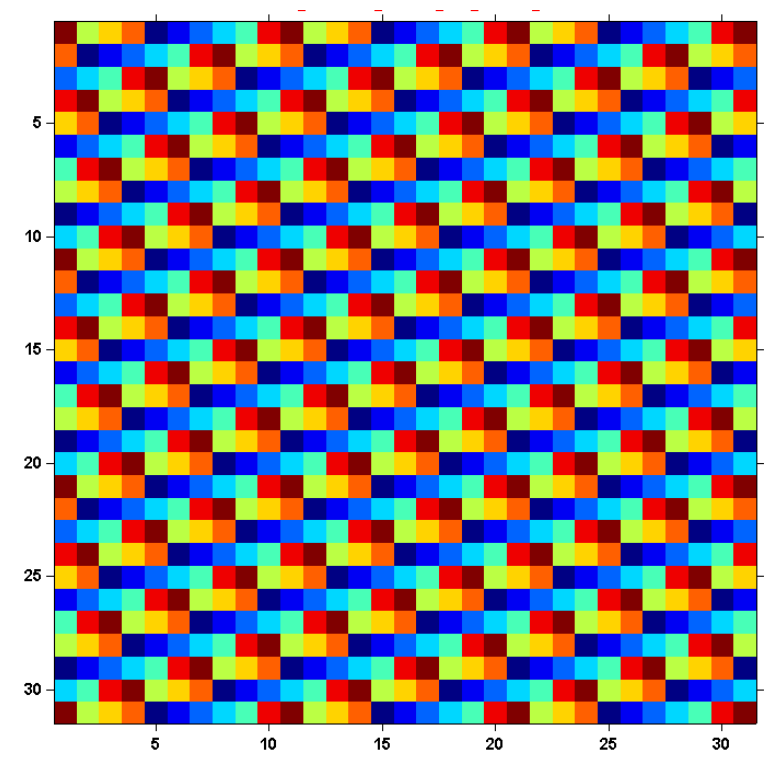

(a)

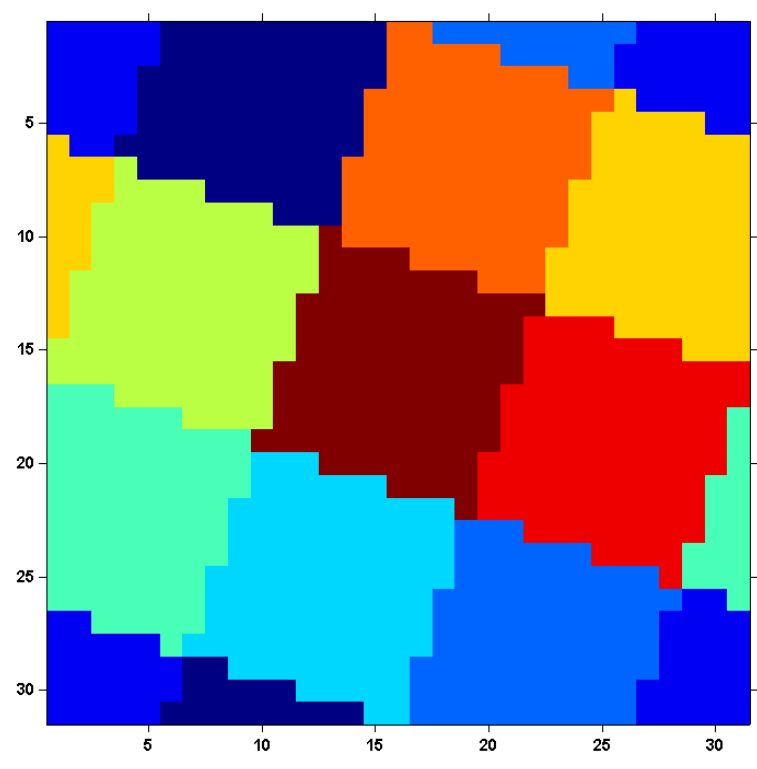

$(6)$

Рис. 3 Разбиение поля $\mathbb{C}(31)$ для $u=3+i(a)$ и его образ при вращении на $w=u^{-1}(б)$

Разумеется, эти классы не обязаны иметь одно и то же число элементов. Такое разбиение поля $\mathbb{C}(31)$ для $u=3+i$ показано на рис. $3, a$, где пиксели, соответствующие элементам одного класса, имеют одно и то же значение, различное для разных классов. В результате все 10 классов показаны различными псевдоцветами, в частности класс $\Theta_{0}(u)$ показан коричневым. Этот класс содержит 97 элементов, а все остальные - по 96.

На рис. 3, 6 показан результат гауссова вращения изображения (см. рис. $3, a)$ на $w=$ $=1 / \bar{u} \in \mathbb{C}(31)$. Видно, что это вращение «собирает вместе» элементы классов $\Theta_{k}(u)$, формируя из них связные на торе блоки пикселей.

Покажем справедливость сделанного выше наблюдения в общем случае. Для этого заметим, что решетку $\Lambda(u)$ можно задать и следующим образом:

$$
\Lambda(u)=\left\{a \boldsymbol{v}_{1}+b \boldsymbol{v}_{2}: a, b \in \mathbb{Z}\right\}=\{u z: z=a+i b \in \mathbb{Z}[i]\}
$$

так что

$$
\Theta_{k}(u)=\left\{\bar{h}_{k}+\overline{u z}: z \in \mathbb{Z}[i] \quad \text { такое, что } u z \in \Gamma\right\},
$$

и, поскольку $w \bar{u}=1$,

$$
\mathscr{R}_{w}\left[\Theta_{k}(u)\right]=w \Theta_{k}(u)=\left\{w \bar{h}_{k}+\bar{z}: u z \in \Gamma \text { для } z \in \mathbb{Z}[i]\right\} .
$$

Здесь z пробегает элементы связного множества, поэтому связным будет и множество $\mathscr{R}_{w}\left[\Theta_{k}(u)\right]$. Тем самым гауссово поле $\mathbb{C}(p)$ разбивается на непересекающиеся связные фрагменты.

Пусть теперь $x, y \in \mathbb{C}(p)$ - два смежных в классе $\mathscr{R}_{w}\left[\Theta_{k}(u)\right]$ пикселя, тогда $x-y= \pm 1$ или $x-y= \pm i$. Поскольку $\mathscr{R}_{w}^{-1}=\mathscr{R}_{w^{-1}}=\mathscr{R}_{\bar{u}}$, до вращения этим пикселам отвечали $\mathscr{R}_{w}^{-1}[x]=\bar{u} x$ и $\mathscr{R}_{w}^{-1}[y]=\bar{u} y$, причем

$$
\mathscr{R}_{w}^{-1}[x]-\mathscr{R}_{w}^{-1}[y]=\bar{u} x-\bar{u} y=\bar{u}(x-y)= \pm \bar{u} \quad \text { или } \quad \pm i \bar{u} .
$$




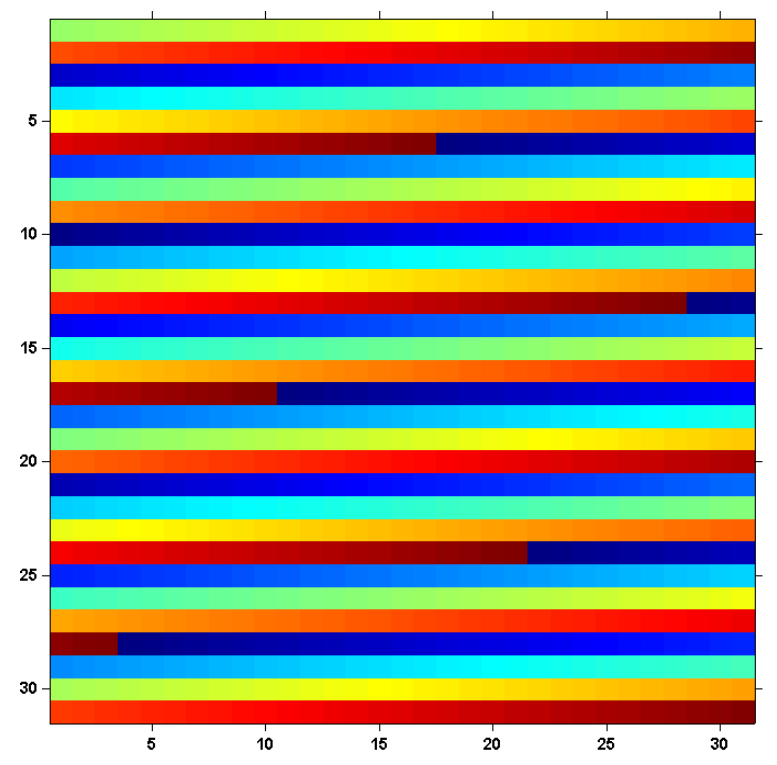

(a)

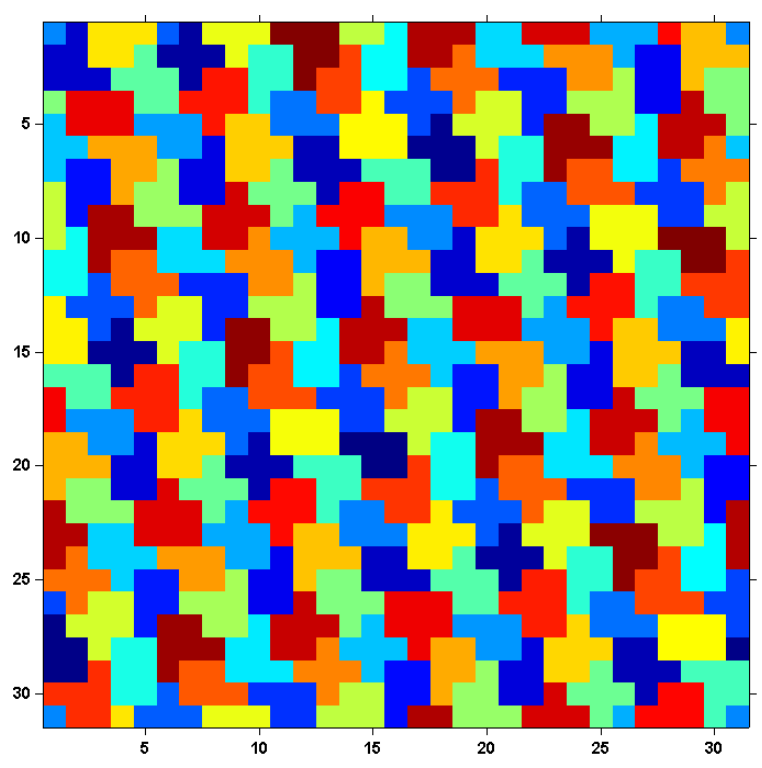

$(6)$

Рис. 4 Разбиение поля $\mathbb{C}(31)$ для $u=7+11 i$ с $N=170(a)$ и его образ при гауссовом вращении $(\sigma)$

Поскольку $u=c+i d$, пиксели $\mathscr{R}_{w}^{-1}[x]$ и $\mathscr{R}_{w}^{-1}[y]$ на торе находятся на манхэттенском расстоянии $c+d<N$ друг от друга, поэтому для малых $N$ и достаточно больших $p$ фрагменты $\mathscr{R}_{w}\left[\Theta_{k}(u)\right]$ выглядят идентичными исходному изображению. Это завершает доказательство теоремы.

Заметим, что для больших $N$ искажения при гауссовых вращениях могут быть весьма значительными. Пример этого показан на рис. 4 , где $u=7+11 i$ и значение $N=170$ велико по сравнению с $p=31$. После вращения изображение разбивается на 170 фрагментов, один из которых содержит 4 пиксела, 73 - по 5 пикселей, 80 - по 6, и 16 - по 7 пикселей.

\section{5 Защита документов на базе гауссовых вращений}

Рассмотренные выше свойства гауссовых вращений позволяют использовать их для защиты документов путем создания на их основе защитных сеток и текстур [27] (рис. 5 и 6). Рисунок 5 демонстрирует пример защитной сетки, состоящей из визуально неразличимых, но различных фрагментов. Тем самым сетку невозможно воссоздать, просто копируя уменьшенные и повернутые копии исходного изображения. Рисунок 6 показывает, как повернутое должным образом изображение можно превратить в декоративный фон, позволяющий полностью воссоздать оригинал и тем самым не позволяющий вносить в него изменения. При этом параметр поворота может быть каким-либо образом связан с особенностями изображения, скажем, быть результатом хеширования даты рождения изображенного лица.

Покажем, как провести верификацию защищенного таким образом документа. Ключевой идеей является введение в гауссовых полях «комплексного логарифма». Вспомним вначале, как это делается на непрерывной комплексной плоскости.

Пусть $\mathbb{C}^{*}$ - мультипликативная группа комплексного поля, а $\mathbb{R}=\langle\mathbb{R},+\rangle$ - аддитивная группа поля действительных чисел. Заметим, что биекция

$$
0 \neq z=r e^{i \theta}=e^{\ln r+i \theta} \leftrightarrow(l, \theta),
$$




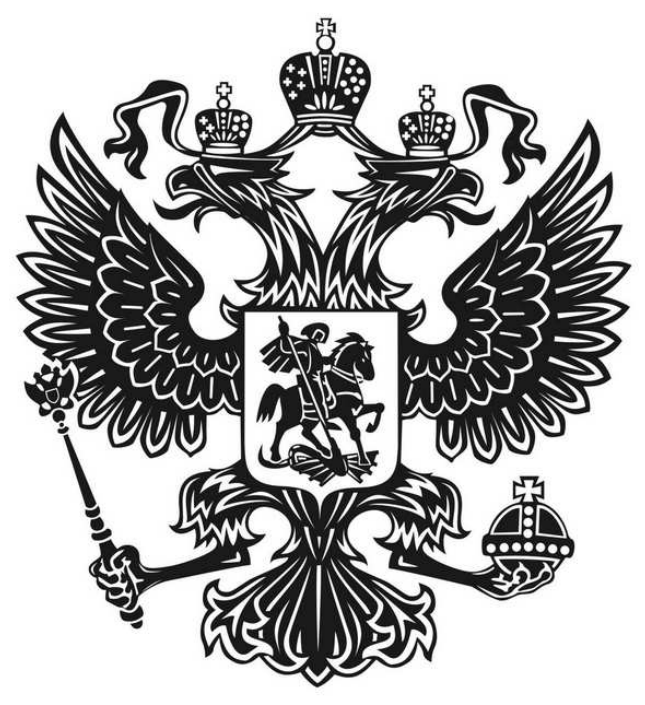

$(a)$

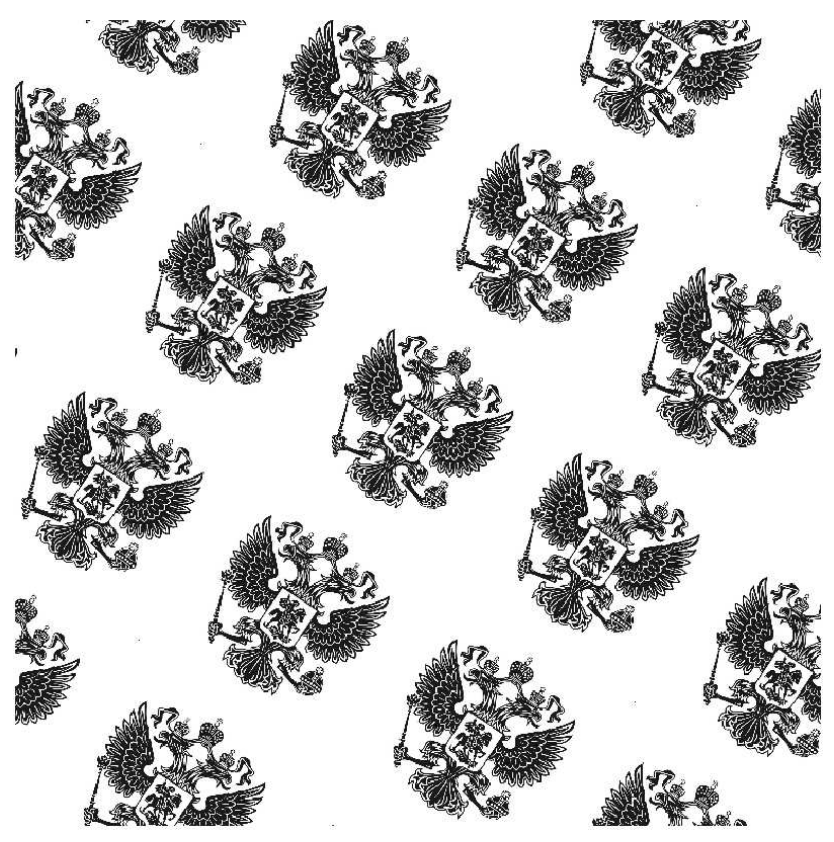

(б)

Рис. 5 Пример защитной сетки: $(a)$ исходное изображение размера $751 \times 751 ;(\sigma)$ результат его вращения на $(3+2 i)^{-1} \in \mathbb{C}(751)$

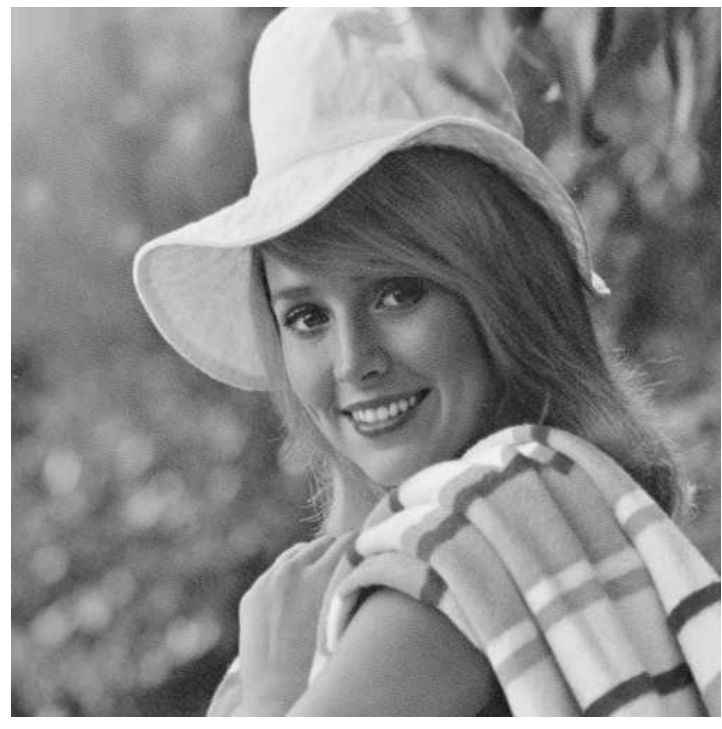

$(a)$

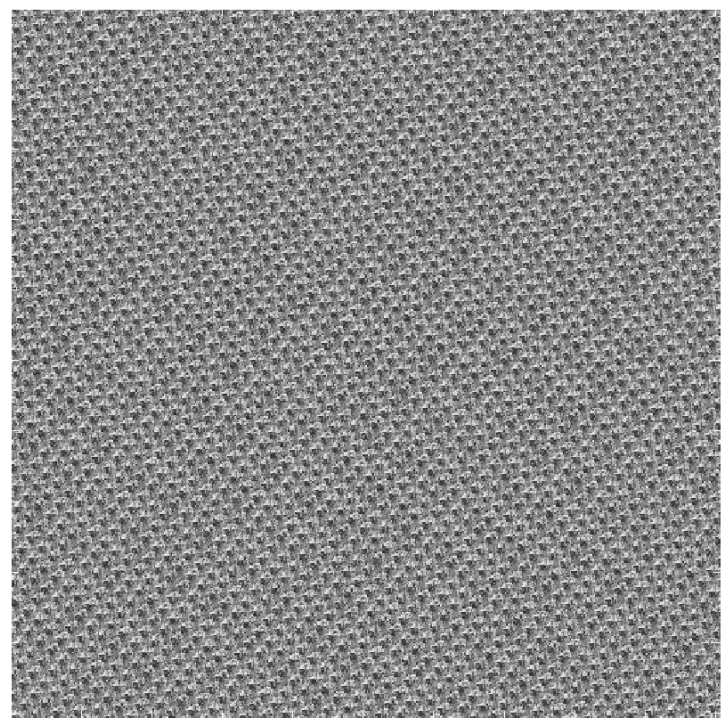

$(6)$

Рис. 6 Пример защитной текстуры: ( $a$ ) изображение Elaine на поле $\mathbb{C}(503) ;(\sigma)$ его поворот на $w=(37+31 i)^{-1} \in \mathbb{C}(503)$

где $l=\ln r \in \mathbb{R}$ и $0 \leqslant \theta<2 \pi$, между ненулевыми комплексными числами $z$ и их полярнологарифмическими координатами $(l, \theta)$ порождает изоморфизм

$$
\mathbb{C}^{*} \simeq \mathbb{R} \times(\mathbb{R} / 2 \pi \mathbb{Z})
$$

Перенесем предыдущую конструкцию на поле $\mathbb{C}(p)$. Для этого заметим, что его мультипликативная группа $\mathbb{C}^{*}(p)=\mathbb{C}(p) \backslash\{0\}$ является циклической [22, с. 314], и тем самым порождается некоторым примитивным элементом $g$. В частности, нетрудно проверить, 
что элементы $g=2+7 i$ и $p=1+19 i$ примитивны в $\mathbb{C}^{*}(71)$, а $g=1+5 i-$ примитивен для $p=251$.

Следующий результат элементарно проверяется.

Лемма 2. Для каждого $p=4 k+3$ числа $m=(p-1) / 2=2 k+1$ и $n=2(p+1)=8(k+1)$ являются взаимно-простыми, $\operatorname{gcd}(m, n)=1$.

Поскольку $m n=p^{2}-1=\left|\mathbb{C}^{*}(p)\right|$, отсюда немедленно вытекает [22, с. 163] следующий аналог разложения (1).

Утверждение 1. Мультипликативная группа гауссового поля $\mathbb{C}(p)$ есть прямое произведение циклических групп порядков $m=(p-1) / 2$ и $n=2(p+1)$,

$$
\mathbb{C}^{*}(p) \simeq \mathbb{Z}_{m} \times \mathbb{Z}_{n}
$$

Будем называть $(2)$ полярным разложением поля $\mathbb{C}(p)$. Перенесем с его помощью на $\mathbb{C}(p)$ понятие комплексного логарифма. Для этого определим отображение $\operatorname{Exp}_{g}: \mathbb{Z}_{m} \times$ $\times \mathbb{Z}_{n} \rightarrow \mathbb{C}^{*}(p)$ следующим образом:

$$
\operatorname{Exp}_{g}(l, \theta)=g^{n l+m \theta}=z \in \mathbb{C}^{*}(p),
$$

где $(l, \theta) \in \mathbb{Z}_{m} \times \mathbb{Z}_{n}$. Таким образом, $\operatorname{Exp}_{g}$ является изоморфизмом между аддитивной группой кольца $\mathbb{Z}_{m} \times \mathbb{Z}_{n}$ и мультипликативной группой поля $\mathbb{C}(p)$.

Определение 3. Отображение $\operatorname{Exp}_{g}: \mathbb{Z}_{m} \times \mathbb{Z}_{n} \rightarrow \mathbb{C}^{*}(p)$ будем называть модулярной экспонентой по основанию $g$, а обратное отображение $\operatorname{Ln}_{g}: \mathbb{C}^{*}(p) \rightarrow \mathbb{Z}_{m} \times \mathbb{Z}_{n}-$ модулярным логарифмом по основанию $g$. Группу $\mathbb{Z}_{m} \times \mathbb{Z}_{n}$ назовем полярной областью поля $\mathbb{C}(p)$.

Непосредственно из определения вытекает «основное логарифмическое тождество»:

$$
\operatorname{Ln}_{g}\left(z_{1} z_{2}\right)=\operatorname{Ln}_{g}\left(z_{1}\right)+\operatorname{Ln}_{g}\left(z_{2}\right) .
$$

Заметим, что $\operatorname{Ln}_{g}(0)$ не определен, а для нахождения $(l, \theta)=\operatorname{Ln}_{g}(z)$ для произвольного $z=g^{s} \in \mathbb{C}^{*}(p)$ необходимо решить диофантово уравнение $n x+m y=s$ и взять

$$
(l, \theta)=(x \bmod m, y \bmod n) \in \mathbb{Z}_{m} \times \mathbb{Z}_{n} .
$$

Пример 1. Пусть $g=1+2 i \in \mathbb{C}^{*}(7)$ и $z=g^{2}=4+4 i$. Тогда $s=2, m=3, n=16$ и уравнение $16 x+3 y=2$ имеет очевидное решение $x=2, y=-10$. Следовательно, $\operatorname{Ln}_{g}(4+4 i)=(2 \bmod 3,-10 \bmod 16)=(2,6) \in \mathbb{Z}_{3} \times \mathbb{Z}_{16}$.

Назовем пару $(l, \theta) \in \mathbb{Z}_{m} \times \mathbb{Z}_{n}$ «полярно-логарифмическими координатами» элемента $z \in \mathbb{C}^{*}(p)$ на полярной области.

Рассмотрим изображение $f$ в новых координатах, определив функцию $\psi: \mathbb{Z}_{m} \times \mathbb{Z}_{n} \rightarrow \mathbb{R}$ так, что

$$
\psi\left(\operatorname{Ln}_{g}(z)\right)=f(z), \quad 0 \neq z \in \mathbb{C}^{*}(p) .
$$

Определение 4. Преобразование $\mathscr{P}_{g}[f] \stackrel{\text { def }}{=} \psi$ назовем полярно-логарифмическим преобразованием $f$ по основанию $g$ или просто полярным преобразованием. Изображение $\psi$ на торе $\mathbb{Z}_{m} \times \mathbb{Z}_{n}$ будем называть полярной формой для $f$.

Следующее утверждение показывает, что преобразование $\mathscr{P}$ действительно может считать дискретным аналогом перехода в полярно-логарифмическую систему координат. Его доказательство немедленно следует из «основного логарифмического тождества» (3). 
Утверждение 2. Если $\mathscr{P}_{g}[f(z)]=\psi(l, \theta)$, то

$$
\mathscr{P}[f(w z)]=\psi\left(l-l_{0}, \theta-\theta_{0}\right),
$$

где $0 \neq w \in \mathbb{C}(p)$ и $\operatorname{Ln}(w)=\left(l_{0}, \theta_{0}\right)$.

Другими словами, справедливо

Следствие 1. Гауссов поворот изображения равносилен циклическому сдвигу его полярной формы.

Как хорошо известно [28], циклические сдвиги изображений легко распознаются, например, с помощью преобразования Фурье. В частности, модули Фурье-образов изображений на рис. 5 и 6 совпадают, а их различие означало бы попытку взлома защитной сетки или текстуры. Более того, анализ Фурье-образов позволяет определить и параметр поворота $w$, тем самым верифицируя подлинность защитной текстуры.

Заметим, что методы защиты информации на конечных полях, использующие преобразования, отличные от гауссовых вращений, рассматривались в [29-31].

\section{6 Заключение}

В работе рассмотрено преобразование цифровых изображений над «конечными комплексными полями», называемое гауссовым вращением и строящееся как формальный аналог вращения в непрерывной комплексной плоскости. Доказано, что при определенных условиях результат такого «вращения» напоминает несколько уменьшенных и повернутых копий оригинала, несмотря на то что эти «копии» образованы различными пикселями. Рассмотрена возможность создания на основе гауссова вращения защитных фонов и текстур для предотвращения несанкционированного изменения документов. Приведен метод верификации защищенных таким образом документов.

Авторы благодарят неизвестного рецензента за замечания, способствовавшие улучшению работы.

\section{Литература}

[1] Hoggar S. G. Mathematics of digital images: Creation, compression, restoration, recognition. Cambridge: Cambridge University Press, 2006. 854 p.

[2] Pratt W. K. Digital image processing. - John Wiley \& Sons, 2007. 782 p.

[3] Owen C., Makedon F. High quality alias free image rotation // 30th Asilomar Conference on Signals, Systems, and Computers Proceedings. - Pacific Grove, CA, USA, 1996.

[4] Larkin K., Oldfield M., Klemm H. Fast Fourier method for the accurate rotation of sampled images // Opt. Commun., 1997. Vol. 139. P. 99-106.

[5] Cox R. W., Tong R. Two and three dimensional image rotation using the FFT // IEEE T. Image Proc., 1999. Vol. 8. No. 9. P. 1297-1299.

[6] Park W., Leibon G., Rockmore D. N., Chirikjian G.S. Accurate image rotation using hermite expansions // IEEE T. Image Proc., 2009. Vol. 18. No. 9. P. 1988-2003.

[7] Каркищенко А. Н., Мнухин В. Б. Топологическая фильтрация для распознавания и анализа симметрии цифровых изображений // Машинное обучение и анализ данных, 2014. Т. 1. № 8. C. $966-987$.

[8] Лабунеи В. Г. Теоретико-числовые преобразования над квадратичными полями // Сложные системы управления. - Киев: Институт кибернетики УССР, 1982. С. 30-37. 
[9] Вариченко Л.В., Лабунеи В. Г., Раков М.А. Абстрактные алгебраические системы и цифровая обработка сигналов. - Киев: Наукова Думка, 1986. 248 с.

[10] Чернов В. М. Корепанов А. О. Теоретико-числовые преобразования в задачах цифровой обработки сигналов. - Самара: Изд-во СГАУ, 2006. 112 с.

[11] Чернов В. М. Арифметические методы синтеза быстрых алгоритмов дискретных ортогональных преобразований. - М.: Физматлит, 2007. 264 с.

[12] Campello de Souza R.M., de Oliveira H.M., Kauffman A. N. Trigonometry in finite fields and a new Hartley transform // Symposium (International) on Information Theory Proceedings. Cambridge, MA, USA, 1998. P. 293.

[13] Bandeira J., Campello de Souza R. New trigonometric transforms over prime finite fields for image filtering // 6th Telecommunications Symposium (International) Proceedings. - FortalezaCe, Brazil, 2006. P. 628-633. doi: 10.1109/ITS.2006.4433235.

[14] Мнухин В. Б. Цифровые изображения на комплексном дискретном торе // Машинное обучение и анализ данных, 2013. Т. 1. № 5. С. 542-551.

[15] Каркищенко А.Н., Мнухин В. Б. Применение модулярных логарифмов на комплексных дискретных торах в задачах обработки цифровых изображений // Вестник Ростовского гос. ун-та путей сообщения, 2013. Т. 3. С. 147-153.

[16] Mnukhin V.B. Fourier-Mellin transform on a complex discrete torus // 11th Conference (International) "Pattern Recognition and Image Analysis: New Information Technologies" Proceedings. - Samara, 2013. P. 102-105. doi: 10.13140/RG.2.1.4366.4086.

[17] Mnukhin V. B. Transformations of digital images on complex discrete tori // Pattern Recognition Image Anal., 2014. Vol. 24. No. 4. P. 552-560. doi: 10.1134/S1054661814040142.

[18] Campello de Souza R. M., de Oliveira H. M., Silva D. The $Z$ transform over finite fields. arXiv preprint 1502.03371, 2015.

[19] Karkishchenko A. N., Mnukhin V. B. Fourfold symmetry detection in digital images based on finite Gaussian fields // Adv. Intell. Syst., 2016. Vol. 451. P. 153-162. doi: 10.1007/978-3-319-33816$3 \_16$.

[20] Ireland K., Rosen M. A classical introduction to modern number theory. - New York, NY, USA: Springer, 1994. $416 \mathrm{p}$.

[21] Baker H. G. Complex Gaussian integers for Gaussian graphics // ACM Sigplan Notices, 1993. Vol. 28. No. 11. P. 22-27.

[22] Dummit D. S., Foote R. M. Abstract algebra. - John Wiley \& Sons, 2004. 932 p.

[23] Karkishchenko A.N., Mnukhin V.B. Threefold symmetry detection in hexagonal images based on finite Eisenstein fields // Comm. Com. Inf. Sc., 2017. Vol. 661. P. 281-292. doi: 10.1007/9783-319-52920-2_26.

[24] Karkishchenko A.N., Mnukhin V.B. Hexagonal images processing over finite Eisenstein fields // Procedia Engineer., 2017. Vol. 201. P. 287-295. doi: 10.1016/j.proeng.2017.09.633.

[25] Conway J. H., Sloane N. J. A. Sphere-packings, lattices, and groups. - New York, NY, USA: Springer-Verlag, 1987. $792 \mathrm{p}$.

[26] Barvinok, A. Integer points in polyhedra. - Zuerich, Switzerland: European Mathematical Society Publishing House, 2008. 199 p. doi: 10.4171/052.

[27] Cheddad A., Condell J., Curran K., Mc Kevitt P. Digital image steganography: Survey and analysis of current methods // Signal Process., 2010. Vol. 90. No.3. P. 727-752. doi: 10.1016/j.sigpro.2009.08.010.

[28] Easton R. L., Jr. Fourier methods in imaging. - John Wiley \& , 2010. 930 p. 
[29] Lima J.B., de Souza R. M. Histogram uniformization for digital image encryption // 25th SIBGRAPI Conference on Graphics, Patterns and Images Proceedings. - Washington, D.C., USA: IEEE Computer Society, 2012. P. 55-62. doi: 10.1109/SIBGRAPI.2012.17.

[30] Lima J.B., Lima E.A.O., Madeiro F. Image encryption based on the finite field cosine transform // Image Commun., 2013. Vol. 2. No.10. P. 1537-1547. doi: 10.1016/ j.image.2013.05.008.

[31] Lima J. B., Madeiro F., Sales F. J. R. Encryption of medical images based on the cosine number transform // Image Commun., 2015. Vol. 35. No. 3. P. 1-8. doi: 10.1016/j.image.2015.03.005.

Поступила в редакцию 01.09.2017

\title{
Gaussian rotations for graphic information protection*
}

\author{
A. N. Karkishchenko and V.B. Mnukhin \\ karkishalex@gmail.com; mnukhin.valeriy@mail.ru
}

Southern Federal University, 105/42 Bolshaya Sadovaya Str., Rostov-on-Don, Russia

Digital images over "finite complex planes" are considered jointly with transformations of Gaussian rotations. It is proved that under some special conditions, results of such transformations seem to be formed by several zoomed out copies of the rotated original, though all such "copies" are formed by different pixels of the original image. Based on Gaussian rotations, some methods for tamper resistent protection of graphic information are considered. A method for verification of protected information is also introduced.

Keywords: digital image; finite field; Gaussian integers; rotations; security printing; steganography

DOI: $10.21469 / 22233792.3 .1 .05$

\section{References}

[1] Hoggar, S. G. 2006. Mathematics of digital images: Creation, compression, restoration, recognition. Cambridge: Cambridge University Press. 854 p.

[2] Pratt, W. K. 2007. Digital image processing. John Wiley \& Sons. 782 p.

[3] Owen, C., and F. Makedon. 1996. High quality alias free image rotation. 30th Asilomar Conference on Signals, Systems, and Computers Proceedings. Pacific Grove, CA.

[4] Larkin, K., M. Oldfield, and H. Klemm. 1997. Fast Fourier method for the accurate rotation of sampled images. Opt. Commun. 139:99-106.

[5] Cox, R. W., and R. Tong. 1999. Two and three dimensional image rotation using the FFT. IEEE T. Image Proc. 8(9):1297-1299.

[6] Park, W., G. Leibon, D. N. Rockmore, and G. S. Chirikjian. 2009. Accurate image rotation using hermite expansions. IEEE T. Image Proc. 18(9):1988-2003.

[7] Karkishchenko, A. N., and V. B. Mnukhin. 2014. Topologicheskaya fil'tratsiya dlya raspoznavaniya i analiza simmetrii tsifrovykh izobrazheniy [Topological filtration for digital images recognition and symmetry analysis]. J. Machine Learning Data Anal. 1(8):966-987.

\footnotetext{
*The research was supported by the Russian Foundation for Basic Research (grants 16-07-00648 and 17-2002017).
} 
[8] Labunets, V. 1982. Teoretiko-chislovye preobrazovaniya nad kvadratichnumi polyami [Numbertheoretic transforms over quadratic fields]. Slozhnye sistemy upravleniya [Complex Control Systems]. Kiev: Institute of Cybernetics of the USSR. 30-37.

[9] Varitschenko, L., V. Labunets, and M. Rakov. 1986. Abstraknye algebraicheskie sistemy $i$ tsifrovaya obrabotks signalov [Abstract algebraic systems and digital signal processing]. Kiev: Naukova Dumka. 248 p.

[10] Chernov, V.M., and A. O. Korepanov. 2006. Teoretiko-chislovye preobrazovaniya $v$ zadachakh tsifrovoy obrabotki signalov [Number-theoretic transforms in digital image processing]. Samara: SGAU. 112 p.

[11] Chernov, V.M. 2007. Arifmeticheskie metody sinteza bystrykh algoritmov diskretnykh ortogonal'nykh preobrazovaniy [Arithmetic methods for fast algorithms for discrete orthogonal transforms development]. Moscow: FIZMATLIT. 264 p.

[12] Campello de Souza, R. M., H. M. de Oliveira, and A. N. Kauffman. 1998. Trigonometry in finite fields and a new Hartley transform. Symposium (International) on Information Theory Proceedings. Cambridge, MA. 293.

[13] Bandeira, J., and R. Campello de Souza. 2006. New trigonometric transforms over prime finite fields for image filtering. 6th Telecommunications Symposium (International) Proceedings. Fortaleza-Ce, Brazil. 628-633. doi: 10.1109/ITS.2006.4433235.

[14] Mnukhin, V.B. 2013. Tsifrovye izobrazheniya na kompleksnom diskretnom tore [Digital images on a complex discrete torus]. J. Machine Learning Data Anal. 1(5):540-548.

[15] Karkishchenko, A. N., and V.B. Mnukhin. 2013. Primenenie modulyarnykh logarifmov na konpleksnykh diskretnykh torakh $\mathrm{v}$ zadachakh obrabotki tsifrovykh izobrazheniy [Applications of modular logarithms on complex discrete tori in problems of digital image processing]. Vestnik Rostovskogo gos. un-ta putey soobshcheniya [Bull. of the Rostov State University of Railway Transport] 3:147-153.

[16] Mnukhin, V.B. 2013. Fourier-Mellin transform on a complex discrete torus. 11th Conference (International) "Pattern Recognition and Image Analysis: New Information Technologies" Proceedings. Samara. 102-105. doi: 10.13140/RG.2.1.4366.4086.

[17] Mnukhin, V. B. 2014. Transformations of digital images on complex discrete tori. Pattern Recognition Image Anal. 24(4):552-560. doi: 10.1134/S1054661814040142.

[18] Campello de Souza, R. M., H. M. de Oliveira, and D. Silva. 2015. The $Z$ transform over finite fields. arXiv preprint 1502.03371.

[19] Karkishchenko, A. N., and V.B. Mnukhin. 2016. Fourfold symmetry detection in digital images based on finite Gaussian fields. Adv. Intell. Syst. 451:153-162. doi: 10.1007/978-3-319-33816-3_16.

[20] Ireland, K., and M. Rosen. 1994. A classical introduction to modern number theory. New York, NY: Springer. $416 \mathrm{p}$.

[21] Baker, H. G. 1993. Complex Gaussian integers for Gaussian graphics. ACM Sigplan Notices 28(11):22-27.

[22] Dummit, D. S., and R. M. Foote. 2004. Abstract algebra. John Wiley \& Sons. 932 p.

[23] Karkishchenko, A.N., and V.B. Mnukhin. 2017. Threefold symmetry detection in hexagonal images based on finite Eisenstein fields. Comm. Com. Inf. Sc. 661:281-292. doi: 10.1007/978-3319-52920-2_26.

[24] Karkishchenko, A. N., and V. B. Mnukhin. 2017. Hexagonal images processing over finite Eisenstein fields. Procedia Engineer. 201:287-295. doi: 10.1016/j.proeng.2017.09.633.

[25] Conway, J.H., and N. J. A. Sloane. 1987. Sphere-packings, lattices, and groups. New York, NY: Springer-Verlag. 792 p. 
[26] Barvinok, A. 2008. Integer points in polyhedra. Zuerich, Switzerland: European Mathematical Society Publishing House. 199 p. doi: 10.4171/052.

[27] Cheddad, A., J. Condell, K. Curran, and P. Mc Kevitt. 2010. Digital image steganography: Survey and analysis of current methods. Signal Process. 90(3):727-752. doi: 10.1016/j.sigpro.2009. 08.010.

[28] Easton, R. L. Jr. 2010. Fourier methods in imaging. John Wiley \& Sons. 930 p.

[29] Lima, J.B., and R. M. de Souza. 2012. Histogram uniformization for digital image encryption. 25th SIBGRAPI Conference on Graphics, Patterns and Images Proceedings. Washington, D.C.: IEEE Computer Society. 55-62. doi: http://dx.doi.org/10.1109/SIBGRAPI.2012.17

[30] Lima, J. B., E. A. O. Lima, and F. Madeiro. 2013. Image encryption based on the finite field cosine transform. Image Commun. 28(10):1537-1547. doi: 10.1016/j.image.2013.05.008.

[31] Lima, J. B., F. Madeiro, and F. J. R. Sales. 2015. Encryption of medical images based on the cosine number transform. Image Commun. 35(3):1-8. doi: 10.1016/j.image.2015.03.005.

Received September 01, 2017 


\title{
Об эффективности схем комплексирования данных для распознавания образов по ансамблю изображений
}

\author{
С. Н. Ганебных, М. М. Ланге \\ sng@ccas.ru; lange_mm@ccas.ru \\ ФИЦ «Информатика и управление» РАН, Россия, г. Москва, ул. Вавилова, 44/2
}

\begin{abstract}
Исследуются метрические многоклассовые классификаторы на ансамбле изображений от источников различной модальности. Классификаторы принимают коллективные решения по составным объектам, заданным наборами изображений, по одному от каждого источника. Разделяющие функции порождаются элементарными NN (nearest neighbor) или SVM (support vector machine) классификаторами типа «класс против всех». Исследуются две оригинальные схемы комплексирования данных, которые используют в разделяющих функциях либо композиции мер на множествах изображений источников (General Measure, GM), либо композиции мягких решений по изображениям источников (General Similarity, GS). В терминах вероятности ошибок предлагаемые схемы сравниваются с известной схемой голосования композиций жестких решений по изображениям источников (Majority Vote, MV). Сравнительная эффективность трех исследованных схем комплексирования данных продемонстрирована оценками доли ошибок распознавания лиц на ансамбле, заданном тремя декоррелированными компонентами RGB изображений. Экспериментально получены меньшие доли ошибок в схемах GM и GS по сравнению со схемой MV.
\end{abstract}

Ключевые слова: многоклассовый классификатор; ансамбль изображений; схема комплексирования; голосование по большинству; обобщенная мера; обобщенное сходство; распознавание лич

DOI: $10.21469 / 22233792.3 .1 .06$

\section{1 Введение}

Фундаментальные результаты по теории классификации с использованием ансамблей источников различной модальности демонстрируют возможность уменьшения доли ошибок путем объединения решений классификаторов по объектам индивидуальных источников [1]. Ансамбль порождает составные объекты, заданные наборами объектов одного класса, по одному от каждого источника. Способы построения коллективных решений по предъявляемым составным объектам базируются на различных схемах комплексирования данных. Широкое распространение получила схема комплексирования решений независимых классификаторов по объектам источников на основе голосования по большинству (Majority Vote) [2,3]. В схемах голосования используются композиции жестких решений в форме суммарных голосов классификаторов по объектам источников, и коллективное решение по составному объекту принимается в пользу класса, получившего наибольший суммарный голос. В работах $[4,5]$ предложена схема комплексирования источников, в которой используется единый классификатор составных объектов с решающим правилом на основе обобщенной меры (General Measure) на ансамбле источников. Обобщенная мера является композицией мер на множествах объектов отдельных источников и позволяет

*Работа выполнена при частичной финансовой поддержке РФФИ, проекты № 15-01-04671 и № 15-07-07516. 
формировать коллективные решения с помощью одного классификатора с разделяющими функциями, строящимися в пространстве составных объектов. Теоретически показана возможность достижения меньшей вероятности ошибок в схеме GM по сравнению со схемой MV [5]. Помимо указанных схем целесообразно исследовать схему комплексирования мягких решений независимых классификаторов по объектам источников. Такие решения дают значения сходства объектов источников с классами, а их композиции - значения обобщенного сходства (General Similarity) составного объекта с соответствующими классами. В схеме GS коллективные решения по составным объектам выносятся единым классификатором с разделяющими функциями, построенными на значениях обобщенного сходства.

Модель классификации по ансамблю источников сходна с моделью кодирования сообщений непрерывного алфавита на основе квантования [6]. В модели кодирования используются схемы с одномерным (скалярным) или многомерным (векторным) квантованием, которые преобразуют блоки непрерывных сообщений в блоки дискретных значений с последующим их блоковым кодированием со скоростью, близкой к энтропии. Блоковое кодирование с одномерным квантованием использует набор независимых скалярных квантователей для отдельных сообщений, а блоковое кодирование с многомерным квантованием использует единый квантователь векторов сообщений в пространстве, размерность которого определяется длиной блоков. Квантами скалярного квантователя являются отрезки действительной оси, которые в многомерном пространстве дают непересекающиеся кубы, а квантами векторного квантователя - многогранники Вороного, которые порождаются покрытием пространства телами, согласованными с мерой расстояния в многомерном пространстве [7]. Эффективность оптимального скалярного и векторного квантования исследована соответственно в работах $[8,9]$. Из приведенных в этих работах оценок энтропии выхода квантователя и оценок погрешности следует, что при фиксированной энтропии в пересчете на элемент блока оптимальное векторное квантование обеспечивает меньшую погрешность по сравнению с оптимальным скалярным квантованием.

Учитывая, что в предлагаемых схемах GM и GS коллективные решения выносятся одним классификатором, а в традиционной схеме MV такие решения строятся на композиции решений ансамбля классификаторов, идеологически схемы GM и GS сопоставимы с векторным квантованием блоков, а схема MV - со скалярным квантованием блоков. Отмеченная аналогия позволяет предположить возможность достижения более высокого качества классификации на основе применения схем GM и GS по сравнению со схемой MV.

Цель настоящей работы заключается в исследовании сравнительной эффективности классификаторов, построенных на основе указанных схем комплексирования. Рассматриваются классификаторы, образованные наборами элементарных NN и SVM классификаторов типа «класс против всех», разделяющие функции которых вычисляются соответственно по ближайшим соседям в классах [10] и по алгебраическим расстояниям до разделяющих гиперплоскостей [11]. Предлагается процедура обучения, и приводятся результаты тестирования многоклассовых классификаторов на ансамбле декоррелированных компонент RGB изображений лиц [12]. Результатами тестирования являются доли ошибок классификации, демонстрирующие более высокое качество классификаторов, использующих схемы GM и GS по сравнению с классификаторами на основе схемы MV.

\section{2 Формальная постановка задачи}

Рассматривается модель классификации, которая предполагает отнесение набора объектов от ансамбля источников к одному из классов множества $\Omega=\left\{\omega_{i}, i=1, \ldots, c\right\}, c \geqslant 2$, 
с априорными вероятностями $\mathrm{P}\left(\omega_{i}\right)>0: \sum_{i=1}^{c} \mathrm{P}\left(\omega_{i}\right)=1$. Пусть $\mathbf{X}^{M}=\left(\mathbf{X}_{1}, \ldots, \mathbf{X}_{M}\right)-$ ансамбль источников, в котором $\mathbf{X}_{m}, m=1, \ldots, M$, - множество объектов $m$-го источника, принадлежащих классам из $\Omega$. Любая последовательность $\mathbf{x}^{M}=\left(\mathbf{x}_{1}, \ldots, \mathbf{x}_{M}\right)$ объектов $\mathbf{x}_{m} \in \mathbf{X}_{m}, m=1, \ldots, M$, принадлежащих одному и тому же классу, образует составной объект $\mathbf{x}^{M} \in \mathbf{X}^{M}$, класс которого $\omega_{i} \in \Omega$ необходимо найти. Как правило, ансамбль порождается наборами объектов различной модальности, например биометрическими измерениями, полученными от персон, которые образуют множество классов.

Будем считать, что на множестве объектов каждого источника для любой пары объектов $\mathbf{x}_{m} \in \mathbf{X}_{m}$ и $\hat{\mathbf{x}}_{m} \in \mathbf{X}_{m}$ определена мера различия

$$
d\left(\mathbf{x}_{m}, \hat{\mathbf{x}}_{m}\right) \geqslant 0, m=1, \ldots, M,
$$

и на ансамбле для любой пары составных объектов $\mathbf{x}^{M} \in \mathbf{X}^{M}$ и $\hat{\mathbf{x}}^{M} \in \mathbf{X}^{M}$ введена обобщенная мера различия в форме линейной композиции

$$
D\left(\mathbf{x}^{M}, \hat{\mathbf{x}}^{M}\right)=\sum_{m=1}^{M} w_{m} d\left(\mathbf{x}_{m}, \hat{\mathbf{x}}_{m}\right)
$$

с весами источников

$$
W=\left\{w_{m}>0, m=1, \ldots, M\right\} .
$$

На множествах объектов источников $\mathbf{X}_{m}, m=1, \ldots, M$, вводятся разделяющие функции:

$$
g_{i}\left(\mathbf{x}_{m}\right) \propto \mathrm{P}\left(\omega_{i}\right) p\left(\mathbf{x}_{m} \mid \omega_{i}\right), i=1, \ldots, c,
$$

а на ансамбле $\mathbf{X}^{M}$ - разделяющие функции:

$$
g_{i}\left(\mathbf{x}^{M}\right) \propto \mathrm{P}\left(\omega_{i}\right) p\left(\mathbf{x}^{M} \mid \omega_{i}\right), i=1, \ldots, c,
$$

где $p\left(\mathbf{x}_{m} \mid \omega_{i}\right)$ и $p\left(\mathbf{x}^{M} \mid \omega_{i}\right)$ - условные по классу $\omega_{i}$ плотности вероятностей $\mathbf{x}_{m} \in \mathbf{X}_{m}$ и $\mathbf{x}^{M} \in$ $\in \mathbf{X}^{M}$, строящиеся соответственно с использованием мер различия (1) и (2). Согласно формуле Байеса, разделяющие функции вида (4) и (5) пропорциональны соответствующим апостериорным вероятностям $\mathrm{P}\left(\omega_{i} \mid \mathbf{x}_{m}\right)$ и $\mathrm{P}\left(\omega_{i} \mid \mathbf{x}^{M}\right)$ и, следовательно, позволяют минимизировать вероятность ошибки классификации [11].

Пусть

$$
\mathbf{X}_{m}^{\text {train }} \subset \mathbf{X}_{m}, m=1, \ldots, M,
$$

есть обучающая выборка размера $K_{m}=\left\|\mathbf{X}_{m}^{\text {train }}\right\|$ для $m$-го источника. Последовательность

$$
\mathbf{X}^{M-\text { train }}=\left(\mathbf{X}_{1}^{\text {train }}, \ldots, \mathbf{X}_{M}^{\text {train }}\right)
$$

размера $K=\left\|\mathbf{X}^{M}{ }_{-}{ }^{\text {train }}\right\|$ дает обучающую выборку на ансамбле $\mathbf{X}^{M}$. В случае однозначного соответствия объектов источников в ансамбле размеры обучающих выборок источников и ансамбля одинаковы $K_{m}=K, m=1, \ldots, M$. Обучающие выборки (6) разбиты на непересекающиеся кластеры так, что

$$
\mathbf{X}_{m}^{\text {train }}=\bigcup_{i=1}^{c} \mathbf{X}_{i m}^{\text {train }}, m=1, \ldots, M
$$

и последовательность $i$-х кластеров всех источников $\mathbf{X}_{i}^{M \text { train }}=\left(\mathbf{X}_{i 1}^{\text {train }}, \ldots, \mathbf{X}_{i M}^{\text {train }}\right)$ образует $i$-й кластер в обучающей выборке (7). 
Оценки плотностей $p\left(\mathbf{x}_{m} \mid \omega_{i}\right)$ и $p\left(\mathbf{x}^{M} \mid \omega_{i}\right)$ в (4) и (5) строятся на обучающих выборках (6) и (7) с использованием откликов элементарных классификаторов типа «класс $\omega_{i}$ против подмножества $\Omega \backslash \omega_{i}$ ». Отклики формируются в виде неотрицательных функций сходства объектов $\mathbf{x}_{m}$ и $\mathbf{x}^{M}$ с классом $\omega_{i}$, вычисляемых соответственно с использованием мер различия вида (1) или (2) и принимающих значения на отрезке [0,1]. Рассматриваются функции сходства

$$
\left.\begin{array}{l}
s_{i}^{d}\left(\mathbf{x}_{m}\right) \geqslant 0, \mathbf{x}_{m} \in \mathbf{X}_{m}, m=1, \ldots, M ; \\
s_{i}^{D}\left(\mathbf{x}^{M}\right) \geqslant 0, \mathbf{x}^{M} \in \mathbf{X}^{M} ; \\
s_{i}^{W}\left(\mathbf{x}^{M}\right)=\sum_{m=1}^{M} w_{m} s_{i}^{d}\left(\mathbf{x}^{M}\right) \geqslant 0, \mathbf{x}^{M} \in \mathbf{X}^{M},
\end{array}\right\}
$$

которые с точностью до мультипликативных констант дают оценки условных по классам плотностей

$$
p\left(\mathbf{x}_{m} \mid \omega_{i}\right) \propto s_{i}^{d}\left(\mathbf{x}_{m}\right) ; \quad p\left(\mathbf{x}^{M} \mid \omega_{i}\right) \propto s_{i}^{*}\left(\mathbf{x}^{M}\right),
$$

где $s_{i}^{*}\left(\mathbf{x}^{M}\right)$ принимает значения $s_{i}^{D}\left(\mathbf{x}^{M}\right)$ или $s_{i}^{W}\left(\mathbf{x}^{M}\right)$. Отметим, что отклики $s_{i}^{D}\left(\mathbf{x}^{M}\right)$ определяются обобщенной мерой в виде линейной композиции $(2)$, а отклики $s_{i}^{W}\left(\mathbf{x}^{M}\right)$ задаются в форме линейной композиции откликов $s_{i}^{d}\left(\mathbf{x}_{m}\right), i=1, \ldots, M$, приведенной в $(8)$.

Любой набор разделяющих функций $\left\{g_{i}(\mathbf{x}), i=1, \ldots, c\right\}$ на множестве $\mathbf{X}$, построенных с использованием обучающей выборки $\mathbf{X}^{\operatorname{train}} \subset \mathbf{X}$, порождает классификатор $F: \mathbf{X} \rightarrow \Omega$, который дает решение

$$
i_{F}(\mathbf{x})=\arg \max _{i=1}^{c} g_{i}(\mathbf{x})
$$

для номера класса объекта $\mathbf{x} \in \mathbf{X}$. Эффективность классификатора $F$ оценивается средней долей ошибок

$$
\varepsilon_{F}\left(\mathbf{X}^{\mathrm{test}}\right)=\sum_{i=1}^{c} \mathrm{P}\left(\omega_{i}\right) \varepsilon_{F}\left(\mathbf{X}^{\mathrm{test}} \mid \omega_{i}\right)
$$

где $\varepsilon_{F}\left(\mathbf{X}^{\text {test }} \mid \omega_{i}\right)$ - доля ошибочных решений на преобразовании $F$ по объектам тестовой выборки $\mathbf{X}^{\text {test }}$ из класса $\omega_{i} \in \Omega$.

Использование в решающем правиле (10) разделяющих функций (4) с откликами $s_{i}^{d}\left(\mathbf{x}_{m}\right), i=1, \ldots, M$, порождает классификаторы, которые реализуют преобразования $F_{m}: \mathbf{X}_{m} \rightarrow \Omega, m=1, \ldots, M$. Комплексирование жестких решений таких классификаторов по схеме MV дает для предъявляемого составного объекта $\mathbf{x}^{M} \in \mathbf{X}^{M}$ коллективное решение в виде номера класса

$$
j_{\mathrm{MV}}\left(\mathbf{x}^{M}\right)=\arg \max _{i=1}^{c} \sum_{m=1}^{M} w_{m}\left[\arg \max _{i=1}^{c} \mathrm{P}\left(\omega_{i}\right) s_{i}^{d}\left(\mathbf{x}_{m}\right)=j\right],
$$

где $[z]$ - индикатор $z$.

Использование в решающем правиле (10) разделяющих функций (5) с откликами $s_{i}^{D}\left(\mathbf{x}^{M}\right)$ или $s_{i}^{W}\left(\mathbf{x}^{M}\right)$ порождает классификаторы вида $F_{W}^{M}: \mathbf{X}^{M} \rightarrow \Omega$ с коллективным решением по схеме GM:

$$
j_{\mathrm{GM}}\left(\mathbf{x}^{M}\right)=\arg \max _{i=1}^{c} \mathrm{P}\left(\omega_{i}\right) s_{i}^{D}\left(\mathbf{x}^{M}\right)
$$

и с коллективным решением по схеме GS:

$$
j_{\mathrm{GS}}\left(\mathbf{x}^{M}\right)=\arg \max _{i=1}^{c} \mathrm{P}\left(\omega_{i}\right) \sum_{m=1}^{M} w_{m} s_{i}^{d}\left(\mathbf{x}_{m}\right) .
$$




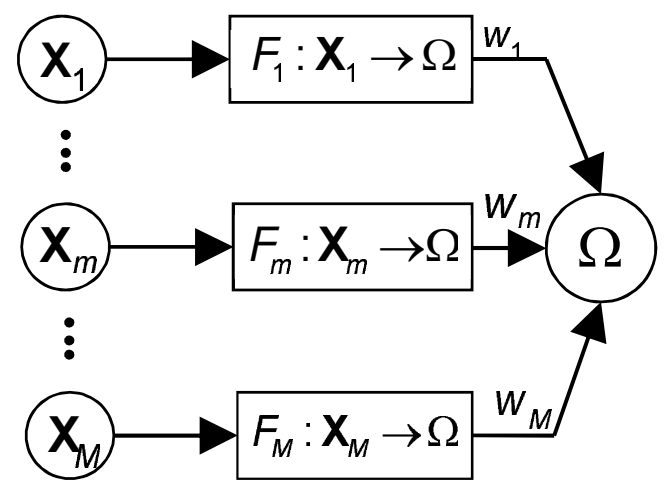

$(a)$

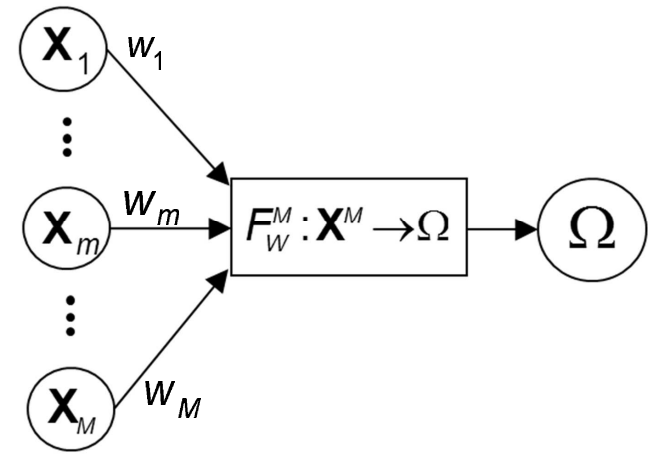

$(6)$

Рис. 1 Блок-схемы классификаторов на основе схем комплексирования MV $(a)$ и GM/GS (б)

Схематически классификаторы, формирующие решения (12)-(14), даны на рис. 1. В приведенных схемах, уровни расположения весов источников соответствуют уровням вычисления композиций, которые используются в разделяющих функциях.

В работе [4] показано, что средняя взаимная информация [13] между ансамблем $\mathbf{X}^{M}$ и множеством классов $\Omega$, в пересчете на один источник ансамбля, в схеме MV не превосходит аналогичной средней взаимной информации в схеме GM. Из этого утверждения следует, что при соответствующем выборе весовых коэффициентов (3) нижняя граница вероятности ошибок в схеме GM меньше или равна нижней границы вероятности ошибок в схеме MV [14]. Для реальных классификаторов, этот результат демонстрирует возможность достижения более высокого качества в схеме GM по сравнению со схемой MV. Учитывая сопоставимость решающих правил (13) и (14), аналогичное соотношение долей ошибок ожидается для схем GS и MV.

В рамках трех указанных схем комплексирования рассматриваются классификаторы, в которых функции сходства (8) формируются на откликах элементарных NN и SVM классификаторов. Элементарные NN классификаторы вычисляют функции сходства с классами для объектов множеств $\mathbf{X}_{m}, m=1, \ldots, M$, и составных объектов ансамбля $\mathbf{X}^{M}$, используя отклонения предъявляемых объектов до ближайших объектов в кластерах обучающих выборок соответственно по мерам (1) и (2). Элементарные SVM классификаторы вычисляют аналогичные функции сходства по вторичным признакам [15], где объект $m$-го источника $\mathbf{x}_{m} \in \mathbf{X}_{m}$ задается вектором расстояний по мере (1) до всех объектов обучающей выборки (6)

$$
\mathbf{x}_{m} \rightarrow \mathbf{y}^{d}\left(\mathbf{x}_{m}\right)=d\left(\mathbf{x}_{m}, \hat{\mathbf{x}}_{m 1}\right), \ldots, d\left(\mathbf{x}_{m}, \hat{\mathbf{x}}_{m K}\right), \hat{\mathbf{x}}_{m k} \in \mathbf{X}_{m}^{\text {train }}, k=1, \ldots, K
$$

а объект ансамбля $\mathbf{X}^{M} \in \mathbf{X}^{M}$ - вектором расстояний по мере (2) до всех объектов обучающей выборки (7)

$$
\mathbf{x}^{M} \rightarrow \mathbf{y}^{D}\left(\mathbf{x}^{M}\right)=D\left(\mathbf{x}^{M}, \hat{\mathbf{x}}_{1}^{M}\right), \ldots, D\left(\mathbf{x}^{M}, \hat{\mathbf{x}}_{K}^{M}\right), \hat{\mathbf{x}}_{k}^{M} \in \mathbf{X}^{M \text { train }}, k=1, \ldots, K .
$$

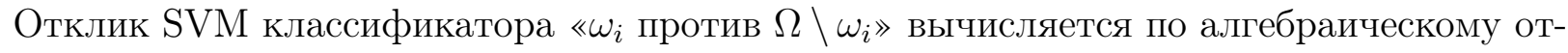
клонению предъявляемого объекта от разделяющей гиперплоскости, которое согласно [11] определяется величиной $\mathbf{a}_{i}^{\top} \mathbf{y}+a_{i}$, где $\mathbf{a}_{\mathbf{i}}$ и $a_{i}-$ соответственно вектор нормали и параметр смещения, оцениваемые по обучающей выборке. С учетом сделанных замечаний введенные в (8) отклики элементарных классификаторов определяются следующими выражениями: 


$$
\begin{aligned}
& s_{i}^{d}\left(\mathbf{x}^{M}\right)=\left\{\begin{array}{ll}
\exp \left\{-\min _{\hat{\mathbf{x}}_{m} \in \mathbf{X}_{i m}^{\text {train }}} d\left(\mathbf{x}_{m}, \hat{\mathbf{x}}_{m}\right)\right\} & \text { для NN; } \\
\left(1+\exp \left\{-\left(\mathbf{a}_{i m}^{\top} \mathbf{y}^{d}\left(\mathbf{x}_{m}\right)+a_{i m}\right)\right\}\right)^{-1} & \text { для SVM; }
\end{array}\right\} \\
& s_{i}^{D}\left(\mathbf{x}^{M}\right)=\left\{\begin{array}{l}
\exp \left\{-\min _{\hat{\mathbf{x}}^{M} \in \mathbf{X}_{i}^{M} \text { train }} D\left(\mathbf{x}^{M}, \hat{\mathbf{x}}^{M}\right)\right\} \\
\left(1+\exp \left\{-\left(\mathbf{a}_{i}^{\top} \mathbf{y}^{D}\left(\mathbf{x}^{M}\right)+a_{i}\right)\right\}\right)^{-1} \text { для } \mathrm{NN} ; \\
\text { для SVM. }
\end{array}\right\}
\end{aligned}
$$

Исследуемая задача заключается в построении процедур обучения классификаторов, использующих схемы комплексирования MV, GS и GM, и проведении их тестирования на ансамбле декоррелированных компонент $I_{1}(\mathrm{R}, \mathrm{G}, \mathrm{B}), I_{2}(\mathrm{R}, \mathrm{G}, \mathrm{B})$ и $I_{3}(\mathrm{R}, \mathrm{G}, \mathrm{B})$ цветных RGB изображений лиц. Результаты тестирования даются в виде средних долей ошибок, полученных на классификаторах объектов индивидуальных источников $I_{1}, I_{2}$ и $I_{3}$ и для классификаторов составных объектов ансамбля $\left(I_{1}, I_{2}, I_{3}\right)$.

\section{3 Представление и мера различия объектов}

В этом разделе рассматривается способ древовидного представления объектов, порождаемых источниками изображений. В пространстве древовидных представлений с многоуровневым разрешением вводятся меры различия вида (1) и (2), которые позволяют вычислять отклики, заданные соотношениями (15), и соответствующие этим откликам разделяющие функции вида (4) и (5) с оценками (9).

Будем считать, что множеством объектов $\mathbf{X}$ любого источника являются образы, выделенные на полутоновых изображениях и удовлетворяющие некоторым ограничениям. Налагаемые ограничения формируют множество допустимых образов, которые заданы наборами пикселей в виде компактных или распределенных двумерных тел, имеющих идентифицируемую систему собственных координат. Учитывая однотипность представлений для источников с номерами $m=1, \ldots, M$, в последующих обозначениях номер источника опущен.

В работе [16], предложен способ представления допустимых образов наборами эллиптических примитивов, структурированными в бинарные деревья. Способ основан на дихотомическом разбиении любого образа $\mathbf{x} \in \mathbf{X}$ на сегменты (наборы пикселей) и аппроксимации каждого сегмента с номером $n$ эллиптическим примитивом $Q_{n}$, который соответствует вершине бинарного дерева. Каждый делимый сегмент с номером $n$ дает пару новых сегментов и соответствующую пару аппроксимирующих примитивов с номерами $2 n+1$ и $2 n+2$. Нумерация сегментов и примитивов производится с учетом ориентации главной собственной оси делимого сегмента. Выбор ориентации оси выполняется с учетом асимметрии делимого сегмента. Корневой примитив $Q_{0}$ аппроксимирует исходный образ $\mathbf{x}$ и имеет номер $n=0$. Концевые вершины дерева примитивов соответствуют неделимым сегментам с числом пикселей не более заданного значения (например, сегменты, состоящие из одного пикселя). Аппроксимирующие примитивы строятся в декартовой системе собственных координат аппроксимируемых сегментов. В случае отсутствия у сегмента с номером $n$ однозначно идентифицируемой системы собственных координат, примитив $Q_{n}$ строится в системе координат сегмента-родителя с номером $\lfloor(n-1) / 2\rfloor$. Таким образом, для построения дерева примитивов, достаточно существования идентифицируемой системы собственных координат исходного образа, который является корневым сегментом с номером $n=0$. 
В соответствии с выбранным способом представления для любого допустимого образа (объекта) $\mathbf{x} \in \mathbf{X}$ строится последовательность представлений

$$
\mathbf{x}^{L}=\left(x_{0}, \ldots, x_{l}, \ldots, x_{L}\right),
$$

образующих полное бинарное дерево глубины $L$, в котором любая промежуточная вершина имеет две исходящие ветви. Любая подпоследовательность $\mathbf{x}^{l}=\left(x_{0}, \ldots, x_{l}\right), l=0, \ldots, L$, в (16) является поддеревом глубины $l$, в котором набор концевых вершин-примитивов

$$
x_{l}=\left\{Q_{n} \mid n-\text { номер концевого примитива в } \mathbf{x}^{l}\right\}
$$

образует $l$-й слой полного дерева глубины $L$. Каждый эллиптический примитив в (17) определяется набором параметров

$$
Q_{n}=\left(\mathbf{r}_{n}, \mathbf{u}_{n}, \mathbf{v}_{n}, z_{n}\right)
$$

где $\mathbf{r}_{n}$ - вектор центра эллипса; $\mathbf{u}_{n}$ и $\mathbf{v}_{n}-$ векторы большой и малой полуосей; $z_{n}$ средний уровень яркости пикселей в аппроксимируемом сегменте. Координаты центра, определяющие вектор $\mathbf{r}_{n}$, и радиусы, определяющие векторы $\mathbf{u}_{n}$ и $\mathbf{v}_{n}$, вычисляются как параметры эллипса рассеяния соответствующего сегмента. Векторы $\mathbf{r}_{n}, \mathbf{u}_{n}$ и $\mathbf{v}_{n}$ задаются в собственной системе координат образа $\mathbf{x}$. Разбиение делимого сегмента с номером $n \geqslant 0$ производится осью, проходящей через центр этого сегмента и параллельной собственной оси сегмента с номером $n=0$ (соответствует образу $\mathbf{x}$ ), относительно которой момент инерции объекта максимален. При указанной нумерации примитив $Q_{n}$ находится в полном дереве на уровне $l=\left\lfloor\log _{2}(n+1)\right\rfloor$. Параметры примитивов (18) с номерами $n \geqslant 0$ нормируются относительно корневого примитива с номером $n=0$.

На рис. 2 даны примеры представлений декоррелированных компонент $I_{1}(\mathrm{R}, \mathrm{G}, \mathrm{B})$, $I_{2}(\mathrm{R}, \mathrm{G}, \mathrm{B})$ и $I_{3}(\mathrm{R}, \mathrm{G}, \mathrm{B})$ цветного RGB изображения лица, полученных с помощью функции decorrstretch пакета программ MATLAB (http://www.mathworks.com/help/images/

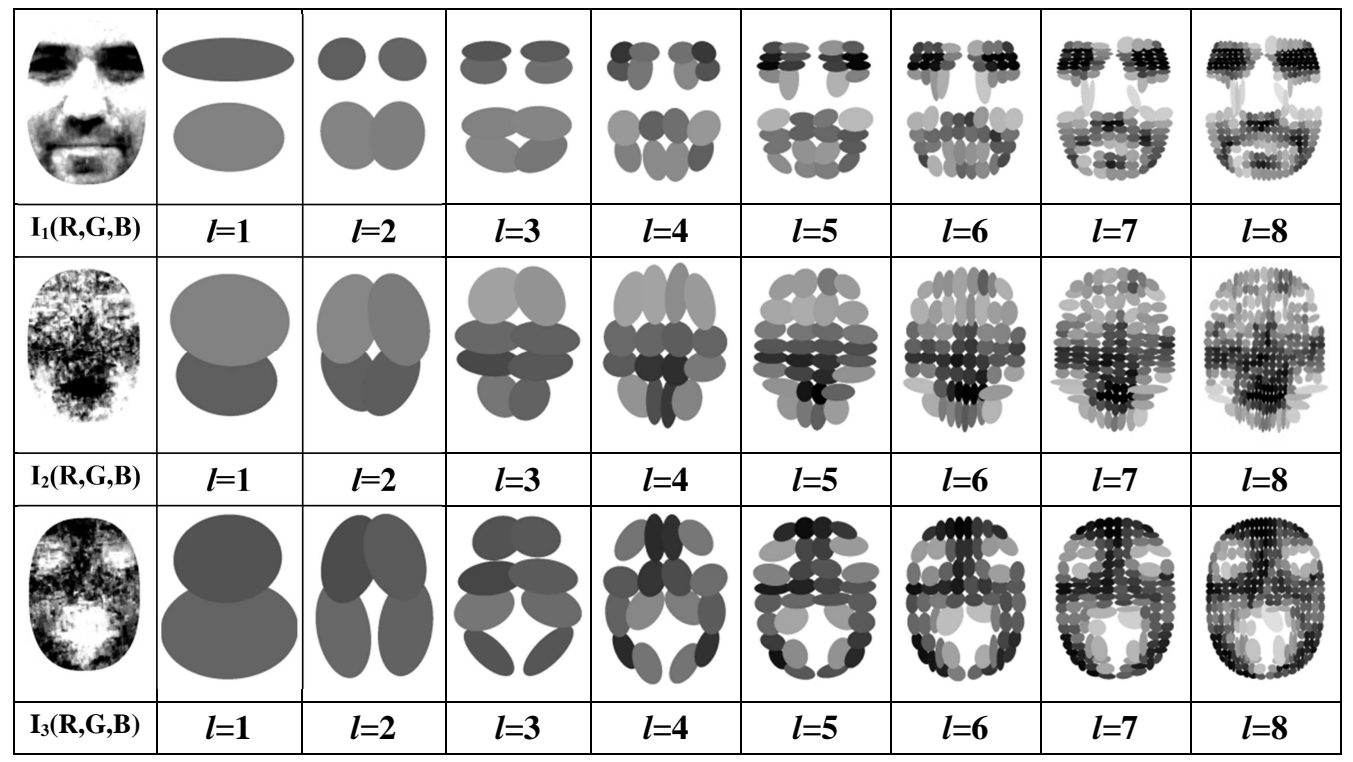

Рис. 2 Примеры древовидных представлений образов лица для декоррелированных компонент цветного RGB изображения 
ref/decorrstretch.html). На указанных компонентах изображения образы лица представлены слоями эллиптических примитивов, которые образуют завершенные бинарные деревья глубины $L=8$ с числом концевых вершин $2^{l}, l=1, \ldots, L$.

Введем для образов $\mathbf{x} \in \mathbf{X}$ и $\hat{\mathbf{x}} \in \mathbf{X}$, представленных деревьями $\mathbf{x}^{L}$ и $\hat{\mathbf{x}}^{L}$ вида (16) меры различия $d^{l}(\mathbf{x}, \hat{\mathbf{x}}) \geqslant 0$ порядка $l=1, \ldots, L$. Мера порядка $l$ вводится на пересечении $\mathbf{x}^{l} \cap \hat{\mathbf{x}}^{l}$, образованном множеством пар соответственных примитивов $Q_{n} \in \mathbf{x}^{l}$ и $\hat{Q}_{n} \in \hat{\mathbf{x}}^{l}$ в $n$-х вершинах поддеревьев $\mathbf{x}^{l} \in \mathbf{x}^{L}$ и $\hat{\mathbf{x}}^{l} \in \hat{\mathbf{x}}^{L}$ глубины $l$. Используя для соответственных примитивов $Q_{n}$ и $\hat{Q}_{n}$ описания в форме $(18)$, определим для поддеревьев $\mathbf{x}^{l}$ и $\hat{\mathbf{x}}^{l}$ следующие функции различия порядка $l$ по параметрам примитивов:

$$
\begin{aligned}
\rho_{\mathrm{r}}\left(\mathrm{x}^{l}, \hat{\mathrm{x}}^{l}\right) & =\sum_{n:\left(Q_{n}, \hat{Q}_{n}\right) \in \mathrm{x}^{l} \cap \hat{\mathbf{x}}^{l}} \lambda_{n}\left\|\mathbf{r}_{n}-\hat{\mathbf{r}}_{n}\right\| ; \\
\rho_{\mathrm{uv}}\left(\mathrm{x}^{l}, \hat{\mathrm{x}}^{l}\right) & =\sum_{n:\left(Q_{n}, \hat{Q}_{n}\right) \in \mathbf{x}^{l} \cap \hat{\mathbf{x}}^{l}} \lambda_{n}\left(\left\|\mathbf{u}_{n}-\hat{\mathbf{u}}_{n}\right\|+\left\|\mathbf{v}_{n}-\hat{\mathbf{v}}_{n}\right\|\right) ; \\
\rho_{\mathrm{z}}\left(\mathrm{x}^{l}, \hat{\mathrm{x}}^{l}\right) & =\sum_{n:\left(Q_{n}, \hat{Q}_{n}\right) \in \mathbf{x}^{l} \cap \hat{\mathbf{x}}^{l}} \lambda_{n}\left\|z_{n}-\hat{z}_{n}\right\|
\end{aligned}
$$

где $\lambda_{n}$ - веса соответственных примитивов:

$$
\lambda_{n}=\frac{\left\lfloor\log _{2}(n+1)\right\rfloor 2^{-\left\lfloor\log _{2}(n+1)\right\rfloor}}{\left.\sum_{n:\left(Q_{n}, \hat{Q}_{n}\right) \in \mathbf{x}^{l} \cap \hat{\mathbf{x}}^{l}} \log _{2}(n+1)\right\rfloor 2^{-\left\lfloor\log _{2}(n+1)\right\rfloor}},
$$

а нормы заданы в метрике $L_{1}$. Функции (19) дают средние отклонения образов обучающей выборки $\mathbf{X}^{\text {train }}$ относительно образа $\hat{\mathbf{x}}$ :

$$
\left.\begin{array}{rl}
\sigma_{\mathrm{r}}\left(\hat{\mathbf{x}}^{l}\right) & =\frac{1}{\left\|\mathbf{X}^{\text {train }}\right\|-1} \sum_{\mathbf{x}^{l}: \mathbf{x} \in \mathbf{X}^{\text {train }}} \rho_{\mathrm{r}}\left(\mathbf{x}^{l}, \hat{\mathbf{x}}^{l}\right) ; \\
\sigma_{\mathrm{uv}}\left(\hat{\mathrm{x}}^{l}\right) & =\frac{1}{\left\|\mathbf{X}^{\text {train }}\right\|-1} \sum_{\mathbf{x}^{l}: \mathbf{x} \in \mathbf{X}^{\text {train }}} \rho_{\mathrm{uv}}\left(\mathbf{x}^{l}, \hat{\mathbf{x}}^{l}\right) ; \\
\sigma_{\mathrm{z}}\left(\hat{\mathbf{x}}^{l}\right) & =\frac{1}{\left\|\mathbf{X}^{\text {train }}\right\|-1} \sum_{\mathbf{x}^{l}: \mathbf{x} \in \mathbf{X}^{\text {train }}} \rho_{\mathbf{z}}\left(\mathbf{x}^{l}, \hat{\mathbf{x}}^{l}\right) .
\end{array}\right\}
$$

С учетом соотношений (19) и (20) мера различия порядка $l=1, \ldots, L$ для пары образов х и $\hat{\mathbf{x}}$ определяется функцией:

$$
d^{l}\left(\mathrm{x}^{l}, \hat{\mathrm{x}}^{l}\right)=\frac{\rho_{\mathrm{r}}\left(\mathrm{x}^{l}, \hat{\mathrm{x}}^{l}\right)}{\sigma_{\mathrm{r}}\left(\hat{\mathrm{x}}^{l}\right)}+\frac{\rho_{\mathrm{uv}}\left(\mathrm{x}^{l}, \hat{\mathrm{x}}^{l}\right)}{\sigma_{\mathrm{uv}}\left(\hat{\mathrm{x}}^{l}\right)}+\frac{\rho_{\mathrm{z}}\left(\mathrm{x}^{l}, \hat{\mathrm{x}}^{l}\right)}{\sigma_{\mathrm{z}}\left(\hat{\mathrm{x}}^{l}\right)} .
$$

Полагая, что источники ансамбля $\mathbf{X}^{M}=\mathbf{X}_{1}, \ldots, \mathbf{X}_{M}$ допускают древовидные представления образов в форме (16), функция (21), вычисленная для объектов $m$-го источника $\mathbf{x}_{m} \in \mathbf{X}_{m}$ и $\hat{\mathbf{x}}_{m} \in \mathbf{X}_{m}$ при значениях $l=1, \ldots, L$, дает семейство мер различия

$$
d^{l}\left(\mathbf{x}_{m}, \hat{\mathbf{x}}_{m}\right) \geqslant 0, l=1, \ldots, L
$$

вида (1). Взвешенная сумма (2) таких мер порождает на ансамбле $\mathbf{X}^{M}$ семейство обобщенных мер различия

$$
D^{l}\left(\mathbf{x}^{M}, \hat{\mathbf{x}}^{M}\right) \geqslant 0, l=1, \ldots, L,
$$


для составных объектов $\mathbf{x}^{M} \in \mathbf{X}^{M}$ и $\hat{\mathbf{x}}^{M} \in \mathbf{X}^{M}$. При любом фиксированном значении $l=$ $=1, \ldots, L$ меры $(22)$ и $(23)$ позволяют, используя соотношения $(15)$, вычислить функции откликов (8), которые совместно с оценками (9) дают разделяющие функции:

$$
\left.\begin{array}{l}
\left\{g_{i}^{l}\left(\mathbf{x}_{m}\right), i=1, \ldots, c\right\} ; \\
\left\{g_{i}^{l}\left(\mathbf{x}^{M}\right), i=1, \ldots, c\right\},
\end{array}\right\}
$$

вида (4) и (5) соответственно на множествах $\mathbf{X}_{m}$ и $\mathbf{X}^{M}$.

\section{4 Обучение и схема тестирования классификаторов}

Обучение и тестирование классификаторов выполняется на ансамбле источников изображений, в котором каждое изображение допускает древовидное представление в форме (16). Применяется процедура многократного разбиения множества составных объектов ансамбля $\mathbf{X}^{M}$ на обучающую $\mathbf{X}^{M-\text { train }}$ и тестовую $\mathbf{X}^{M-{ }^{\text {test }}}$ выборки по схеме $N$ times, 2 fold cross-validation» [17]. Предполагается соответствие объектов источников в ансамбле, благодаря которому на каждом разбиении размеры выборок источников и ансамбля одинаковы и равны $\left\|\mathbf{X}_{m}^{\text {train }}\right\|=\left\|\mathbf{X}_{-}^{M_{-} \text {train }}\right\|$ и $\left\|\mathbf{X}_{m}^{\text {test }}\right\|=\left\|\mathbf{X}^{M_{-}{ }^{\text {test }}}\right\|, m=1, \ldots, M$. С учетом перстановки, каждое разбиение порождает две обучающих и две тестовых выборки.

Обучение включает получение оценок параметров (20), используемых в мере (21), оценивание параметров $\left(\mathbf{a}_{i m}^{\top}, a_{i m}\right)$ и $\left(\mathbf{a}_{i}^{\top}, a_{i}\right)$ элементарных SVM классификаторов и весов источников $w_{m}, m=1, \ldots, M$. Параметры меры $d^{l}\left(\mathbf{x}_{m}, \hat{\mathbf{x}}_{m}\right)$ вычисляются на обучающей выборке $\mathbf{X}_{m}^{\text {train }} \subset \mathbf{X}_{m}$ по представлениям порядка $l$. Параметры $\left(\mathbf{a}_{i m}^{\top}, a_{i m}\right)$ и $\left(\mathbf{a}_{i}^{\top}, a_{i}\right)$ в функциях (15) вычисляются соответственно на парах кластеров $\left(\mathbf{X}_{i m}^{\text {train }}, \mathbf{X}_{m}^{\text {train }} \backslash \mathbf{X}_{i m}^{\text {train }}\right)$ и $\left(\mathbf{X}_{i}^{M-{ }^{\text {train }}}, \mathbf{X}^{M-\text { train }} \backslash \mathbf{X}_{i}^{M-{ }^{\text {train }}}\right), i=1, \ldots, c$, с использованием функции fitcecoc версии SVM из пакета программ MATLAB (http://www.mathworks.com/help/stats/fitcecoc.html). Оценка весового коэффициента $w_{m}$ строится на обучающей выборке $\mathbf{X}_{m}^{\text {train }}$ по представлениям порядка $L$ и зависит от ошибки скользящего контроля $\varepsilon_{F_{m}}^{\mathrm{LOO}}\left(\mathbf{X}_{m}^{\mathrm{train}}\right)$ вида $(11)$, вычисляемой по схеме «leave-one-out» с применением классификатора $F_{m}: \mathbf{X}_{m}^{\text {train }} \rightarrow \Omega$. В качестве весов используются оценки:

$$
w_{m}=-\log \varepsilon_{F_{m}}^{\mathrm{LOO}}\left(\mathbf{X}_{m}^{\mathrm{train}}\right), m=1, \ldots, M .
$$

На каждом текущем разбиении обученным классификаторам предъявляются объекты соответствующих тестовых выборок и вычисляются доли ошибок $\varepsilon_{F}^{(n)}$ вида (11), где $F-$ тип классификатора, зависящий от применяемых элементарных классификаторов и схемы комплексирования. Усреднение долей ошибок тестирования по всем тестовым выборкам дает среднюю долю ошибок скользящего контроля:

$$
\varepsilon_{F}^{\mathrm{CV}-{ }^{\mathrm{test}}}=\frac{1}{2 N} \sum_{n=1}^{2 N} \varepsilon_{F}^{(n)} .
$$

\section{5 Экспериментальные результаты}

Эксперименты выполнены на цветных RGB изображениях лиц, декоррелированные компоненты которых образуют ансамбль из трех источников. Множество изображений содержит 1000 образов от 25 персон, по 40 изображений от каждой персоны, полученных с изменением ракурса съемки. Исходные RGB изображения включают образы, принадлежащие $c=25$ классам с равными априорными вероятностями $\mathrm{P}\left(\omega_{i}\right)=1 / c, i=1, \ldots, 25$. 


\begin{tabular}{|c|c|c|c|c|c|c|}
\hline \multirow{2}{*}{$I$} & \multicolumn{3}{|c|}{ компоненты } & \multicolumn{3}{c|}{ схема комплексирования } \\
\cline { 2 - 7 } & $\mathrm{I}_{1}$ & $\mathrm{I}_{2}$ & $\mathrm{I}_{3}$ & $\mathrm{MV}$ & $\mathrm{GS}$ & GM \\
\hline 1 & 0,1117140 & 0,1638612 & 0,1448992 & 0,0627828 & 0,0153852 & 0,0150468 \\
\hline 2 & 0,0333520 & 0,0180168 & 0,0266888 & 0,0058360 & 0,0020324 & 0,0019460 \\
\hline 3 & 0,0146416 & 0,0040664 & 0,0068072 & 0,0008904 & 0,0001184 & 0,0001492 \\
\hline 4 & 0,0062732 & 0,0024552 & 0,0034436 & 0,0002788 & 0,0000308 & 0,0000404 \\
\hline 5 & 0,0048892 & 0,0016596 & 0,0021540 & 0,0000696 & 0,0000064 & 0,0000164 \\
\hline 6 & 0,0042324 & 0,0009288 & 0,0015676 & 0,0000436 & 0,0000072 & 0,0000160 \\
\hline 7 & 0,0039220 & 0,0005700 & 0,0014464 & 0,0000100 & 0,0000044 & 0,0000052 \\
\hline 8 & 0,0037408 & 0,0006436 & 0,0012724 & 0,0000104 & 0,0000012 & 0,0000024 \\
\hline 9 & 0,0035384 & 0,0006056 & 0,0013616 & 0,0000088 & 0,0000016 & 0,0000028 \\
\hline 10 & 0,0034668 & 0,0005744 & 0,0012992 & 0,0000048 & 0,0000012 & 0,0000020 \\
\hline
\end{tabular}

(a) классификаторы NN

\begin{tabular}{|c|c|c|c|c|c|c|}
\hline \multirow{2}{*}{$I$} & \multicolumn{3}{|c|}{ компоненты } & \multicolumn{1}{c|}{ схема комплексирования } \\
\cline { 2 - 7 } & $\mathrm{I}_{1}$ & $\mathrm{I}_{2}$ & $\mathrm{I}_{3}$ & $\mathrm{MV}$ & $\mathrm{GS}$ & $\mathrm{GM}$ \\
\hline 1 & 0,1185844 & 0,1195664 & 0,1081460 & 0,0524420 & 0,0156568 & 0,0261012 \\
\hline 2 & 0,0411732 & 0,0252852 & 0,0332944 & 0,0087016 & 0,0030976 & 0,0028380 \\
\hline 3 & 0,0166856 & 0,0069608 & 0,0090212 & 0,0013808 & 0,0003380 & 0,0004448 \\
\hline 4 & 0,0061662 & 0,0039560 & 0,0047828 & 0,0003452 & 0,0000676 & 0,0000400 \\
\hline 5 & 0,0033940 & 0,0029600 & 0,0033516 & 0,0002400 & 0,0000576 & 0,0000132 \\
\hline 6 & 0,0023980 & 0,0027340 & 0,0025092 & 0,0002016 & 0,0000328 & 0,0000064 \\
\hline 7 & 0,0022520 & 0,0026772 & 0,0021820 & 0,0002508 & 0,0000152 & 0,0000044 \\
\hline 8 & 0,0019936 & 0,0026448 & 0,0019016 & 0,0002204 & 0,0000068 & 0,0000016 \\
\hline 9 & 0,0019156 & 0,0024452 & 0,0017128 & 0,0001996 & 0,0000064 & 0,0000012 \\
\hline 10 & 0,0019128 & 0,0023692 & 0,0016508 & 0,0001772 & 0,0000072 & 0,0000008 \\
\hline
\end{tabular}

(б) классификаторы SVM

Рис. 3 Ошибки классификации лиц по декоррелированным компонентам RGB изображений и по ансамблю компонент с использованием схем комплексирования MV, GS и GM: (a) классификаторы NN; (б) классификаторы SVM

Декоррелированные компоненты $I_{1}(\mathrm{R}, \mathrm{G}, \mathrm{B}), I_{2}(\mathrm{R}, \mathrm{G}, \mathrm{B})$ и $I_{3}(\mathrm{R}, \mathrm{G}, \mathrm{B})$ RGB изображения образуют источники $\mathbf{X}_{1}, \mathbf{X}_{2}$ и $\mathbf{X}_{3}$ и ансамбль $\mathbf{X}^{3}=\left(\mathbf{X}_{1}, \mathbf{X}_{2}, \mathbf{X}_{3}\right)$ изображений одинаковой мощности, равной 1000. Информативными объектами декоррелированных изображений являются образы лица, ограниченные параметрическим овалом, симметричным относительно нормали к линии глаз. Представления образов заданы наборами эллиптических примитивов, структурированных в бинарные деревья глубины $L=10$. Эксперименты проведены с использованием процедуры скользящего контроля, с параметром $N=2500$. Обучение и тестирование классификаторов с разделяющими функциями вида (24) выполнено на серии древовидных представлений образов порядка $l=1, \ldots, L$.

Результаты классификации в терминах долей ошибок вида (25), полученные для индивидуальных источников и для ансамбля с различными схемами комплексирования, представлены на рис. 3. Строки таблицы при фиксированных значениях $l$ соответствуют средним значениям ошибок скользящего контроля для классификаторов, обученных по схеме «класс против всех», с использованием элементарных классификаторов типа NN и SVM. 


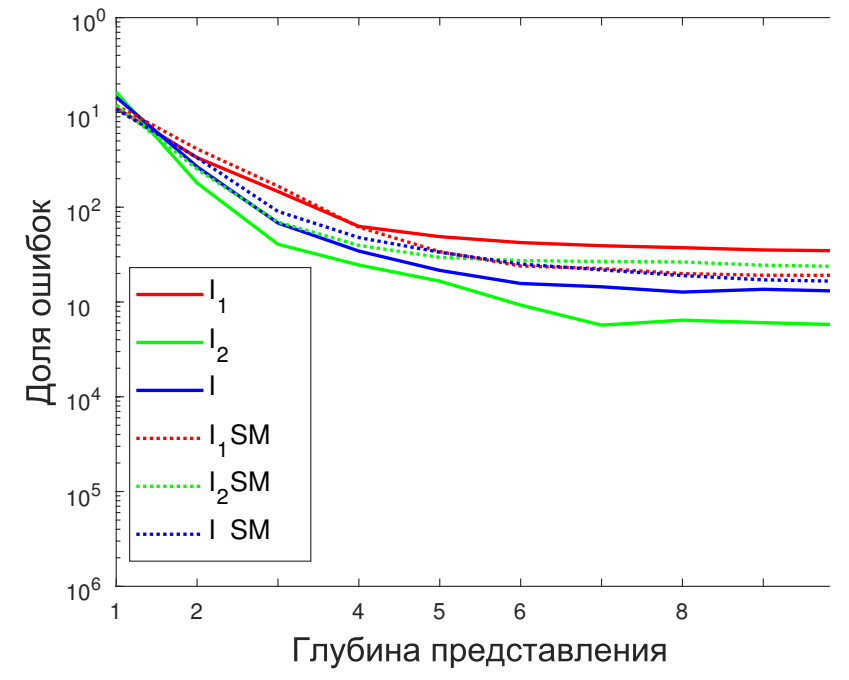

(a) по индивидуальным источникам изображений

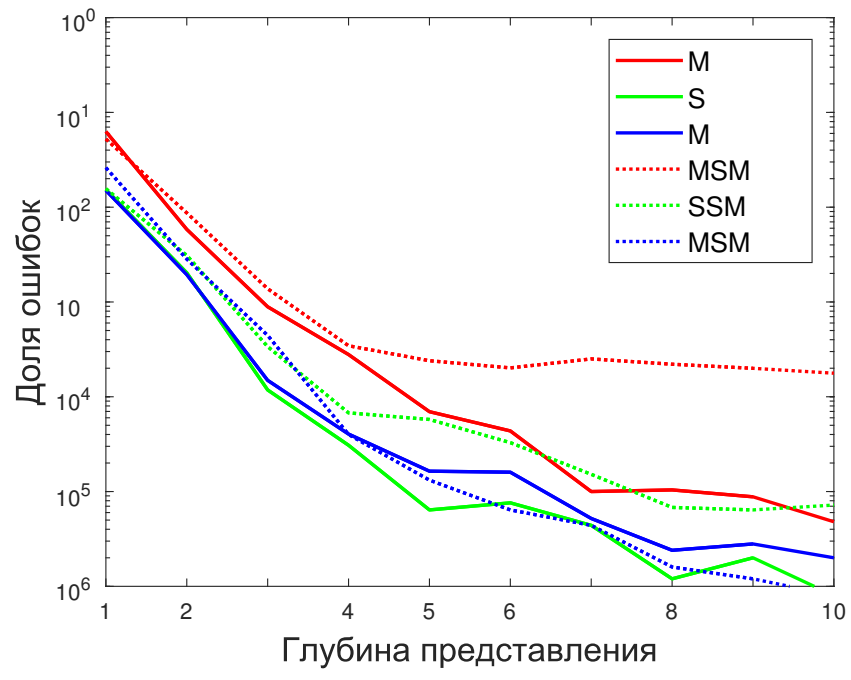

(б) по ансамблю источников

Рис. 4 Графики зависимости ошибок скользящего контроля от глубины представлений для классификаторов лиц с различными схемами комплексирования: (a) по индивидуальным источникам изображений; (б) по ансамблю источников

Зависимости доли ошибок от глубины $l$ используемых представлений образов, построенные по данным таблицы, даны в виде графиков на рис. 4.

При любом фиксированном значении параметра $l$ данные таблиц на рис. 3 демонстрируют более высокую эффективность схем комплексирования GM и GS по сравнению со схемой MV для классификаторов типа NN и SVM. C ростом $l$ вероятность ошибок классификаторов уменьшается, но растет вычислительная сложность и, следовательно, требуемое время на принятие решения. Полученные зависимости вероятности ошибок от параметра $l$ позволяют выбрать наименьшую глубину представляющих деревьев, обеспечивающую требуемое качество классификации.

Необходимо отметить, что вычисление откликов элементарных NN классификаторов на полных кластерах обучающей выборки приводит к переобучению и, следовательно, к завышению доли ошибок. Тот же эффект проявляется в элементарных SVM классификаторах, обучаемых в пространстве завышенной размерности, которая определяется числом элементов обучающей выборки. Уменьшение переобучения может быть достигнуто путем отбора эталонных объектов в кластерах обучающей выборки [10]. Отбор эталонов позволит вычислять отклики элементарных NN классификаторов по эталонным объектам в классах и понизит размерность признакового пространства элементарных SVM классификаторов за счет вычисления расстояний объектов только до эталонных объектов. В целом, отбор эталонов эквивалентен понижению размерности данных [18] и способен повысить разделяющую способность элементарных классификаторов, обучаемых по схеме «класс против всех».

\section{6 Заключение}

В настоящей работе исследованы многоклассовые метрические классификаторы на ансамбле изображений, порождаемых источниками различной модальности. Рассмотрены классификаторы, в которых коллективные решения по предъявляемым наборам изображений строятся на основе двух оригинальных схем комплексирования данных (схемы GM и GS) и традиционной схемы на основе голосования жестких решений по изображениям 
отдельных источников (схема MV). В схеме GM использована композиция мер различия на множествах изображений отдельных источников, которая дает обобщенную меру различия составных объектов на ансамбле изображений. Схема GS использует композицию мягких решений классификаторов по изображениям отдельных источников в виде значений обобщенного сходства предъявляемого составного объекта с классами. Композиции в виде обобщенной меры и обобщенного сходства позволяют применить единый классификатор для построения коллективных решений по предъявляемым наборам изображений от ансамбля источников. Эффективность классификаторов на ансабле источников базируется на средней взаимной информации между ансамблем и множеством классов, которая определяет наименьшую вероятность ошибки для заданной схемы комплексирования. Ранее было доказано, что средняя взаимная информация между множеством составных объектов и множеством классов в схеме GM превосходит среднюю взаимную информацию в схеме MV. Следствием этого результата является возможность достижения меньшей доли ошибок в схеме GM по сравнению со схемой MV.

В терминах доли ошибок экспериментально исследована сравнительная эффективность классификаторов, использующих схемы комплексирования GM, GS и MV, на ансамбле декоррелированных компонент RGB изображений лиц. Эксперименты проведены на классификаторах, обученных по схеме «класс против всех», с использованием разделяющих функций на основе ближайшего соседа (NN) и опорных векторов (SVM). Во всех случаях предложенные схемы комплексирования GM и GS продемонстрировали меньшую долю ошибок по сравнению с известной схемой MV. В перспективе планируется исследовать классификаторы с указанными схемами комплексирования на ансамблях данных других источников с применением решающего алгоритма, допускающего отказ.

\section{Литература}

[1] Kuncheva L. Combining pattern classifiers: Methods and algorithms. - 2nd ed. - Wiley, 2014. $384 \mathrm{p}$.

[2] Lam L., Suen S. Application of majority voting to pattern recognition: An analysis of its behavior and performance // Trans. Sys. Man Cyber. A, 1997. Vol. 27. No. 5. P. 553-568. doi: $10.1109 / 3468.618255$.

[3] Kuncheva L., Whitaker C., Shipp C., Duin R. Limits on the majority vote accuracy in classifier fusion // Pattern Anal. Appl., 2003. Vol. 6. No. 1. P. 22-31. doi: 10.1007/s10044-002-0173-7.

[4] Ланге М. М. Информационный критерий для сравнения классификаторов на ансамбле источников // Тез. докл. 11-й Междунар. конф. «Интеллектуализация обработки информации». - М.: ТОРУС ПРЕСС, 2016. С. 32.

[5] Lange $M$. Information criterion of efficiency for metric classifiers in ensemble of sources // Comm. Com. Inf. Sc., 2017 (in press).

[6] Gray R., Neuhoff D. Quantization // IEEE T. Inform. Theory, 1998. Vol. 44. No. 6. P. 2325-2383. doi: $10.1109 / 18.720541$.

[7] Kolmogorov A., Tikhomirov V. $\varepsilon$-entropy and $\varepsilon$-capacity of sets in functional spaces // Selected works of A.N. Kolmogorov. Vol. III: Information theory and the theory of algorithms. Mathematics and its applications ser. - Springer, 1993. P. 86-170. doi: 10.1007/978-94-017-2973$4 \_7$.

[8] Koshelev V. Quantization with minimum entropy // Probl. Inf. Transm., 1963. Vol. 14. P. 151-156.

[9] Белавкин В.П., Гришанин Б.А. Оптимальное квантование векторных случайных величин // Изв. АН СССР. Сер. Техническая кибернетика, 1970. Т. 1. С. 161-170. 
[10] Lange M., Ganebnykh S. Multiclass pattern recognition in a space of multiresolution representations // Machine Learning Data Anal., 2016. Vol. 2. No. 1. P. 70-88. doi: 10.21469/ 22233792.2.1.06.

[11] Duda R., Hart P., Stork D. Pattern classification. - 2nd ed. - Wiley, 2000. 680 p.

[12] Collection of color faces. http://sourceforge.net/projects/colorfaces/.

[13] Gallager R. Information theory and reliable communication. - Wiley, 1969. 608 p.

[14] Dobrushin R., Tsybakov B. Information transmission with additional noise // IRE T. Inform. Theor., 1962. Vol. 8. No. 5. P. 293-304. doi: 10.1109/TIT.1962.1057738.

[15] Duin R., de Ridder D., Tax D. Experiments with a featureless approach to pattern recognition // Pattern Recogn. Lett., 1997. Vol. 18. No. 11. P. 1159-1166. doi: 10.1016/S0167-8655(97)00138-4.

[16] Ganebnykh S., Lange M., Stepanov D. Metric classifier using multilevel network of templates // Pattern Recognition Image Anal., 2012. Vol. 22. No. 2. P. 265-277. doi: 10.1134/ S1054661812020034.

[17] Theodoridis S., Koutroumbas K. Pattern recognition. - 4th ed. - Academic Press, 2008.978 p.

[18] Tenenbaum J., De Silva V., Langford J. A global geometric framework for nonlinear dimensionality reduction // Science, 2000. Vol. 290. P. 2319-2323.

Поступила в редакиию 18.09.2017

\title{
On efficiency of fusion schemes for pattern recognition in ensemble of images*
}

\author{
S. N. Ganebnykh and M. M. Lange \\ sng@ccas.ru; lange_mm@ccas.ru
}

Federal Research Center "Computer Science and Control" of RAS, 44/2 Vavilova Str., Moscow, Russia

In an ensemble of image sources of different modalities, some metric multiclass classifiers are studied. The classifiers make the collective decisions for the composite objects that are produced by collections of the images with one from each source. The discriminant functions of the multiclass classifiers are produced by the binary "class-vs-all" NN or SVM classifiers. Two original fusion schemes that use the discriminant functions based on the different compositions are suggested. The first scheme uses the compositions of the dissimilarity measures between the images within each source (General Measure, GM) whereas the second scheme uses the compositions of the soft decisions for the images in the submitted composite object (General Similarity, GS). In terms of error rates, the proposed GM and GS fusion schemes are compared with the known MV (Majority Vote) scheme which is based on majority voting the compositions of the hard decisions for the individual source images. The comparative efficiency of the above fusion schemes is supported by the error rates for recognition of the RGB face images given by the ensemble of their three decorrelated components. For the NN and SVM classifiers, the experimental estimations of the error rates show a profit of the GM and GS schemes in comparison with the MV scheme.

Keywords: multiclass classifier; ensemble of images; fusion scheme; majority vote; general measure; general similarity; face recognition

DOI: $10.21469 / 22233792.3 .1 .06$

\footnotetext{
* The research was partially supported by the Russian Foundation for Basic Research (grants 15-01-04671 and 15-07-07516).
} 


\section{References}

[1] Kuncheva, L. 2014. Combining pattern classifiers: Methods and algorithms. 2nd ed. Wiley. 384 p.

[2] Lam, L., and S. Suen. 1997. Application of majority voting to pattern recognition: An analysis of its behavior and performance. Trans. Sys. Man Cyber. A 27(5):553-568. doi: 10.1109/3468. 618255 .

[3] Kuncheva, L., C. Whitaker, C. Shipp, and R. Duin. 2003. Limits on the majority vote accuracy in classifier fusion. Pattern Anal. Appl. 6(1):22-31. doi: 10.1007/s10044-002-0173-7.

[4] Lange, M. 2016. Information criterion for comparison of metric classifiers in ensemble of sources. 11th Conference (International) "Intelligent Data Processing: Theory and Applications". Book of abstracts. Moscow: TORUS PRESS. 33.

[5] Lange, M. 2017 (in press). Information criterion of efficiency for metric classifiers in ensemble of sources. Comm. Com. Inf. Sc.

[6] Gray, R., and D. Neuhoff. 1998. Quantization. IEEE Trans. Inform. Theory 44(6):2325-2383. doi: 10.1109/18.720541.

[7] Kolmogorov, A., and V. Tikhomirov. 1993. $\varepsilon$-entropy and $\varepsilon$-capacity of sets in functional spaces. Selected works of A.N. Kolmogorov. Vol. III: Information theory and the theory of algorithms. Mathematics and its applications ser. Springer. 86-170. doi: 10.1007/978-94-017-2973-4_7.

[8] Koshelev, V. 1963. Quantization with minimum entropy. Probl. Inf. Transm. 14:151-156.

[9] Belavkin, V., and B. Grishanin. 1970. Optimal'noe kvantirovanie vektornykh sluchaynykh velichin [Optimal vector quantization of random variables]. Izv. AN SSSR. Ser. Tekhnicheskaya kibernetika [Sov. J. Comput. Syst. S.] 1:161-170.

[10] Lange, M., and S. Ganebnykh. 2016. Multiclass pattern recognition in a space of multiresolution representations. Machine Learning Data Anal. 2(1):70-88. doi: 10.21469/22233792.2.1.06.

[11] Duda, R., P. Hart, and D. Stork. 2000. Pattern classification. 2nd ed. Wiley. 680 p.

[12] Collection of color faces. Available at: http://sourceforge.net/projects/colorfaces/ (accessed July 4, 2017).

[13] Gallager, R. 1969. Information theory and reliable communication. Wiley. 608 p.

[14] Dobrushin, R., and B. Tsybakov. 1962. Information transmission with additional noise. IRE T. Inform. Theor. 8(5):293-304. doi: 10.1109/TIT.1962.1057738.

[15] Duin, R., D. de Ridder, and D. Tax. 1997. Experiments with a featureless approach to pattern recognition. Pattern Recogn. Lett. 18(11):1159-1166. doi: 10.1016/S0167-8655(97)00138-4.

[16] Ganebnykh, S., M. Lange, and D. Stepanov. 2012. Metric classifier using multilevel network of templates. Pattern Recognition Image Anal. 22(2):265-277. doi: 10.1134/S1054661812020034.

[17] Theodoridis, S., and K. Koutroumbas. 2008. Pattern recognition. 4th ed. Academic Press. 978 p.

[18] Tenenbaum, J., V. De Silva, and J. Langford. 2000. A global geometric framework for nonlinear dimensionality reduction. Science 290:2319-2323.

Received September 18, 2017 